Edward I. Altman

New York University

Duen Li Kao

General Motors Corporation

\title{
Corporate Bond Rating Drift: An Examination of Credit Quality Rating Changes Over Time
}

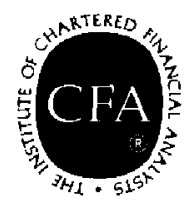

The Research Foundation of

The Institute of Chartered Financial Analysts 


\section{Research Foundation Publications}

Canadian Stocks, Bonds, Bills, and Inflation: 1950-1987

by James E. Hatch and Robert E. White

Closed-Form Duration Measures and Strategy Applications

by Nelson J. Lacey and Sanjay K. Nawalkha

Default Risk, Mortality Rates, and the Performance of Corporate Bonds

by Edward I. Altman

Durations of Nondefault-Free Securities

by Gerald $O$. Bierwag and George G. Kaufman

The Effect of Illiquidity on Bond Price Data: Some Symptoms and Remedies by Oded Sarig and Arthur Warga

The Founders of Modern Finance: Their Prize-winning Concepts and 1990 Nobel Lectures

Initial Public Offerings: The Role of Venture Capitalists

by Joseph T. Lim and Anthony Saunders

A New Perspective on Asset Allocation

by Martin L. Leibowitz

The Poison Pill Anti-takeover Defense: The Price of Strategic Deterrence by Robert F. Bruner

Program Trading and Systematic Risk

by A.J. Senchack, Jr., and John D. Martin

The Role of Risk Tolerance in the Asset Allocation Process: A New Perspective by W.V. Harlow III, CFA and Keith C. Brown, CFA

Selecting Superior Securities

by Marc R. Reinganum

Stock Market Structure, Volatility, and Volume

by Hans R. Stoll and Robert E. Whaley

Stocks, Bonds, Bills, and Inflation: Historical Returns (1926-1987)

by Roger G. Ibbotson and Rex A. Sinquefield

(Published with Business One Irwin) 


\section{Corporate Bond Rating Drift: An Examination of Credit Quality Rating Changes Over Time}


(C) 1991 The Research Foundation of the Institute of Chartered Financial Analysts.

All rights reserved. No part of this publication may be reproduced, stored in a retrieval system, or transmitted, in any form or by any means, electronic, mechanical, photocopying, recording, or otherwise, without the prior written permission of the copyright holder.

This publication is designed to provide accurate and authoritative information in regard to the subject matter covered. It is sold with the understanding that the publisher is not engaged in rendering legal, accounting, or other professional service. If legal advice or other expert assistance is required, the services of a competent professional should be sought.

From a Declaration of Principles joinlly adopted by a Committee of the American Bar Association and a Committee of Publishers.

ISBN 10-diget: 0-943205-12-3 ISBN 13-digiet: 978-0-943205-12-0

Printed in the United States of America

November 1991 


\section{Mission}

The mission of the Research Foundation is to identify, fund, and publish research material that:

- expands the body of relevant and useful knowledge available to practitioners;

- assists practitioners in understanding and applying this knowledge; and

- enhances the investment management community's effectiveness in serving clients.

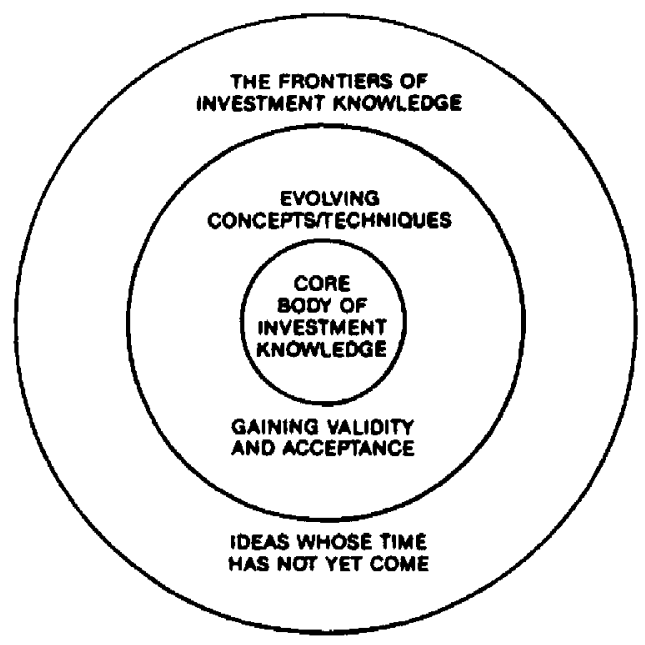

The Research Foundation of

The Institute of Chartered Financial Analysts

P. O. Box 3668

Charlottesville, Virginia 22903

Telephone: 8041977-6600

Fax: 804/977-1103 


\section{Table of Contents}

Foreword $\ldots \ldots \ldots \ldots \ldots \ldots \ldots \ldots \ldots \ldots \ldots$ ix

Preface $\ldots \ldots \ldots \ldots \ldots \ldots \ldots \ldots \ldots \ldots \ldots$ xiii

Chapter 1. Introduction $\ldots \ldots \ldots \ldots \ldots \ldots \ldots \ldots, 1$

Chapter 2. Empirical Analysis of Bond Rating Drift .... 5

Chapter 3. Modeling Bond Rating Drift ......... 27

Chapter 4. Rating Changes and Bondholders' Wealth ... 45

Chapter 5. Practical Implications and Future Research .. 47

Appendix A. Bond Rating Agencies and Systems ...... 57

Appendix B. Rating Drift Tables, 1970-79 and 1980-89 . . 63

Appendix C. Parameter Estimation for an MS Model .... 71

References ........................ 75 


\section{Foreword}

That bond ratings drift over time is not amazing. The surprise is that we know virtually nothing about the drift, up or down, sector to sector, from class to class, or over time. The Altman-Kao study fills the gaps.

\section{The Initial Results}

For the entire 19-year study period, fewer and fewer bonds retained their original ratings as the investment horizon lengthened. The AAA-rated bonds had the greatest stability at the outset, yet even they declined during the entire period. The least stable category was the BB-rated issues, the highest of the junk bond category. Bonds rated $\mathrm{A}$ and above had a greater tendency to be downgraded than to be upgraded, especially AA issues. For all categories, the changes are even more dramatic as the investment horizon increases. BBB bonds had more upgrades than downgrades for all holding period horizons. Bonds issued most recently in the period were less stable than those issued earlier in the period. The least stable were the BB- and CCC-rated issues.

The incidence of downgrades was greater in the 1980s than in the 1970s. Lower grade junk bonds had a positive "balance of change" (upgrades minus downgrades) for the entire period, but were negative for the most recent subperiod (1983 to 1988). Bond ratings were far less stable in the second 10-year period than in the first 10-year period, again with bonds that were originally rated $\mathrm{A}$ or above displaying a tendency for downgrades to exceed upgrades.

Within various economic sectors, the different grades of industrial bonds seemed to be more stable in retaining their original ratings than were those of nonindustrial firms. Captive finance companies exhibited considerably less stability than their nonfinance counterparts, although the sample size is small. Financial institutions and finance companies in general had greater stability in ratings than did industrial finance companies. Yet when compared with industrial bonds, the results are mixed and ambiguous.

Differentiating utility companies between those with substantial nuclear exposure and all others, the nonnuclear electric power company bonds tended to retain their ratings far more frequently than those of nuclear powered utilities.

The authors' results are comparable with a major study by Moody's, with no significant differences between the two. 


\section{The Model and its Results}

Chapter 3, "Modeling Bond Rating Drift," emphasizes the central role that sophisticated techniques play in analyzing bond data. The important conclusion of this chapter is that stochastic models - that is, those that assume uncertain and random characteristics-may be used to describe bond rating drift.

The issue is this: Do bond ratings possess stochastic or deterministic characteristics? If they are stochastic, ratings follow a random walk; if they are deterministic, the drift itself may be used to forecast, and therefore garner, excess returns. Stochastic models permit estimates to be revised by incorporating new information from the first analysis.

The authors use Markov chains. This technique builds on what is known at the outset about the distribution of bond ratings and their likelihood of change to construct a model that is predictive of future change and that itself is conditional on the probability of the past observations and the probabilities of the new matrix.

Three variants of Markov chains are tested: (1) stationary, in which the probabilities are assumed to be constant over time; (2) nonstationary, in which the probabilities change from period to period; and (3) mover-stayer, in which all the bonds are classified as those that stay in their same state during the entire period and those that move with changing probabilities from one state or time period to another.

Procedurally, deviations from the estimated values are taken as the errors of the model's predictions. Both the stationary and nonstationary models underestimated the observed percentages of ratings unchanged. The model's ability to estimate degenerated as the horizon increased. The mover-stayer model had very low estimated errors for most rating categories, although it too degenerated over longer periods, mainly because of the instability in the BBB rating category.

The models were far more successful in estimating unchanged rankings than in estimating upgrades and downgrades. All three models had significant predictive ability for three-year horizons for most rating categories. For more extended periods, the mover-stayer model was the best predictor.

Methodologically, predicting from sample data is not acceptable because it creates a self-fulfilling prophesy. The common approach is to back test the results or to use the results of data not in the sample itself. The benchmark is a naive model that only observes changes from one period to the next. The Markov stationary and nonstationary models outperformed any of the historical models for all the horizons examined up to seven years. 


\section{The Implications}

Changes in credit quality are of interest to all investors and portfolio managers because such changes affect returns and therefore wealth. Most studies indicate that a large part of a price change in bonds (or stocks) occurs prior to the actual rating change announcement.

If an investor holds bonds until their maturity, rating changes may be irrelevant. But most portfolio managers do not hold until maturity. Consequently, expected rates of return must be adjusted for the probability of rating change and the resulting effect on overall returns. For this reason, the Altman-Kao study has significant implications for investment analysts and portfolio managers.

Knowing the transition pattern of bond ratings is useful in itself, but knowing the magnitude of yesterday's changes in invaluable. For example, the historical data may be used as a first approximation to estimating dislocations within a portfolio as credit ratings change, particularly downward. For insurance companies, this may be one ingredient in setting up loss reserves.

Here is another application: The past 10 years witnessed an avalanche of derivative securities, the dominate one in the bond market being collateralized bond obligations. Knowledge of bond rating drift helps to structure more finely such debt.

One of the most important insights of this study is the help it provides in determining the risk tolerance a portfolio manager may wish to assume, given the presence of portfolio drift. What does a portfolio manager do, for example, when the distribution of credit ratings changes from the target-say, from an average of investment-grade bonds to an average of below-investment-grade bonds? Altman and Kao's answer from their study is to determine the probabilities of change and fine tune the portfolio based on a weighted average of expected ratings.

Finally, the authors suggest that a bond portfolio manager who fails to take rating drift into account will overestimate the performance of individual bonds and the whole portfolio under some assumed yield curve changes.

Fixed-income securities continue to be an enigma of the times. Duration, convexity, and embedded options, to mention a few, have revised the standard methods of analysis. Thanks to the likes of Altman and Kao, we continue to gain deeper and wider insights on this important vehicle. The Research Foundation delights in funding scholarship such as this.

Charles A. D'Ambrosio, CFA

Director

The Research Foundation of

The Institute of Chartered Financial Analysts 


\section{Preface}

In the preface to Default Risk, Mortality Rates, and the Performance of Corporate Bonds, a study published by the Research Foundation of the Institute of Chartered Financial Analysts in 1989, one of this monograph's authors remarked that the analyses of "corporate debt security performance are certainly not complete with the publication of this study.... We do not consider credit quality changes, except when they result in a default. Subsequent research will, I hope, integrate these rating transitions into the analysis" (Altman 1989a). Perhaps the primary evidence of credit quality changes over time is the evolution of an issue's bond rating, a matter that is documented and discussed in depth in this monograph.

Using Standard \& Poor's bond rating history from 1970 through September 1989 , we investigated the 10 -year experience of all new issues, covering the entire range of ratings, from 1970 through 1988 . We found, for example, that the propensity of original ratings to remain unchanged for five years after issuance was 69.8 percent for AAA-rated issues and 65.7 percent for BBBrated issues. Because AAA-rated issues that change ratings can only be downrated, and because the BBB-rated issues experienced a greater proportion of upgrades (21.6 percent) than downgrades (12.6 percent), holding BBB-rated bonds was probably more advantageous than holding AAA-rated bonds. During the sample period, all bond rating classes, with the exception of BBB-rated bonds, showed a dominance of downgrades over upgrades. This is especially true for the 1980 s.

We also explored rating changes for different economic sectors, (e.g., industrials, finance, utilities, and so forth), as well as for different subperiods. We do not present the transition matrixes of ratings in these economic sectors in this monograph, but these data are available in an unpublished working paper (Altman and Kao 1991).

In addition to the descriptive analysis, we used stationary and nonstationary Markov chain models to explore the transition process of bond ratings. We found that the Markov models, including those with movers (issues whose ratings change) and stayers (issues whose ratings do not change), produce better forecasts than a naive historical extrapolation. The study also addresses, primarily in conceptual and illustrative terms, the implications of this rating drift analysis for bond portfolio performance. Readers who are mainly interested in 
the descriptive aspects of this study may wish merely to glance over the more analytical modeling discussion.

Our study has several practical applications for bond portfolio management. Expectations of credit quality changes, as well as interest rate and default probabilities, can be used to guide portfolio managers and individual investors more precisely. Performance analysis, both ex ante and ex post, can be enhanced with credit quality change estimates. Our results should also prove relevant to creators, investors, analysts, and insurers who are involved in the growing markets for collateralized bond obligations and highly leveraged loan obligations. Estimates of gains and losses from credit quality changes are also relevant to the computation of loss reserves for actuarial and for capital allocation purposes.

Our appreciation goes to the Research Foundation of the Institute of Chartered Financial Analysts for its financial support and to Standard \& Poor's Corporation for providing data, encouragement, and feedback on an earlier draft. Special thanks to Lourdes Tanglao for her assistance in preparing the manuscript. 


\section{Introduction}

One of the most important indicators of a corporation's credit quality is the bond rating that independent agencies assign to its outstanding, publicly traded indebtedness. Moody's developed the first rating system in the United States in 1914, followed in 1922 by Poor's Corporation (predecessor to Standard \& Poor's Corporation). Bond rating has evolved into a mini-industry comprising at least four major U.S. firms and a number of similar entities outside the United States. In addition, debt ratings are assigned by regulatory and quasi-regulatory organizations such as the National Association of Insurance Commissioners, which rates debt held by insurance companies. A more detailed description of bond ratings and rating agencies can be found in Appendix A, in Altman and Kao (1991), and also in Ederington and Yawitz (1987).

Bond ratings are usually first assigned to public debt at the time of issuance. Periodically, the rating agencies review their initial ratings and may change them. If in the agency's assessment a company's credit quality has improved, its rating will be upgraded; if its credit quality has deteriorated, its rating will be downgraded. A coincident effect, in some proximity to the date of the rating change, is a change in the price of the issue reflecting a decrease (for an upgrade) or an increase (for a downgrade) in the required yield to investors in that security. Although this price response to rating changes is well understood, in general terms, by the investment community, it has never been studied in a rigorous and comprehensive manner. Studies have been done, however, on the price impact of rating changes (see, for example, Katz 1974, Grier and Katz 1976, Hettenhouse and Satoris 1976, and Weinstein 1977).

Altman (1989b) presented some preliminary estimates of Moody's bond rating changes from 1980 through 1988, and as we were completing this monograph, more comprehensive descriptive work on Moody's issuer rating changes was published by Lucas and Lonski (1991); their results are discussed in the second chapter of this monograph. 


\section{Research Objectives}

The primary purpose of our research was to investigate rating changes over time. According to today's conventional practice of bond portfolio evaluation, the rating of a bond is assumed to remain unchanged. The existence of possible bond rating drift adds another dimension to the uncertainty of bond portfolio management. Possible changes in bond rating profiles of individual bonds or of a portfolio during the investment horizon imply that a bond portfolio manager must assess the potential effects this drift has on his investment strategies. Because the bond rating change would result in a change in bond yield demanded by an investor, it alters the relative values and interest rate sensitivities of individual bonds or sectors during the holding period. Consequently, it may change how a portfolio manager implements investment strategies such as portfolio restructuring and optimization, bond swaps, and duration management.

Using Standard \& Poor's bond rating history, we attempted to answer a number of questions:

- What was the experience of corporate bonds with respect to changes in rating from the time of issuance to various time periods after issuance?

- Was the tendency greater for bonds of various initial ratings to be upgraded or downgraded during the first 10 years after issuance?

- During each of the 10 years, what was the specific experience of bonds of different credit quality; that is, what is the ex post probability of rating changes, by specific rating?

- Did the rating change probabilities vary by the time period of issuance and the economic sector of the company?

- Can the bond rating change process be modeled effectively? That is, is there a conditional relationship between a bond's initial year(s) rating change and its longer term propensity to change or not to change? Is the rating drift experience stationary or nonstationary with respect to the age and prior movement of bonds?

In this study, we investigated new bond issuance rated by Standard \& Poor's Corporation (S\&P) for the period January 1, 1970, through December 31, 1988, with rating changes recorded through September 30, 1989. We analyzed major letter-category rating changes only (e.g., from $\mathrm{AA}$ to $\mathrm{A}$ or $\mathrm{B}$ to $\mathrm{BB}$ ) and not intrarating changes (e.g., $\mathrm{AA}$ to $\mathrm{AA}+$ or $\mathrm{AA}-$ ). Thus, a change from $\mathrm{AA}-$ to $\mathrm{A}+$ is treated the same as a change from $\mathrm{AA}$ to $\mathrm{A}$. We believe that omission of 
these within-category changes does not produce any systematic bias in the results. ${ }^{1}$

\section{Methodology}

Initially, we examined the rating histories of 7,195 nonconvertible bonds that had at least one year of existence and that had received an initial S\&P rating. From the population of more than 9,000 bonds issued during the 19 -year period from January 1, 1970, through September 30, 1989, we eliminated convertibles ( 1,162 issues), those in existence for less than one year (586 issues), and those initially nonrated.

We examined the ratings of these bonds for 10 years after their issuance, through September 1989. A list of the number of bonds issued in each of the 10 years is given in Table 1 . Table 2 lists the number of bonds analyzed in each original rating category by the number of years of rating history. Naturally, the number of observations in each rating category diminishes as the number of

TABLE 1. Sample of Bonds by Year of Issuance

\begin{tabular}{lccc}
\hline Year & Number & Year & Number \\
\hline & & 1980 & 302 \\
1970 & 349 & 1981 & 272 \\
1971 & 304 & 1982 & 410 \\
1972 & 232 & 1983 & 366 \\
1973 & 174 & 1984 & 398 \\
1974 & 262 & 1985 & 739 \\
1975 & 346 & 1986 & 965 \\
1976 & 262 & 1987 & 676 \\
1977 & 245 & 1988 & 464 \\
1978 & 223 & & $4,5 \overline{92}$ \\
1979 & 206 & &
\end{tabular}

Sample total $=7,195$

${ }^{1}$ The number of original categories would change from 7 , encompassing all major letter categories, to 20 , encompassing plus and minus categories as well. The intrarating process continued after its 1974 inception and was completed in 1986 when Standard \& Poor's added pluses and minuses to the CCC category. See Fridson (1991) for a discussion of how the Moody's modified ratings (e.g., 1, 2, and 3 categories within letter ratings) may help to interpret the increase in default rates in recent years for B-rated issues. Moody's instituted its modifiers in 1982. 
TABLE 2. Original Bond Issues, by Number of Years of Rating History

\begin{tabular}{|c|c|c|c|c|c|c|c|c|c|c|}
\hline \multirow{2}{*}{$\begin{array}{l}\text { Original } \\
\text { Rating }\end{array}$} & \multirow[b]{2}{*}{1} & \multirow[b]{2}{*}{2} & \multirow[b]{2}{*}{3} & \multicolumn{4}{|c|}{ Years of Rating History } & \multirow[b]{2}{*}{8} & \multirow[b]{2}{*}{0} & \multirow[b]{2}{*}{10} \\
\hline & & & & 4 & 5 & 6 & 7 & & & \\
\hline AAA & 649 & 601 & 541 & 492 & 450 & 375 & 321 & 262 & 248 & 238 \\
\hline $\mathrm{AA}$ & 1,917 & 1,744 & 1,510 & 1,230 & 1,048 & 875 & 759 & 649 & 611 & 576 \\
\hline A & 2,410 & 2,194 & 1,938 & 1,644 & 1,429 & 1,251 & 1,096 & 969 & 891 & 831 \\
\hline $\mathrm{BBB}$ & 1,090 & 950 & 807 & 636 & 514 & 397 & 335 & 287 & 245 & 217 \\
\hline $\mathrm{BB}$ & 237 & 217 & 170 & 129 & 103 & 78 & 60 & 54 & 46 & 37 \\
\hline B & 702 & 594 & 431 & 293 & 222 & 163 & 118 & 94 & 67 & 52 \\
\hline $\mathrm{CCC}$ & 173 & 118 & 77 & 44 & 28 & 17 & 13 & 12 & 9 & 7 \\
\hline $\mathrm{CC}$ & 13 & 11 & 9 & 3 & 1 & 1 & 1 & 1 & 1 & 1 \\
\hline C & 1 & 1 & 0 & 0 & 0 & 0 & 0 & 0 & 0 & 0 \\
\hline $\mathrm{D}^{\mathrm{a}}$ & 3 & 2 & 2 & 0 & 0 & 0 & 0 & 0 & 0 & 0 \\
\hline Total & 7,195 & 6,440 & 5,485 & 4,471 & 3,795 & 3,157 & 2,703 & 2,318 & 2,117 & 1,959 \\
\hline
\end{tabular}

assued in a distressed or defaulted restructuring.

years of the investment horizon increases. For example, 649 AAA-rated issues had at least one year of experience, 450 had at least five years, and 238 had 10 years. Only 1,959 of the 7,195 issues in the sample had the full 10 years of experience.

In addition to examining the full sample for all years, we also analyzed rating histories for the 1970s and 1980s separately, for two subperiods-1977 to 1982 and 1983 to 1989. In Altman and Kao (1991), we compared rating histories by economic sector.

After observing the rating histories of the aggregate sample and of the various subsamples, we assessed the degree of correlation or association between the initial year's rating and subsequent rating changes. We used several Markov chain approaches to investigate whether a time-dependency relationship exists in rating changes. If so, then it might be possible to model this phenomenon so as to provide more precise expectations about future rating changes, given some existing experience on particular bond issues.

We then discuss, in conceptual terms, the impact of a rating change on bondholder wealth. In addition to the rating change "event," we also note the recent phenomenon whereby securities and companies are put on S\&P's Credit Watch, in almost all cases prior to a rating change. This procedure was started by S\&P on November 2, 1981. A more detailed analysis of these events will be undertaken in future work. 


\section{Empirical Analysis of Bond Rating Drift}

This chapter presents the results of our empirical analysis of bond rating change over time. One of the more intriguing and difficult issues of this study was the possibility that the results would differ depending on the time period examined. We explored this possibility by looking at rating drift for different time periods.

\section{Potential Time Period Bias}

The proportion of bonds changing ratings might be quite different depending upon the specific time period covered. Our study covers new issues from January 1, 1970, through December 31, 1988, and rating changes on those issues through September 1989. In actuality, the first decade of the study period was, in general, a rather positive one for bond rating changes, both in stability of the initial ratings and in ratio of upgrades to downgrades. In contrast, during the second major subperiod, 1980 to 1989, ratings were less stable and were more frequently downgraded than upgraded.

One could argue that the most recent experience on bond rating changes reflects rating drift more accurately than the first period and therefore the results for the entire sample period may not be as indicative of the future. The argument could be based on the enormous corporate debt burden built up in the mid- and late 1980s, which resulted in a greater incidence of downgrading and higher default risk for highly leveraged bonds.

Although this argument is correct for bonds issued from 1986 to 1989, it is not necessarily correct for those issues brought to market after 1989. Indeed, new issues for the foreseeable future may be conservatively marketed, and the bias may be toward the more creditworthy companies and their bonds. If this is true, then the experience of new issues in the $1980 \mathrm{~s}$, and particularly during the 1983 to 1988 subperiod, will not be representative of the bond rating drift of new issues in the next decade. Indeed, a distinct deleveraging of U.S. corporations will probably take place in the 1990 s, which should increase the 
proportion of upgrades. We also agree with Blume, Keim, and Patel (1991) that rating changes and defaults are primarily a function of the economic climate and are less dependent on the individual characteristics of bonds.

An additional argument is that regardless of individual firm characteristics and the riskiness of the bonds issued, the initial rating assigned to the bonds reflects the rating agency's best evaluation of that risk. Therefore, the propensity for ratings to change in the future should be independent of the initial rating.

We believe that the most representative long-term rating drift analysis that we report is for the entire $1970-89$ period. This period included several business cycles, nuclear- and nonnuclear-related incidents for public utilities, the period of growth of newly issued junk bonds, as well as periods when junk bonds were virtually nonexistent. Also, this sample period obviously includes the most observations.

\section{Rating Drift Results for the Entire Sample}

The first empirical investigation was of the entire sample of 7,195 corporate bond issues for the 19-year sample period, 1970 to 1988. Table 3 shows rating drift results for the sample of bonds from 1 to 10 years after issuance. The proportions of the issues that retained their initial bond ratings appear on the diagonals.

As expected, in all rating categories, a continuously declining proportion of the bonds retained their initial ratings as the investment horizon lengthened. The AAA-rated issues had the greatest stability during the earlier years in that a comparatively high proportion retained their initial rating. This is not surprising, because the rating for these issues can change in only one direction-down-while all other categories can be either upgraded or downgraded. Only 69.8 percent of the AAA-rated bonds with a five-year or longer history retained their top rating in the fifth year, but this proportion seems to have stabilized after the fifth year. Of the 238 issues that were in existence for 10 years, 52.1 percent still had an AAA rating.

The issues with a single-A, single- $\mathrm{B}$, or a $\mathrm{CCC}$ rating had higher 10 -year stabilities than the AAA issues. The $\mathrm{CCC}$ data are of little significance, however. Only 7 issues had a 10 -year history, and only 28 had a 5 -year history. Of those, only 28.6 percent retained their rating for the five years. ${ }^{2}$

\footnotetext{
${ }^{2}$ Note that only a very small number of issues are rated below $\mathrm{CCC}$. These ratings are of no concern here because the number of observations is so small and because they represent subordinated issues of senior bonds rated CCC. The three issues rated D were new issues exchanged for already defaulted ones.
} 
TABLE 3. Rating Drift Results for All Issues, by Age of Bond, 1970-89 (percent of original rating group)

\begin{tabular}{|c|c|c|c|c|c|c|c|c|c|c|c|}
\hline \multirow{2}{*}{$\begin{array}{l}\text { Age and } \\
\text { Number } \\
\text { of Issues }\end{array}$} & \multirow{2}{*}{$\begin{array}{c}\text { Original } \\
\text { Rating }\end{array}$} & \multicolumn{10}{|c|}{ Rating at Given Age } \\
\hline & & AAA & $\mathrm{AA}$ & A & $\mathrm{BBB}$ & $\mathrm{BB}$ & B & $\mathrm{CCC}$ & $\mathrm{CC}$ & $\mathrm{C}$ & $\mathrm{D}$ \\
\hline \multicolumn{12}{|l|}{1 Year } \\
\hline 649 & $\mathrm{AAA}$ & 94.3 & 5.5 & 0.1 & 0.0 & 0.0 & 0.0 & 0.0 & & & \\
\hline 1,917 & $\mathrm{AA}$ & 0.7 & 92.6 & 6.4 & 0.2 & 0.1 & 0.1 & 0.0 & 0.0 & 0.0 & 0.0 \\
\hline 2,410 & $\mathrm{~A}$ & 0.0 & 2.6 & 92.1 & 4.7 & 0.3 & 0.2 & 0.0 & 0.0 & 0.0 & 0.0 \\
\hline 1,090 & $\mathrm{BBB}$ & 0.0 & 0.0 & 5.5 & 90.1 & 2.9 & 1.1 & 0.1 & 0.0 & 0.0 & 0.0 \\
\hline 237 & $\mathrm{BB}$ & 0.0 & 0.0 & 0.0 & 6.8 & 86.1 & 6.3 & 0.9 & 0.0 & 0.0 & 0.0 \\
\hline 702 & B & 0.0 & 0.0 & 0.2 & 1.6 & 1.7 & 94.0 & 1.7 & 0.3 & 0.0 & 0.6 \\
\hline 173 & $\mathrm{CCC}$ & 0.0 & 0.0 & 0.0 & 0.0 & 0.0 & 2.8 & 92.5 & 0.0 & 2.3 & 2.3 \\
\hline 13 & $\mathrm{CC}$ & 0.0 & 0.0 & 0.0 & 0.0 & 0.0 & 0.0 & 0.0 & 84.6 & 15.4 & 0.0 \\
\hline 1 & $\mathrm{C}$ & 0.0 & 0.0 & 0.0 & 0.0 & 0.0 & 0.0 & 0.0 & 0.0 & 100.0 & 0.0 \\
\hline 3 & $\mathrm{D}$ & 0.0 & 0.0 & 0.0 & 0.0 & 0.0 & 0.0 & 0.0 & 0.0 & 0.0 & 100.0 \\
\hline \multicolumn{12}{|l|}{2 Years } \\
\hline 609 & $\mathrm{AAA}$ & 86.9 & 12.2 & 0.5 & 0.3 & 0.1 & 0.0 & 0.0 & 0.0 & 0.0 & 0.0 \\
\hline 1,744 & $\mathrm{AA}$ & 1.3 & 84.9 & 12.4 & 1.0 & 0.1 & 0.3 & 0.0 & 0.0 & 0.0 & 0.0 \\
\hline 2,194 & $\mathrm{~A}$ & 0.0 & 5.4 & 84.3 & 9.1 & 1.0 & 0.2 & 0.0 & 0.0 & 0.0 & 0.0 \\
\hline 950 & BBB & 0.1 & 0.4 & 9.6 & 82.5 & 4.3 & 2.2 & 0.2 & 0.1 & 0.0 & 0.5 \\
\hline 217 & $\mathrm{BB}$ & 0.0 & 0.0 & 0.9 & 10.6 & 73.7 & 12.4 & 1.8 & 0.0 & 0.0 & 0.5 \\
\hline 594 & B & 0.0 & 0.0 & 0.9 & 1.4 & 3.2 & 84.8 & 6.9 & 0.9 & 0.7 & 1.3 \\
\hline 118 & $\mathrm{CCC}$ & 0.0 & 0.0 & 0.0 & 0.0 & 0.0 & 6.8 & 80.5 & 1.7 & 4.3 & 6.7 \\
\hline 11 & $\mathrm{CC}$ & 0.0 & 0.0 & 0.0 & 0.0 & 0.0 & 9.1 & 9.1 & 54.5 & 0.0 & 27.3 \\
\hline 1 & C & 0.0 & 0.0 & 0.0 & 0.0 & 0.0 & 0.0 & 0.0 & 0.0 & 100.0 & 0.0 \\
\hline 2 & $\mathrm{D}$ & 0.0 & 0.0 & 0.0 & 0.0 & 0.0 & 0.0 & 0.0 & 0.0 & 0.0 & 100.0 \\
\hline \multicolumn{12}{|l|}{3 Years } \\
\hline 541 & AAA & 81.0 & 15.7 & 2.6 & 0.7 & 0.0 & 0.0 & 0.0 & 0.0 & 0.0 & 0.0 \\
\hline 1,510 & $\mathrm{AA}$ & 2.0 & 77.8 & 17.5 & 2.0 & 0.2 & 0.1 & 0.1 & 0.0 & 0.0 & 0.3 \\
\hline 1,938 & $\mathrm{~A}$ & 0.3 & 6.9 & 78.9 & 12.0 & 1.3 & 0.7 & 0.0 & 0.0 & 0.0 & 0.0 \\
\hline 807 & $\mathrm{BBB}$ & 0.3 & 0.7 & 14.6 & 73.4 & 7.0 & 2.1 & 0.7 & 0.0 & 0.0 & 1.2 \\
\hline 170 & $\mathrm{BB}$ & 0.6 & 0.6 & 1.8 & 17.1 & 62.9 & 11.7 & 3.0 & 0.6 & 0.0 & 1.8 \\
\hline 431 & B & 0.3 & 0.3 & 1.1 & 1.9 & 4.2 & 75.4 & 10.7 & 1.2 & 1.4 & 3.7 \\
\hline 77 & $\mathrm{CCC}$ & 0.0 & 0.0 & 1.3 & 0.0 & 2.6 & 14.3 & 66.3 & 1.3 & 2.6 & 11.7 \\
\hline 9 & $\mathrm{CC}$ & 0.0 & 0.0 & 0.0 & 0.0 & 0.0 & 11.1 & 11.1 & 44.4 & 0.0 & 33.3 \\
\hline 0 & $\mathrm{C}$ & 0.0 & 0.0 & 0.0 & 0.0 & 0.0 & 0.0 & 0.0 & 0.0 & 0.0 & 0.0 \\
\hline 2 & $\mathrm{D}$ & 0.0 & 0.0 & 0.0 & 0.0 & 0.0 & 0.0 & 0.0 & 0.0 & 0.0 & 100.0 \\
\hline
\end{tabular}

Note: Numbers in boldface are percent of issues with unchanged ratings.

Table continued on page 8 . 


\section{TABLE 3-Continued}

\begin{tabular}{rlrlrrrrrrrrr}
\hline $\begin{array}{l}\text { Age and } \\
\text { Number } \\
\text { of Issues }\end{array}$ & Original & Rating & AAA & AA & A & BBB & BB & B & CCC & CC & C & D \\
\cline { 3 - 12 } & & & & & & & & & & & & \\
4 Years & & & & & & & & & & & \\
492 & AAA & $\mathbf{7 6 . 2}$ & 18.5 & 2.6 & 2.4 & 0.0 & 0.2 & 0.0 & 0.0 & 0.0 & 0.0 \\
1,230 & AA & 1.9 & $\mathbf{7 2 . 5}$ & 21.0 & 3.7 & 0.8 & 0.0 & 0.0 & 0.0 & 0.0 & 0.1 \\
1,644 & A & 0.5 & 7.9 & $\mathbf{7 5 . 6}$ & 13.3 & 2.0 & 0.6 & 0.0 & 0.0 & 0.0 & 0.1 \\
636 & BBB & 0.3 & 0.9 & 17.5 & $\mathbf{6 8 . 9}$ & 7.2 & 2.8 & 1.4 & 0.0 & 0.0 & 0.9 \\
129 & BB & 0.0 & 0.0 & 4.7 & 19.4 & $\mathbf{5 6 . 6}$ & 10.9 & 2.4 & 1.5 & 0.0 & 4.7 \\
293 & B & 0.3 & 0.0 & 1.4 & 3.8 & 7.5 & $\mathbf{6 5 . 2}$ & 12.6 & 0.7 & 1.7 & 6.8 \\
44 & CCC & 0.0 & 0.0 & 2.3 & 2.3 & 0.0 & 25.0 & $\mathbf{4 5 . 5}$ & $\mathbf{9 . 1}$ & 0.0 & 15.9 \\
3 & CC & 0.0 & 0.0 & 0.0 & 0.0 & 0.0 & 33.3 & 33.3 & $\mathbf{3 3 . 3}$ & 0.0 & 0.0 \\
0 & C & 0.0 & 0.0 & 0.0 & 0.0 & 0.0 & 0.0 & 0.0 & 0.0 & $\mathbf{0 . 0}$ & 0.0 \\
0 & D & 0.0 & 0.0 & 0.0 & 0.0 & 0.0 & 0.0 & 0.0 & 0.0 & 0.0 & $\mathbf{0 . 0}$
\end{tabular}

$\begin{array}{rlrrrrrrrrrr}5 \text { Years } & & & & & & & & & & & \\ 450 & \text { AAA } & \mathbf{6 9 . 8} & 23.5 & 2.9 & 3.6 & 0.0 & 0.0 & 0.0 & 0.0 & 0.2 & 0.0 \\ 1,048 & \text { AA } & 2.5 & \mathbf{6 7 . 9} & 22.8 & 5.2 & 1.1 & 0.3 & 0.1 & 0.0 & 0.0 & 0.0 \\ 1,429 & \text { A } & 0.4 & 9.2 & \mathbf{7 2 . 5} & 15.2 & 1.9 & 0.7 & 0.0 & 0.0 & 0.0 & 0.1 \\ 514 & \text { BBB } & 0.4 & 1.6 & 19.6 & \mathbf{6 5 . 7} & 7.6 & 1.7 & 1.9 & 0.0 & 0.0 & 1.4 \\ 103 & \text { BB } & 0.0 & 0.0 & 7.7 & 20.4 & \mathbf{4 0 . 8} & 16.5 & 6.8 & 1.0 & 0.0 & 6.8 \\ 222 & \text { B } & 0.4 & 0.0 & 2.7 & 4.5 & 8.6 & \mathbf{5 9 . 9} & 13.5 & 0.4 & 0.9 & 9.0 \\ 28 & \text { CCC } & 0.0 & 0.0 & 3.6 & 3.6 & 0.0 & 35.7 & \mathbf{2 8 . 6} & 7.1 & 0.0 & 21.4 \\ 1 & \text { CC } & 0.0 & 0.0 & 0.0 & 0.0 & 0.0 & 0.0 & 0.0 & \mathbf{1 0 0 . 0} & 0.0 & 0.0 \\ 0 & \text { C } & 0.0 & 0.0 & 0.0 & 0.0 & 0.0 & 0.0 & 0.0 & 0.0 & \mathbf{0 . 0} & 0.0 \\ 0 & \text { D } & 0.0 & 0.0 & 0.0 & 0.0 & 0.0 & 0.0 & 0.0 & 0.0 & 0.0 & \mathbf{0 . 0}\end{array}$

6 Years

$\begin{array}{rlrrrrrrrrrr}375 & \text { AAA } & \mathbf{6 8 . 3} & 25.0 & 3.4 & 2.9 & 0.0 & 0.0 & 0.0 & 0.0 & 0.0 & 0.3 \\ 875 & \text { AA } & 2.5 & \mathbf{6 3 . 4} & 26.0 & 6.0 & 1.4 & 0.3 & 0.0 & 0.0 & 0.0 & 0.3 \\ 1,251 & \text { A } & 0.8 & 8.5 & \mathbf{7 0 . 3} & 16.4 & 2.7 & 1.2 & 0.0 & 0.0 & 0.0 & 0.1 \\ 397 & \text { BBB } & 0.2 & 2.3 & 21.2 & \mathbf{6 3 . 5} & 7.0 & 3.0 & 1.0 & 0.0 & 0.0 & 1.8 \\ 78 & \text { BB } & 0.0 & 0.0 & 10.3 & 24.4 & \mathbf{4 1 . 0} & 11.6 & 7.7 & 0.0 & 0.0 & 5.1 \\ 163 & \text { B } & 0.6 & 0.0 & 4.9 & 3.1 & 6.2 & \mathbf{5 7 . 7} & 15.3 & 0.0 & 0.6 & 11.7 \\ 17 & \text { CCC } & 5.9 & 0.0 & 0.0 & 0.0 & 0.0 & \mathbf{5 8 . 9} & \mathbf{2 3 . 5} & 11.8 & 0.0 & 0.0 \\ 1 & \text { CC } & 0.0 & 0.0 & 0.0 & 0.0 & 0.0 & 0.0 & 0.0 & \mathbf{1 0 0 . 0} & 0.0 & 0.0 \\ 0 & \text { C } & 0.0 & 0.0 & 0.0 & 0.0 & 0.0 & 0.0 & 0.0 & 0.0 & \mathbf{0 . 0} & 0.0 \\ 0 & \text { D } & 0.0 & 0.0 & 0.0 & 0.0 & 0.0 & 0.0 & 0.0 & 0.0 & 0.0 & \mathbf{0 . 0}\end{array}$

Note: Numbers in boldface are percent of issues with unchanged ratings. 
TABLE 3-Continued

\begin{tabular}{|c|c|c|c|c|c|c|c|c|c|c|c|}
\hline \multirow{2}{*}{$\begin{array}{l}\text { Age and } \\
\text { Number } \\
\text { of Issues }\end{array}$} & \multirow{2}{*}{$\begin{array}{c}\text { Original } \\
\text { Rating }\end{array}$} & \multicolumn{10}{|c|}{ Rating at Given Age } \\
\hline & & AAA & AA & A & BBB & BB & B & $\mathrm{CCC}$ & $\mathrm{CC}$ & $\mathrm{C}$ & $\mathrm{D}$ \\
\hline \multicolumn{12}{|l|}{7 Years } \\
\hline 321 & $\mathrm{AAA}$ & 66.0 & 28.1 & 3.4 & 2.5 & 0.0 & 0.0 & 0.0 & 0.0 & 0.0 & 0.0 \\
\hline 759 & $\mathrm{AA}$ & 3.2 & 56.4 & 31.9 & 6.9 & 1.4 & 0.1 & 0.0 & 0.0 & 0.0 & 0.1 \\
\hline 1,096 & A & 0.6 & 9.3 & 68.1 & 17.9 & 3.3 & 0.6 & 0.0 & 0.0 & 0.0 & 0.1 \\
\hline 335 & BBB & 0.0 & 2.4 & 25.7 & $\mathbf{5 8 . 8}$ & 8.4 & 2.1 & 0.9 & 0.0 & 0.0 & 1.8 \\
\hline 60 & $\mathrm{BB}$ & 0.0 & 1.7 & 13.3 & 21.7 & 36.7 & 18.3 & 3.3 & 0.0 & 0.0 & 5.0 \\
\hline 118 & B & 0.8 & 0.0 & 5.9 & 5.1 & 6.7 & 52.6 & 16.9 & 1.7 & 0.8 & 9.3 \\
\hline 13 & $\mathrm{CCC}$ & 7.7 & 0.0 & 0.0 & 0.0 & 0.0 & 61.5 & 23.1 & 7.7 & 0.0 & 0.0 \\
\hline 1 & $\mathrm{CC}$ & 0.0 & 0.0 & 0.0 & 0.0 & 0.0 & 0.0 & 0.0 & 100.0 & 0.0 & 0.0 \\
\hline 0 & $\mathrm{C}$ & 0.0 & 0.0 & 0.0 & 0.0 & 0.0 & 0.0 & 0.0 & 0.0 & 0.0 & 0.0 \\
\hline 0 & $\mathrm{D}$ & 0.0 & 0.0 & 0.0 & 0.0 & 0.0 & 0.0 & 0.0 & 0.0 & 0.0 & 0.0 \\
\hline \multicolumn{12}{|l|}{8 Years } \\
\hline 262 & AAA & 59.9 & 31.7 & 6.1 & 1.9 & 0.0 & 0.4 & 0.0 & 0.0 & 0.0 & 0.0 \\
\hline 649 & $\mathrm{AA}$ & 4.6 & 51.9 & 31.7 & 10.3 & 1.2 & 0.2 & 0.0 & 0.0 & 0.0 & 0.0 \\
\hline 969 & $A$ & 0.8 & 10.2 & 65.2 & 19.8 & 2.9 & 0.6 & 0.3 & 0.0 & 0.0 & 0.1 \\
\hline 287 & $\mathrm{BBB}$ & 0.0 & 1.7 & 27.9 & 55.4 & 8.7 & 3.1 & 2.1 & 0.0 & 0.0 & 1.0 \\
\hline 54 & $\mathrm{BB}$ & 0.0 & 1.9 & 13.0 & 20.3 & 31.5 & 22.2 & 7.4 & 0.0 & 0.0 & 3.7 \\
\hline 94 & B & 1.1 & 1.1 & 6.4 & 4.2 & 6.4 & 47.9 & 18.1 & 1,1 & 4.2 & 9.6 \\
\hline 12 & $\mathrm{CCC}$ & 8.3 & 0.0 & 0.0 & 0.0 & 0.0 & 58.3 & 25.0 & 8.3 & 0.0 & 0.0 \\
\hline 1 & $\mathrm{CC}$ & 0.0 & 0.0 & 0.0 & 0.0 & 0.0 & 0.0 & 0.0 & 100.0 & 0.0 & 0.0 \\
\hline 0 & $\mathrm{C}$ & 0.0 & 0.0 & 0.0 & 0.0 & 0.0 & 0.0 & 0.0 & 0.0 & 0.0 & 0.0 \\
\hline 0 & $D$ & 0.0 & 0.0 & 0.0 & 0.0 & 0.0 & 0.0 & 0.0 & 0.0 & 0.0 & 0.0 \\
\hline \multicolumn{12}{|l|}{9 Years } \\
\hline 248 & AAA & 54.8 & 34.7 & 7.3 & 2.8 & 0.0 & 0.4 & 0.0 & 0.0 & 0.0 & 0.0 \\
\hline 611 & $\mathrm{AA}$ & 4.1 & 49.8 & 29.1 & 15.2 & 1.5 & 0.2 & 0.2 & 0.0 & 0.0 & 0.0 \\
\hline 891 & A & 0.9 & 12.1 & 63.2 & 19.1 & 3.4 & 0.9 & 0.3 & 0.0 & 0.0 & 0.1 \\
\hline 245 & BBB & 0.0 & 2.4 & 32.7 & 49.4 & 7.3 & 5.7 & 1.2 & 0.0 & 0.0 & 1.2 \\
\hline 46 & BB & 0.0 & 2.2 & 13.0 & 23.9 & 19.5 & 17.4 & 17.4 & 0.0 & 0.0 & 6.5 \\
\hline 67 & B & 1.5 & 1.5 & 1.5 & 9.0 & 10.4 & 46.3 & 11.9 & 1.5 & 3.0 & 13.5 \\
\hline 9 & $\mathrm{CCC}$ & 11.1 & 0.0 & 0.0 & 0.0 & 0.0 & 11.1 & 77.8 & 0.0 & 0.0 & 0.0 \\
\hline 1 & $\mathrm{CC}$ & 0.0 & 0.0 & 0.0 & 0.0 & 0.0 & 0.0 & 0.0 & 100.0 & 0.0 & 0.0 \\
\hline 0 & $\mathrm{C}$ & 0.0 & 0.0 & 0.0 & 0.0 & 0.0 & 0.0 & 0.0 & 0.0 & 0.0 & 0.0 \\
\hline 0 & $\mathrm{D}$ & 0.0 & 0.0 & 0.0 & 0.0 & 0.0 & 0.0 & 0.0 & 0.0 & 0.0 & 0.0 \\
\hline
\end{tabular}


TABLE 3-Continued

\begin{tabular}{|c|c|c|c|c|c|c|c|c|c|c|c|}
\hline Age and & & & & & Rat & ig at & ren & ge & & & \\
\hline of Issues & Rating & AAA & $\mathrm{AA}$ & A & $\mathrm{BBB}$ & $\mathrm{BB}$ & B & $\mathrm{CCC}$ & $\mathrm{CC}$ & C & D \\
\hline
\end{tabular}

10 Years

$\begin{array}{rlrrrrrrrrrr}238 & \text { AAA } & \mathbf{5 2 . 1} & 35.7 & 7.1 & 4.6 & 0.0 & 0.4 & 0.0 & 0.0 & 0.0 & 0.0 \\ 576 & \text { AA } & 3.5 & \mathbf{4 6 . 7} & 27.6 & 19.2 & 2.4 & 0.2 & 0.0 & 0.0 & 0.0 & 0.3 \\ 831 & \text { A } & 0.8 & 12.5 & \mathbf{6 1 . 5} & 20.2 & 3.4 & 0.9 & 0.6 & 0.0 & 0.0 & 0.1 \\ 217 & \text { BBB } & 0.0 & 2.8 & 36.8 & \mathbf{4 3 . 3} & 8.3 & 4.6 & 1.9 & 0.0 & 0.0 & 2.3 \\ 37 & \text { BB } & 0.0 & 0.0 & 10.8 & 27.0 & \mathbf{2 1 . 6} & 13.5 & 18.9 & 2.7 & 0.0 & 5.4 \\ 52 & \text { B } & 1.9 & 0.0 & 7.7 & 9.6 & 5.7 & \mathbf{5 3 . 9} & 9.6 & 0.0 & 0.0 & 11.5 \\ 7 & \text { CCC } & 0.0 & 0.0 & 0.0 & 0.0 & 0.0 & 0.0 & \mathbf{8 5 . 7} & 0.0 & 0.0 & 14.3 \\ 1 & \text { CC } & 0.0 & 0.0 & 0.0 & 0.0 & 0.0 & 0.0 & 0.0 & \mathbf{1 0 0 . 0} & 0.0 & 0.0 \\ 0 & \text { C } & 0.0 & 0.0 & 0.0 & 0.0 & 0.0 & 0.0 & 0.0 & 0.0 & \mathbf{0 . 0} & 0.0 \\ 0 & \text { D } & 0.0 & 0.0 & 0.0 & 0.0 & 0.0 & 0.0 & 0.0 & 0.0 & 0.0 & \mathbf{0 . 0}\end{array}$

Note: Numbers in boldface are percent of issues with unchanged ratings.

The least stable category appears to be BB-rated issues, the highest of the "junk bond" categories. Only 86.1 percent of these issues retained their initial rating with just one year of experience, and this proportion falls to 40.8 percent in Year 5 and to 21.6 percent in Year 10.

For the entire transition matrix, the drop-off in stability both down and up the rating scale appears to be somewhat symmetrical, converging on the $\mathrm{BB}$ rating. This pattern is not perfectly symmetrical, however, because the B-rated bonds tended to have greater stability than the $\mathrm{CCCs}$, and after the second year, A-rated issues had greater stability than AA-rated issues. In fact, the A-rated issues had the highest stability from Year 5 on, a finding that was not anticipated.

\section{Likelihood of Upgrade or Downgrade}

Is a change in rating more likely to be an upgrade or a downgrade? The tendency of an issue to be upgraded or downgraded can be assessed by comparing the experience of the different rating categories over time. Table 4 presents upgrade/downgrade results for the $\mathrm{A}$ and $\mathrm{B}$ groups of ratings by the amount of the rating change for 1-, 5-, and 10-year horizons. Figure 1 compares the tendencies to be upgraded or downgraded within rating groups for each year of the 10-year analysis period.

The most striking result is that bonds rated in the A and above investmentgrade categories all have a greater tendency to be downgraded than to be 
TABLE 4. Rating Changes, 1-, 5-, and 10-Year Horizons, Selected Ratings, 1971-89 (percent of original rating group)

\begin{tabular}{|c|c|c|c|c|c|c|}
\hline \multirow[b]{2}{*}{ Change } & \multicolumn{6}{|c|}{ Original Rating } \\
\hline & $\mathrm{AAA}$ & $\mathrm{AA}$ & A & $\mathrm{BBB}$ & $\mathrm{BB}$ & B \\
\hline \multicolumn{7}{|l|}{ 1-year horizon } \\
\hline No change & 94.3 & 92.6 & 92.0 & 90.1 & 86.1 & 94.0 \\
\hline Upgrades & - & 0.7 & 2.6 & 5.5 & 6.8 & 3.5 \\
\hline One & - & 0.7 & 2.6 & 5.5 & 6.8 & 1.7 \\
\hline Two & - & - & 0.0 & 0.0 & 0.0 & 1.6 \\
\hline Three & 一 & - & - & 0.0 & 0.0 & 0.2 \\
\hline More than three & - & -. & $\ldots$ & - & 0.0 & 0.0 \\
\hline Downgrades & 5.6 & 6.8 & 5.2 & 4.4 & 7.2 & 2.6 \\
\hline One & 5.5 & 6.4 & 4.7 & 2.9 & 6.3 & 1.7 \\
\hline Two & 0.1 & 0.2 & 0.3 & 1.1 & 0.9 & 0.3 \\
\hline Three & 0.0 & 0.1 & 0.2 & 0.1 & 0.0 & $0.6^{a}$ \\
\hline More than three & 0.0 & 0.1 & 0.0 & $0.3^{\mathrm{a}}$ & 0.0 & 0.0 \\
\hline \multicolumn{7}{|l|}{ 5-year horizon } \\
\hline No change & 69.8 & 67.9 & 72.5 & 65.7 & 40.8 & 59.9 \\
\hline Upgrades & - & 2.5 & 9.6 & 21.6 & 28.1 & 16.2 \\
\hline One & - & 2.5 & 9.2 & 19.6 & 20.4 & 8.6 \\
\hline Two & - & - & 0.4 & 1.6 & 7.7 & 4.5 \\
\hline Three & - & - & - & 0.4 & 0.0 & 2.7 \\
\hline More than three & - & - & - & - & 0.0 & 0.4 \\
\hline Downgrades & 30.2 & 29.5 & 17.9 & 12.6 & 31.3 & 23.8 \\
\hline One & 23.5 & 22.8 & 15.2 & 7.6 & 16.5 & 13.5 \\
\hline Two & 2.9 & 5.2 & 1.9 & 1.7 & 6.8 & 0.4 \\
\hline Three & 3.6 & 1.1 & 0.7 & 1.9 & 1.0 & 0.9 \\
\hline More than three & 0.2 & 0.4 & $0.1^{\mathrm{a}}$ & $1.4^{\mathrm{a}}$ & $6.8^{\mathrm{a}}$ & $9.0^{\mathrm{a}}$ \\
\hline \multicolumn{7}{|l|}{ 10-year horizon } \\
\hline No change & 52.1 & 46.7 & 61.5 & 43.3 & 21.6 & 53.9 \\
\hline Upgrades & - & 3.5 & 13.3 & 39.6 & 37.8 & 24.9 \\
\hline One & - & 3.5 & 12.5 & 36.8 & 22.0 & 5.7 \\
\hline Two & - & - & 0.8 & 2.8 & 10.8 & 9.6 \\
\hline Three & - & - & - & 0.0 & 0.0 & 7.7 \\
\hline More than three & - & - & - & - & 0.0 & 1.9 \\
\hline Downgrades & 47.8 & 49.7 & 25.2 & 17.1 & 40.5 & 21.1 \\
\hline One & 35.7 & 27.6 & 20.2 & 8.3 & 13.5 & 9.6 \\
\hline Two & 7.1 & 19.2 & 3.4 & 4.6 & 18.9 & 0.0 \\
\hline Three & 4.6 & 2.4 & 0.9 & 1.9 & 2.7 & 0.0 \\
\hline More than three & 0.4 & $0.5^{\mathrm{a}}$ & $0.7^{\mathrm{a}}$ & $2.3^{\mathrm{a}}$ & $5.4^{\mathrm{a}}$ & $11.5^{a}$ \\
\hline
\end{tabular}


upgraded, regardless of the investment time horizon. Within five years, 30.2 percent of the AAA bonds were downgraded-23.5 percent to AA, 2.9 percent to $\mathrm{A}, 3.6$ percent to $\mathrm{BBB}$, and one issue dropped below $\mathrm{BBB}{ }^{3}$

The results are perhaps even more dramatic for AA issues. After five years, only 2.5 percent of the 1,048 originally issued AAs had their rating increased, while 22.8 percent dropped one rating to A, 5.2 percent to $\mathrm{BBB}$, and 1.5 percent to below BBB. For the 10-year horizon, 3.5 percent of the 576 AAs were upgraded, while 2.9 percent dropped all the way to junk bond status, including the 0.3 percent that defaulted. The latter were the Texaco issues that defaulted in 1987.

These differential propensities become greater as the time horizon increases. For example, the proportion of A-rated bond downgrades was 17.9 percent compared to 9.6 percent for upgrades at 5 years and 25.2 percent compared to 13.3 percent at 10 years (Table 4 ).

The issues in the $\mathrm{B}$ group exhibit a different kind of rating drift over time. At the BBB level, for the first time, the proportion of upgrades exceeds that of downgrades for all holding period horizons. The category that had the most similarity between upgrades and downgrades was BB-rated bonds, although for some holding periods, the proportions for downgrades were narrowly higher. For other horizons, however, namely Years 3, 4, 6, and 7, upgrades were higher. B-rated bonds presented the least-clear results. Upgrades led downgrades for the 1- and 10-year horizons, but the reverse was the case for the 5 -year horizon. Indeed, of the 10 years observed, only the first and last intervals (1- and 10-year horizons) favored upgrades (see Figure 1).

For the 1970-89 period, then, the only bond rating category that clearly showed a greater propensity for upgrades than for downgrades was the BBB class, even for the 1980 s, when downgrades generally dominated upgrades. This result is consistent with Altman's (1990b) finding that the BBB category realized the highest return spread over Treasury bonds in the 1980s, compared with all other corporate bond rating classes. The AAA-, AA-, and A-rated bonds clearly showed a greater propensity for downgrades than for upgrades. The BB- and B-rated bonds showed no clear differential.

The question is whether these results are sensitive to the time period chosen for analysis. Individual-year results are likely to be sensitive to the general health of the economy. The 1980s, and particularly the late 1980s, had

\footnotetext{
${ }^{3}$ The same appears to be true for 10 years, although 0.4 percent (one issue) dropped to $\mathrm{B}$ in 10 years. Prior work (Altman 1991) had shown a few AAAs actually defaulting. These defaults, however, must have occurred more than 10 years after issuance.
} 


\section{FIGURE 1. Bond Rating Drift Experience (percentage changed or unchanged)}
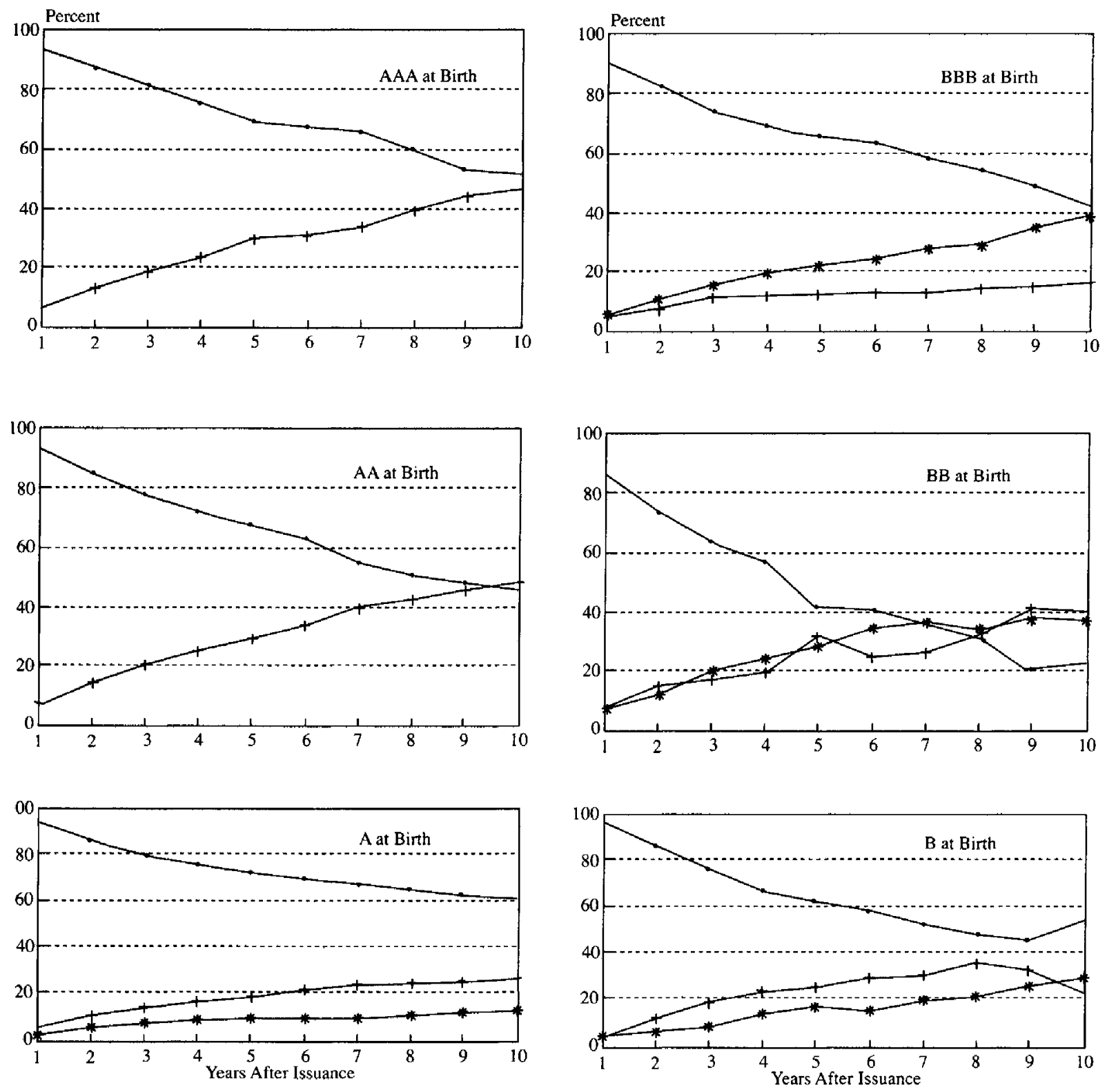

$\rightarrow$ Unchanged + Downgraded - Upgrade

- Unchanged + Downgraded $\rightarrow$ Upgrade 
vastly higher numbers of downgrades than upgrades. Analysis of the 1970-89 period, however, conceals some of these effects because it encompasses several general economic cycles as well as the leverage binge of the mid- and late 1980 s.

\section{Results for Different Time-Period Intervals}

The corporate bond market, like so many other financial systems, goes through distinct cycles of activity and performance. One of the most relevant cycles for these securities is the business cycle. Indeed, Blume and Keim (1989) found that, adjusted for aggregate economic activity, the aging effect on bond defaults is less meaningful. Vanderhoof et al. (1989) and Altman and Nammacher (1987) also tracked defaults over various cycles of aggregate economic activity and found evidence of default relationships with longer business cycles but not with individual-year economic change.

Rating changes are also likely to be related to aggregate economic activity. In a growing economy, upgrades can be expected to dominate as companies perform better and as the rating agencies perceive that performance will continue to improve. The converse is likely in a declining economy. The relationship between rating changes and economic activity may be hard to determine, however, because of changes in other variables that affect ratings. For example, periods of fundamental changes in key variables that affect ratings, such as capital structure ratios, are likely to be accompanied by rating changes. In the mid- and late 1980s, for example, downgrades exceeded upgrades as companies increased leverage significantly.

When both economic activity and leverage are increasing, the direction of rating changes is unpredictable. A higher level of economic activity will increase earnings and cash flow, while more leverage increases interest burdens. The likely net effect on coverage ratios is uncertain.

To investigate the effect of this potential time dependency on rating changes, we observed rating changes separately for the 1970-79 and the 1980-89 periods. We also looked at the early stages of the junk bond market's revival from 1977 to 1982 and the later period of high growth in new issuance of junk bonds from 1983 to 1988 . This latter period is also coincident with an increased number and rate of bond defaults and heightened expectations of increased defaults in the future (Altman 1990a).

Several complications arose in comparing results for specific investment horizons from one sample period to another. Results for bonds newly issued during the two 10-year subperiods (1970-79 and 1980-89) are not strictly comparable, for example. In the 1970-79 period, 2,603 issues had at least one year of experience. Because the history of these bonds could be traced through 
September 1989, a large number $(1,959)$ of these issues had 10 years of experience. For the 1980-88 issuance period, the number of bonds with at least 1 year of experience was greater $(4,592)$, but none of these bonds had 10 years of experience because the sample end-point was less than 10 years. Only 1,258 of the $1980-88$ issues (27.4 percent of the total) had five years of experience, but five years of experience in the later subperiod only covers rating changes for bonds issued from 1980 to 1984. A bond issued in 1985 had only four years of experience.

If the aging phenomenon (i.e., bonds' increasing marginal propensity to default over time) advocated by Asquith et al. (1989) is in evidence, and if aging experience changes over time with a new crop of bonds, then what occurs in one time period would not be expected to recur in the next. For example, the five-year experience of bonds issued between 1980 and 1984 may not be the same as that of those issued between 1985 and 1989. At a later point, we will compare the five-year experience of bonds issued from 1977 to 1982 with those issued between 1980 and 1984. Because this study includes rating experience only through September 1989, we cannot assess the five-year experience of bonds issued after 1984 .

Comparison of 1970-79 and 1980-89 Results. The 1980-88 period had more bond issuance than the earlier period (4,592 as opposed to 2,603 ), reflecting the growing attractiveness of fixed-income securities to investors and corporations' increasing use of leverage. The reverse could be the case in the 1990s as deleveraging of companies becomes more prevalent.

Table 5 presents a comparison of the one- , three-, and five-year rating stability of bonds in the $1970-79$ period with that in the $1980-89$ period. The analysis does not go beyond the five-year horizon because the number of observations in the later subperiod (the 1980s) diminishes significantly. The entire rating drift for both periods is given in Appendix B. Appendix B also indicates, for the two decades, the extent of the rating changes-for example, the proportion of originally rated issues that had one or more changes in either direction.

The overwhelming finding is that the stability of ratings in the more recent issuance period is far less than that in the earlier period. This was the case regardless of the bond rating or the specific year subsequent to the initial issuance. For example, 97.4 percent of the AAA-rated bonds retained their rating for one year after issuance during the earlier sample period, and 91.6 percent did so in the later period. Five years after issuance, the earlier sample period's AAA retention fell to 80.0 percent, while the later period's retention fell dramatically to just 49.3 percent. This difference was partially a reflection of 


\section{TABLE 5. Stability of Ratings: New Issuance, 1970-79 and 1980-88}

\begin{tabular}{|c|c|c|c|c|}
\hline \multirow{2}{*}{$\begin{array}{l}\text { Original } \\
\text { Rating } \\
\text { and Age }\end{array}$} & \multicolumn{2}{|c|}{$1970-79$ Issues } & \multicolumn{2}{|c|}{$1980-88$ Issues } \\
\hline & Number & Unchanged (\%) & Number & Unchanged (\%) \\
\hline \multicolumn{5}{|l|}{$A A A$} \\
\hline 1 year & 302 & 97.4 & 347 & 91.6 \\
\hline 3 years & 302 & 92.1 & 239 & 6.9 \\
\hline 5 years & 300 & 80.0 & 150 & 49.3 \\
\hline \multicolumn{5}{|l|}{$A A$} \\
\hline 1 year & 698 & 95.3 & 1,219 & 91.1 \\
\hline 3 years & 695 & 80.3 & 815 & 75.8 \\
\hline 5 years & 688 & 67.6 & 360 & 68.6 \\
\hline \multicolumn{5}{|l|}{$A$} \\
\hline 1 year & 1,066 & 96.3 & 1,344 & 88.6 \\
\hline 3 years & 1,058 & 87.9 & 880 & 68.0 \\
\hline 5 years & 1,040 & 77.7 & 389 & 58.9 \\
\hline \multicolumn{5}{|l|}{$B B B$} \\
\hline 1 year & 327 & 96.3 & 763 & 87.4 \\
\hline 3 years & 323 & 87.9 & 484 & 63.6 \\
\hline 5 years & 315 & 74.3 & 199 & 52.3 \\
\hline \multicolumn{5}{|l|}{$B B$} \\
\hline 1 year & 69 & 98.6 & 168 & 81.0 \\
\hline 3 years & 67 & 70.1 & 103 & 58.3 \\
\hline 5 years & 64 & 46.9 & 39 & 30.8 \\
\hline \multicolumn{5}{|l|}{$B$} \\
\hline 1 year & 122 & 97.5 & 580 & 93.3 \\
\hline 3 years & 120 & 82.5 & 311 & 72.7 \\
\hline 5 years & 115 & 68.7 & 107 & 50.5 \\
\hline \multicolumn{5}{|l|}{$C C C$} \\
\hline 1 year & 18 & 100.0 & 155 & 91.6 \\
\hline 3 years & 15 & 46.7 & 62 & 71.0 \\
\hline 5 years & 14 & 35.7 & 14 & 21.4 \\
\hline
\end{tabular}

the large number of nuclear-related electric public utility and commercial bank downgrades in the 1980s.

The least stable retention rates, both in the initial and in the later sample periods, were among the $\mathrm{BB}$ - and $\mathrm{CCC}$-rated issues. By the fifth year, retention for the $\mathrm{BBs}$ fell to 46.9 percent in the earlier period and to 30.8 
percent in the later period; the comparable rates for the CCCs were 35.7 percent and 21.4 percent, respectively. The CCCs had extremely small sample sizes, however, and the BB samples, although somewhat larger, were still relatively small.

The only rating category that did not display greater five-year instability in the 1980-89 period than in the 1970-79 period was the AA-rated bonds-68.6 percent unchanged as opposed to 67.6 percent in the earlier period. One possible reason was that some of the AA-rated electric public utility issues that were downgraded were subsequently upgraded as rate relief and cash flows improved. In the first few years after issuance, AAs had lower stability in the 1980-89 period. This phenomenon reversed itself only in the fifth year after issuance. This was not true for any other rating category, however, so we can conclude that rating instability did indeed increase in the 1980s.

We also analyzed rating changes during two additional, shorter subperiods1977 to 1982 and 1983 to 1988 . These results, as well as those for each of the two decades, are shown in Table 6. A complete listing of rating changes for the earlier subperiods for the entire 10-year horizon can be found in Altman and Kao (1991).

Some of the more important, although not necessarily surprising, findings are:

- The incidence of downgrades was far greater in the 1980 s than in the 1970s, and this dominance was found in most, but not all, original rating classes.

- The lower grade junk bond issues (rated below BBB) experienced a positive "balance of change" (upgrades minus downgrades) for most of the entire sample period, but the balance reversed itself for the most recent subperiod (1983 to 1988).

- The balance of change for the A-rated and above-investment-grade bonds was extremely unfavorable throughout the entire sample period. Downgrades exceeded upgrades for every rating and every subperiod for the one-, three-, and five-year horizons.

- The one exception to the upgrade/downgrade imbalance for the entire sample period, as well as the subperiods, is the apparent excellent postissuance performance of the BBB-rated issues.

- BB-rated bonds performed quite well in terms of rating changes, except for the more recent subperiod, 1983 to 1988.

- The balance of change completely reversed in the CCC class comparing the 1970-79 period (when upgrades dominated) to the 1983-88 period (when downgrades dominated, especially for the five-year horizon). 
TABLE 6. Upgrades and Downgrades for Sample Subperiods

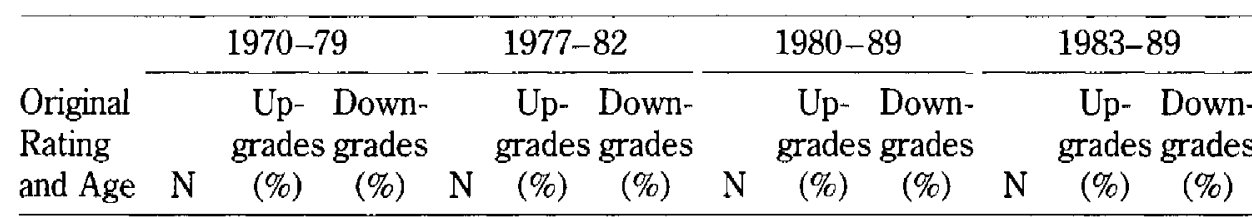

$A A A$

$\begin{array}{lrlrllrllrrrr}1 \text { year } & 302 & - & 2.6 & 214 & - & 8.9 & 347 & - & 8.4 & 219 & - & 5.5 \\ 3 \text { years } & 302 & - & 8.0 & 207 & - & 28.5 & 239 & - & 33.1 & 115 & - & 21.2 \\ 5 \text { years } & 300 & - & 20.0 & 197 & - & 46.7 & 164 & - & 50.7 & 39 & - & 35.9\end{array}$

$A A$

$\begin{array}{lllllllllllll}1 \text { year } & 698 & 1.1 & 3.6 & 439 & 2.3 & 3.8 & 1219 & 0.4 & 8.5 & 944 & 0.3 & 9.5\end{array}$

$\begin{array}{lllllllllllll}3 \text { years } & 695 & 2.4 & 17.3 & 431 & 3.2 & 19.1 & 815 & 1.6 & 22.6 & 559 & 1.6 & 24.5\end{array}$

$\begin{array}{lllllllllllll}5 \text { years } & 688 & 2.8 & 29.8 & 390 & 2.1 & 32.8 & 360 & 1.9 & 29.5 & 132 & 2.3 & 29.6\end{array}$

A

$\begin{array}{lllllllllllll}1 \text { year } & 1,066 & 1.3 & 2.3 & 545 & 2.4 & 4.4 & 1344 & 3.8 & 7.6 & 1013 & 4.3 & 8.4\end{array}$

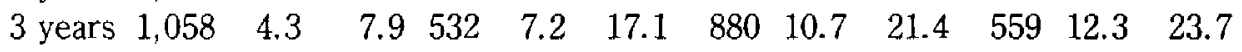

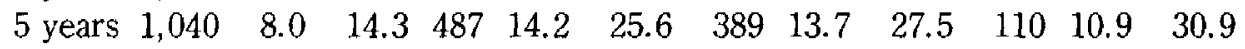

$B B B$

$\begin{array}{lllllllllllll}1 \text { year } & 327 & 2.1 & 1.5 & 221 & 2.7 & 4.6 & 763 & 6.9 & 5.6 & 606 & 7.9 & 5.7\end{array}$

$\begin{array}{lllllllllllll}3 \text { years } & 325 & 8.6 & 3.4 & 219 & 16.0 & 14.6 & 484 & 20.2 & 16.0 & 329 & 20.6 & 15.5\end{array}$

$\begin{array}{lllllllllllll}5 \text { years } & 321 & 18.1 & 7.9 & 187 & 24.5 & 16.0 & 199 & 27.1 & 20.6 & 74 & 25.7 & 23.0\end{array}$

$B B$

$\begin{array}{lllllllllllll}1 \text { year } & 69 & 0.0 & 1.4 & 59 & 10.2 & 3.4 & 168 & 9.5 & 9.5 & 145 & 6.9 & 10.4\end{array}$

$\begin{array}{lllllllllllll}3 \text { years } & 67 & 19.4 & 10.5 & 54 & 26.0 & 16.7 & 103 & 20.4 & 21.4 & 84 & 17.9 & 21.5\end{array}$

$\begin{array}{lllllllllllll}5 \text { years } & 64 & 31.2 & 21.9 & 51 & 37.3 & 33.4 & 39 & 23.1 & 46.3 & 21 & 4.8 & 67.1\end{array}$

$B$

$\begin{array}{lllllllllllll}1 \text { year } & 122 & 2.4 & 0.0 & 162 & 3.1 & 0.0 & 580 & 3.6 & 3.1 & 514 & 3.7 & 3.6\end{array}$

$\begin{array}{lllllllllllll}3 \text { years } & 120 & 11.6 & 5.8 & 157 & 10.7 & 8.8 & 311 & 6.1 & 21.2 & 248 & 5.6 & 22.9\end{array}$

$\begin{array}{lllllllllllll}5 \text { years } & 115 & 20.0 & 11.3 & 135 & 17.0 & 22.1 & 107 & 12.1 & 37.4 & 61 & 16.4 & 32.9\end{array}$

$C C C, C C, C$

$\begin{array}{lllllllllllll}1 \text { year } & 18 & 0.0 & 0.0 & 18 & 5.6 & 0.0 & 170 & 3.0 & 3.6 & 167 & 2.6 & 6.0\end{array}$

$\begin{array}{lllllllllllll}3 \text { years } & 15 & 46.7 & 6.7 & 15 & 53.3 & 0.0 & 72 & 11.1 & 19.4 & 68 & 10.3 & 21.1\end{array}$

$\begin{array}{lllllllllllll}5 \text { years } & 14 & 57.1 & 7.1 & 13 & 84.6 & 0.0 & 14 & 28.6 & 50.0 & 11 & 9.1 & 63.6\end{array}$ 
Time-Period Differences in Stability. In our rating stability comparison of the 1970s with the 1980s, we assessed changes for up to five years after issuance. The sample of bonds issued in the 1980s diminishes as the horizon increases, and even a five-year experience only covers bonds issued from 1980 to 1984. Hence, comparisons for longer than five years are meaningless.

Downgrade proportions increased in almost every bond rating class and for the entire one- to five-year horizon in the $1980 \mathrm{~s}$ compared with the $1970 \mathrm{~s}$. Upgrade percentages also tended to increase in the most recent subperiod, but not nearly as much as downgrades. This confirms the conclusion that bond ratings, in general, were far less stable in the later decade. The reasons for this reduction in stability are many, including more economic and interest rate volatility, increased corporate leverage, lower cash flow and earnings coverages, and perhaps a greater propensity on the part of rating agencies to move more quickly and decisively to discover a firm's deterioration and reflect it in a downgrade. The rating agencies have been sensitive to criticism that the ratings do not reflect a company's credit deterioration fast enough to help warn investors.

Junk bond returns are sensitive to defaults and yield spreads, and they also reflect changes in a firm's creditworthiness after the initial designation as a junk bond. This is true for newly issued bonds, as well as fallen angels (see Altman 1991). Although a convincing case has been made that new-issue credit quality deteriorated after about 1985 (Wigmore 1990), this should not affect subsequent ratings if the rating agencies evaluate the new issues without bias.

Downgrades far exceeded upgrades in the one- to five-year horizon periods for new issuance from 1983 to 1988 (Table 6). Indeed, 67.1 percent of the BB-rated, 32.9 percent of the B-rated, and 63.6 percent of the CCC-rated bonds were downgraded within five years after issuance in the 1983-88 period. This compares with just 21.9 percent, 11.3 percent, and 7.1 percent, respectively, for the 1970-79 period.

Bonds originally rated $\mathrm{A}$ or above displayed a consistent tendency for downgrades to exceed upgrades, regardless of the period of time studied. Of course, AAA ratings can only go down, if they change at all, but the fact that more than half of the AAAs issued in the 1980-88 period dropped in rating within five years is surprising. This proportion was only 20 percent for the $1970-79$ period. AA-rated bonds tended to have very little chance of an upgrade (less than 3 percent within five years), and fairly uniformly, about 30 percent of the issues could be expected to be downgraded within five years. A-rated bonds had a greater likelihood of upgrades than AA-rated issues, although their downgrades still exceeded their upgrade percentages by about two to one. This ratio has a good deal of statistical significance because the number of observa- 
tions was high and the upgrade proportion was not so low as to make the ratio irrelevant, as was the case for AA-rated issues.

The BBB-rated category was the only one that showed a dominance of rating upgrades over downgrades regardless of the sample period studied or the length of the investment horizon. This was true for the 10-year horizon, as well, although it is not shown in Table 5. For the five-year horizon, BBB upgrades exceeded downgrades by more than two to one in the 1970-79 period; upgrades exceeded downgrades in the $1980-89$ period as well, although the margin was small. These favorable results for the BBB category are in agreement with earlier findings (Altman 1990b) dealing with net investment returns of BBB-rated bonds compared with all other corporate bond rating classes for the past decade (1980 to 1989).

BB-rated bonds, the "quality" junk bond rating class, generally had a higher percentage of upgrades than downgrades for the earlier sample periods but not for the more recent ones. Indeed, for the 1970s, upgrades easily dominated downgrades, while the two were about the same for the 1980-89 period (except for the five-year horizon, for which downgrade percentages were about twice those for upgrades). The sample size for this category, 39 issues, was quite small, however. The CCCs also showed a complete reversal from the first decade to the second, with downgrades (to default) dominating upgrades in the more recent period.

\section{Economic Sector Results}

We also analyzed bond rating drift for companies classified by economic sector. The sectors analyzed and the number of issues by year of issue for each sector are shown in Table 7. Industrial issues include all that are not finance, public utility, or foreign issues. These primarily include manufacturing, transport, retail, and other service firms. The rating history of these economic sectors' issues can be found in Altman and Kao (1991). Here, we will comment only on some of the general findings of that study.

The industrial group sample and probably the other finance and electric utilities with nuclear facilities categories had sufficient sample sizes for careful analysis of rating drift over time. Each of these samples had more than 1,000 issues with at least one year of rating history.

The Industrial Sector. The industrial bond sample constituted 43.6 percent of the entire 7,195-issue sample. Hence, any comparison between industrial firm rating drift and the entire sample is based on differences between those industrials and all other sector groupings. A comparison of industrial firms and the entire sample leads to the following findings: 
TABLE 7. Sample Distribution by Issuance Year and Economic Sector

\begin{tabular}{lrrrrrrrrr}
\hline Issuance & & & IND & OTH & UTL & UTL & OTH & ALL & \\
Year & IND & FIN & FIN & N-NK & NUK & UTL & OTH & Total \\
\hline 1970 & 132 & 13 & 14 & 39 & 97 & 46 & 8 & 349 \\
1971 & 129 & 19 & 16 & 32 & 83 & 24 & 1 & 304 \\
1972 & 70 & 19 & 16 & 33 & 74 & 17 & 3 & 232 \\
1973 & 62 & 8 & 8 & 18 & 63 & 12 & 3 & 174 \\
1974 & 104 & 14 & 11 & 36 & 81 & 13 & 3 & 262 \\
1975 & 160 & 22 & 16 & 34 & 83 & 26 & 5 & 346 \\
1976 & 85 & 26 & 37 & 36 & 55 & 17 & 6 & 262 \\
1977 & 94 & 22 & 39 & 22 & 54 & 7 & 7 & 245 \\
1978 & 101 & 21 & 22 & 20 & 47 & 1 & 11 & 223 \\
1979 & 95 & 13 & 25 & 22 & 36 & 9 & 6 & 206 \\
1980 & 145 & 18 & 43 & 11 & 71 & 11 & 3 & 302 \\
1981 & 118 & 23 & 31 & 17 & 55 & 12 & 16 & 272 \\
1982 & 144 & 48 & 97 & 16 & 79 & 14 & 12 & 410 \\
1983 & 139 & 42 & 92 & 12 & 52 & 14 & 15 & 366 \\
1984 & 138 & 43 & 129 & 7 & 43 & 7 & 31 & 398 \\
1985 & 367 & 72 & 161 & 18 & 68 & 27 & 26 & 739 \\
1986 & 508 & 78 & 169 & 42 & 113 & 35 & 20 & 965 \\
1987 & 311 & 84 & 166 & 18 & 67 & 21 & 9 & 676 \\
1988 & 234 & 47 & 112 & 5 & 40 & 20 & 6 & 464 \\
Total & 3,136 & 632 & 1,204 & 438 & 1,261 & 333 & 191 & 7,195 \\
\hline
\end{tabular}

Key: IND $\quad=$ All industrial companies

IND FIN = Financial subsidiaries of industrial companies

OTH FIN = Financial institutions other than IND FIN

UTL N-NK = Electric public utilities not associated with nuclear power

UTL NUK = Electric public utilities with nuclear power

OTH UTL = Other utilities, primarily telephone and gas companies

ALL OTH = All other, primarily REITs

- Investment-grade industrial firms appear to be more stable in retaining their original ratings than all other nonindustrial firm issues. This is the case for the entire 10-year investment holding period.

- For noninvestment-grade original ratings, the difference between industrial sector firm issues and all other sectors is less clear. On balance, the industrial issues appear to be slightly more stable, especially for the five-year holding period. 
The Financial Sector. Comparing industrial firm issues with industrial firm finance issues, the latter, primarily captive finance companies, are clearly less stable than their nonfinance counterparts. These results are not definitive, however, for two reasons. First, the sample size for industrial finance issues is rather small; only 283 issues have five-year rating period experience, and only A-rated issues have more than 100 issues. Second, industrial firm issues are not being compared with their own industrial finance company issues. Hence, the reason for the industrial issues' greater rating stability may be based on the credit characteristics of different firms rather than sector differences between industrials and finance industrials. Actually, a comparison of captive industrial finance issues with issues of their industrial parents would be of little interest because, since 1981, the two are almost always assigned the same rating by S\&P staff. Still, the results here are a bit surprising in that industrial finance companies would appear to have more solid assets (basically parent company receivables) to back up their indebtedness.

Issues by all other finance companies, primarily financial institutions, had significantly more stable ratings than did industrial finance issues. For example, the three-year holding period horizon shows other finance company issues with original rating retention ranging from 87.5 percent for $B$-rated issues (not counting the 100 percent retention for just two CCC-rated issues) down to 72.1 percent unchanged for BBBs. The industrial finance issue unchanged-rating range was from 71.3 percent for AA down to 44.4 percent for $\mathrm{BB}$ and $\mathrm{B}$. Only 50 percent of the AAA-rated industrial finance issues retained their ratings for three years, while 78.1 percent of the other finance issues retained their AAA rating.

The findings were mixed for the comparison of industrial firm issues with other financial institution issues. For example, AAA industrials retained their rating better than AAA financial institutions (87.0 percent compared to 78.1 percent and 77.6 percent compared to 69.1 percent for three- and five-year horizons, respectively).

$\mathrm{AA}$ - and A-rated issues were quite similar for these two sector groupings. Industrial BBBs had much higher stability for five years than their financial institution counterparts (65.8 percent compared to 51.2 percent), but not for three years. In contrast, for B-rated issues, financial institutions had a considerably higher retention rate than did industrial issues $(87.5$ percent compared to 76.4 percent and 73.3 percent compared to 61.9 percent for three and five years, respectively).

The Public Utility Sectors. The public utility sectors comprise electric power companies, both with and without nuclear facilities, and all other public 
utilities, primarily telephone and gas companies. ${ }^{4}$ Because most public utility new issues receive an investment-grade rating, the two meaningful classes for comparison are AA- and A-rated issues. Indeed, the majority of the nonnuclear, nuclear, and other utility issues- 82 percent, 68 percent, and 68 percent, respectively-were in these two rating classes.

The nuclear and nonnuclear electric utility issues are analyzed separately because the former came under intense pressure, particularly in the $1980 \mathrm{~s}$, to cancel, postpone, or phase out the use of this power source. Therefore, issues of nuclear-powered or potentially nuclear-powered utilities would be expected to display less-stable rating histories, and that is exactly the case.

For the entire spectrum of holding periods and for all bond rating classes, except AAA, nonnuclear electric power company issues retained their ratings far more often than did those of nuclear-powered utilities. Only the AAA nonnuclear utility class, which had a very small sample size (seven issues) displayed less stability. Every AAA issue was downgraded by the fifth year, while 43.4 percent of the 53 nuclear-related utility AAA issues were downgraded. In all other cases, nuclear-related company issues were more likely to experience a rating change, and this change was usually a downgrade for AAand A-rated issues. In contrast, $\mathrm{BBB}$ original ratings for nuclear-powered utilities had about an equal propensity to be upgraded or downgraded by the fifth year (15.1 percent upgrades and 14.5 percent downgrades).

Because the nuclear power question appears to have affected the rating history of those utility issues, the most relevant rating drift experience for subsequent forecasting application can likely be derived from the nonnuclear utility sample.

\section{The Moody's Study}

The Moody's study by Lucas and Lonski (1991) has several differences, as well as similarities, to this study. Both cover descriptive data on rating changes for about the same overall period of time (1970 to 1989 or 1990), and both report on similar subperiods. The Moody's study obviously examines its own ratings and we examine S\&P ratings, but the results should not be biased because of this difference. Other, more important, differences in the two studies are the following:

- The Moody's study concentrates on about 4,000 individual issuers, including U.S. and international debt issuers, covering industrials, utili-

\footnotetext{
${ }^{4}$ We are indebted to several of the rating services, particularly Standard \& Poor's and Fitch, for providing us with information on nuclear-related issues.
} 
ties, financial institutions, sovereign countries, and structured finance entities that issued long-term debt. In addition, about 2,500 commercial paper issuers were also examined. Our study examines 7,195 issues (not issuers) but is concerned only with intermediate- and long-term corporate bonds.

- The Moody's study categorized all issuers by their actual or implied senior, unsecured debt rating, requiring a significant number of issuers with no senior issue to have their ratings implied from nonsenior issues. Of their issuers, 26 percent had only subordinated issues and received a one-rating "upgrade," and 18 percent of the issuers had only secured bonds and received a one-rating "downgrade" (or a one-tick downgrade after Moody's introduction of rating modifiers; see Appendix A).

- The Moody's study concentrates primarily on one-year rating changes, regardless of the age of the bond. It also shows changes for up to 10 years. Our study looks at rating changes subsequent to the original issue date only and covers up to 10 years of experience. In all cases, the Moody's results are based on various horizon periods with no reference to whether the bond is newly issued or in existence for a number of years. Although we concentrate on postissue experience, our stochastic model does consider the prior experience of an issue in order to estimate future rating changes.

- The Moody's study is a descriptive report with little interpretive commentary, and no attempt was made to model the rating change experience. Our study includes extensive modeling of rating drift.

Because we examine the postissuance period and Moody's does not, the two studies' results are not exactly comparable. Nevertheless, the descriptive differences in results are not major. Both studies find that corporate creditworthiness, as measured by rating changes, became much more volatile in the 1980 s compared to the 1970 s and that downgrades dominated upgrades, especially in the 1980s. A few other comparisons between the two studies are presented in Table 8.

With the exception of $\mathrm{Ba} / \mathrm{BB}$ ratings, all of the other rating categories show more stability - that is, a greater proportion of issues unchanged-in our study than in the Moody's study for the same holding period horizons. This difference in stability is particularly marked for the 5 - and 10-year horizons. Part of these differences may be explained by the fact that the Moody's results include 1990, a fairly unstable year, particularly for downgrades, and our results do not. Upon closer scrutiny, however, the 1990 results appear to be no different from those for the average year during the 1982-89 period (see Lucas and Lonski 1991, 


\section{TABLE 8. Rating Stability, Moody's and Standard \& Poor's, Various Holding Periods (percent of original rating group)}

\begin{tabular}{|c|c|c|c|c|c|c|}
\hline \multirow{3}{*}{$\begin{array}{l}\text { Original } \\
\text { Rating }\end{array}$} & \multicolumn{6}{|c|}{ Unchanged Ratings } \\
\hline & \multicolumn{3}{|c|}{ Moody's $1970-90$} & \multicolumn{3}{|c|}{ S\&P $1970-89$} \\
\hline & 1 Year & 5 Years & 10 Years & 1 Year & 5 Years & 10 Years \\
\hline $\mathrm{Aaa} / \mathrm{AAA}$ & 93 & 65 & 47 & 94 & 70 & 52 \\
\hline $\mathrm{Aa} / \mathrm{AA}$ & 92 & 54 & 37 & 93 & 68 & 47 \\
\hline $\mathrm{A} / \mathrm{A}$ & 92 & 60 & 43 & 92 & 73 & 62 \\
\hline $\mathrm{Baa} / \mathrm{BBB}$ & 90 & 51 & 31 & 90 & 66 & 43 \\
\hline $\mathrm{Ba} / \mathrm{BB}$ & 87 & 42 & 22 & 86 & 42 & 22 \\
\hline $\mathrm{B} / \mathrm{B}$ & 87 & 42 & 20 & 94 & 60 & 54 \\
\hline $\mathrm{Caa} / \mathrm{CCC}$ & 86 & 35 & 16 & 93 & 29 & - \\
\hline
\end{tabular}

Source: Table 3 of this report and Lucas and Lonski (1991), pp. 13 and 17.

Figure 1). If some kind of aging effect is present, however, then to lump bonds of various ages together clouds the results somewhat for bonds of any given age.

The Moody's and S\&P results for one-year rating drift are essentially identical for most of the rating classes with the exception of the lowest two classes (B and $\mathrm{Caa} / \mathrm{CCC}$ ). For these two, S\&P's initial ratings were far more stable for the one-year horizon than were Moody's. The latter, again, were for one year regardless of the issue's age. This would imply that the aging effect becomes more relevant as the bond gets older and as the rating class becomes lower. A noninvestment-grade bond appeared to have a greater propensity to be downgraded in one year if it was not just issued. As we have pointed out elsewhere (Altman 1990a), the aging phenomenon may not be consistent over time as the bond gets older, at least with respect to defaulting bonds.

Perhaps a more relevant question is whether a new issue is more likely to retain its rating for, say, five years than an issue that is already two or three years old. This probably is the case, because a bond issuer receives its most intense credit rating scrutiny when its issue is new; thereafter, analysis of the issuer's creditworthiness is not nearly as intense and timely. Hence, a significant drift in creditworthiness may occur before the various agencies review a credit. Moreover, the timeliness and thoroughness of rating reviews may have improved in recent years. This certainly is the case for junk bonds in the late 1980s, when the S\&P staff devoted to the low-grade sector expanded 
dramatically. These factors could affect the reliability of rating drift results encompassing bonds of different ages and time periods. The intensity and timeliness of rating scrutiny with respect to new issues in comparison with seasoned ones could very well account for a significant proportion of the differences in the two studies' results. 


\section{Modeling Bond Rating Drift}

The first step in modeling bond rating drift is to determine whether it is a stochastic or a deterministic process. A process is called stochastic if its operation can be described by a random variable and a probability distribution that indicates the relative likeliness of each possible value. In contrast, the function and values of a deterministic process can be illustrated specifically in terms of one or more mathematical formulas.

Once a model is identified as stochastic, the parameters can be updated as current actual transition matrixes become available. The estimation process requires successive one-step transition matrixes (e.g., a one-year transition horizon) observed at present time: $P(t, t+1)$ where $t$ is the beginning period, $t+1$ the ending period, and $t=0,1,2, \ldots, T$. After the parameters are calculated, the transition matrixes over a longer period (e.g., $P(0,2), P(0,3), \ldots, P(0, T)$ ) can be estimated by applying the properties of an assumed model. With respect to bond rating changes, this estimation procedure can be implemented not only for newly issued bonds but also for seasoned bonds. In this case, the starting time period of a multiple-step transition matrix, $k$, is the number of years since the bond was issued, and transition matrixes estimated are $\hat{P}(k, k+2)$, $\hat{P}(k, k+3), \ldots$, and $\hat{P}(k, T)$. Although we concentrate on newly issued bonds, we will also present results based on the age of the bond.

\section{The Markov Chain Process}

The Markov chain process is a stochastic model that describes certain time series. It consists of an initial distribution of observations with a finite number of categories (or states) and the matrixes of transition (change) probabilities. The transition probability, $p_{i k(t)}$, is the conditional probability of being in state $k$ at time $(t)$, given that the observation was in state $i$ at time $(t-1) ; i$ and $k$ are in a state space $\{1,2, \ldots, W\}$. The transition probabilities have the following properties: 


$$
P_{i k}(t) \geq 0 \text {, and } \sum_{k=1}^{W} P_{i k(t)}=1 \text {. }
$$

The underlying assumptions of the simplest form of Markov chain are rather stringent. The model assumes that the population is homogeneous and the first-order movement of observations follows a single transition rule-that is, the future transition is solely determined by the present state and is independent of the way in which the present state has developed. A higher order Markovian process implies the time dependence of the process on previous transitions. A seminal study by Anderson and Goodman (1957) provides an excellent discussion of the statistical properties of Markov chains. For a more complete discussion of Markov chain models, specifically the estimation procedures, see Appendix $\mathrm{C}$ of this monograph.

\section{Application of the Process}

Since the 1950s, the concept of the Markov chain process has been developed and increasingly applied to examine social and economic transition behaviors. Examples include the social mobility of working labor (Blumen et al. 1955, Singer and Spilerman 1974), political attitudes (Anderson 1954), and consumer purchasing behavior (Telser 1963). Actual implementations of Markov chain processes in a variety of practical decision-making situations were reviewed by White $(1985,1988)$.

In finance, the concept of Markov chains was applied to model the dynamic processes in stock price movements (Dryden 1969, Ryan 1973, McQueen and Thorley 1991), the pricing behavior of stock index futures (Goldenberg 1988), changes in interest rates (Pye 1966, Wilbur 1983), the payment behavior of credit card receivables (Cyert, Davidson, and Thompson 1962; Frydman, Kallberg, and Kao 1985), and warrant pricing (Samuelson 1971). These empirical works have shown that stochastic processes are better representations of transition processes than are deterministic models.

In this study, we tested the following popular discrete-time, first-order stochastic models:

- Stationary Markov chains $(M K V \rightarrow S)$, in which transition probabilities are assumed to be constant over time;

- Nonstationary Markov chains (MKV-NS), in which transition probabilities are not stationary; and

- The mover-stayer model (MS), a generalization of the Markov model. First introduced by Blumen et al. (1955), the MS model assumes that the 
population consists of two subgroups (instead of one, as in the case of a simple Markov model): the "stayers," which remain in the same state during the entire sample period, and the "movers," which have a transition (change) pattern that follows a simple stationary Markovian transition probability matrix. Note that a mover can stay in the same state for certain periods of time before making changes.

In the bond rating application, the MKV-S implies that the rating drift process follows a constant transition matrix, whereas the MKV-NS assumes that the probability that a rating will change or remain unchanged is not constant. For an MS model, the stayers are those that remain in the same rating category at all times, and the rating change of the movers follows constant transition probabilities from one period to the next.

Table 9 presents the parameters (estimated transition matrixes) of stationary Markov chain models and mover-stayer models for 1970 to 1989 and for the decades of the $1970 \mathrm{~s}$ and $1980 \mathrm{~s}$. It shows the average one-step transition matrixes of stationary Markov chains (i.e., the average of $P(0,1), P(1,2)$, $P(2,3), \ldots, P(T-1, T))$ and stayer proportions and mover transition matrixes of mover-stayer models. One-step transition matrixes of bonds with different ages $[P(k, k+1), k=0,1, \ldots, T-1]$ were essentially the estimated parameters of nonstationary Markov chains. Because the time period is a year shorter for the $1980 \mathrm{~s}$, the parameters of the MKV-S and MS models were estimated using transition information over 7 years instead of 10 years.

As shown in Table 9, average transition matrixes of the stationary Markov chains were more stable than mover matrixes of the mover-stayer models for all three test periods. Further, because of the existence of stayers in the MS model, the percentages of ratings remaining unchanged in the mover transition matrixes were smaller than those of the MKV-S model's average transition matrixes. These estimated parameters and the properties of the models were used to calculate rating transition matrixes of longer transition horizons (i.e., $P(0, k), k=2,3, \ldots, T)$. The estimated multiple-step transition matrixes were then compared with the actual transition matrixes to examine the model's ability to describe the rating drift process. The differences between the two are the estimate errors.

\section{Results}

The estimate errors of the percentages of ratings remaining unchanged (the diagonal elements) by the three stochastic models for bonds issued from January 1970 to September 1988 are presented in Table 10. Because the sample size of low-grade new issues is relatively small, the observations with 
TABLE 9. Estimated Parameters of Markov Chain and Mover-Stayer Models

\begin{tabular}{|c|c|c|c|c|c|c|c|c|c|c|c|}
\hline \multirow{3}{*}{$\begin{array}{l}\text { Original } \\
\text { Rating }\end{array}$} & \multicolumn{5}{|c|}{ Stationary Markov Chain } & \multicolumn{6}{|c|}{ Mover-Stayer Model } \\
\hline & \multicolumn{5}{|c|}{ Average Transition Matrix } & \multirow[b]{2}{*}{ Stayer } & \multicolumn{5}{|c|}{ Mover Transition Matrix } \\
\hline & AAA & $\mathrm{AA}$ & A & $\mathrm{BBB}$ & $\mathrm{NIG}$ & & AAA & $A A$ & A & $\mathrm{BBB}$ & $\mathrm{NIG}$ \\
\hline \multicolumn{12}{|l|}{$1970-89$} \\
\hline AAA & 91.7 & 7.8 & 0.5 & 0.0 & 0.0 & 43.1 & 83.1 & 15.8 & 1.0 & 0.0 & 0.0 \\
\hline AA & 1.1 & 90.5 & 7.8 & 0.3 & 0.2 & 35.4 & 1.9 & 84.0 & 13.3 & 0.6 & 0.3 \\
\hline A & 0.1 & 2.5 & 90.9 & 6.1 & 0.3 & 57.5 & 0.3 & 5.7 & 79.1 & 14.1 & 0.7 \\
\hline $\mathrm{BBB}$ & 0.1 & 0.2 & 7.0 & 86.2 & 6.5 & 36.5 & 0.2 & 0.3 & 10.2 & 80.0 & 9.4 \\
\hline NIG & 0.0 & 0.1 & 0.4 & 6.0 & 93.5 & 71.7 & 0.1 & 0.1 & 1.2 & 17.4 & 81.2 \\
\hline \multicolumn{12}{|l|}{$1970-79$} \\
\hline AAA & 92.7 & 6.7 & 0.6 & 0.0 & 0.0 & 30.9 & 88.9 & 10.2 & 0.9 & 0.0 & 0.0 \\
\hline $\mathrm{AA}$ & 1.3 & 91.7 & 6.7 & 0.3 & 0.0 & 24.0 & 1.7 & 88.6 & 9.2 & 0.5 & 0.0 \\
\hline A & 0.1 & 2.1 & 92.7 & 5.0 & 0.1 & 52.8 & 0.1 & 4.5 & 84.5 & 10.7 & 0.2 \\
\hline $\mathrm{BBB}$ & 0.1 & 0.1 & 6.1 & 88.7 & 5.1 & 28.7 & 0.1 & 0.1 & 7.9 & 85.3 & 6.6 \\
\hline $\mathrm{NIG}$ & 0.1 & 0.1 & 0.5 & 5.6 & 93.8 & 71.0 & 0.1 & 0.1 & 1.4 & 15.8 & 82.5 \\
\hline \multicolumn{12}{|l|}{$1980-88$} \\
\hline AAA & 92.1 & 7.7 & 0.1 & 0.1 & 0.1 & 34.7 & 86.4 & 13.2 & 0.1 & 0.2 & 0.1 \\
\hline $\mathrm{AA}$ & 1.3 & 86.6 & 11.5 & 0.3 & 0.3 & 7.2 & 1.4 & 85.4 & 12.5 & 0.3 & 0.3 \\
\hline A & 0.4 & 3.8 & 86.9 & 8.2 & 0.9 & 47.3 & 0.7 & 7.3 & 74.6 & 15.7 & 1.6 \\
\hline $\mathrm{BBB}$ & 0.2 & 0.6 & 8.2 & 82.0 & 9.0 & 31.0 & 0.3 & 0.9 & 11.4 & 74.8 & 12.6 \\
\hline NIG & 0.0 & 0.0 & 0.3 & 6.5 & 93.2 & 90.0 & 0.1 & 0.1 & 1.4 & 32.6 & 65.7 \\
\hline
\end{tabular}

Note: $\mathrm{NIG}=$ Noninvestment grade .

rating BB and below were combined as "noninvestment-grade issues" (NIGs). The parameters of all three models were estimated using the data available in the entire 10-year postissuance period. In an attempt to understand the models' predictive ability for shorter time frames, the estimates for the periods of three, five, and seven years from the bond's original issuance are also provided in Table 10.

Both stationary and nonstationary simple Markov chain models (MKV-S and MKV-NS) underestimate the observed percentages of the "rating unchanged" issues in all the time periods and rating categories. A negative estimate error is when the actual result is greater than the estimate; a positive estimate error is the converse. In general, the magnitude of these discrepancies increases as the transition horizon becomes longer. In addition, the $\mathrm{BBB}$ rating category produces considerably higher estimate errors than the other rating categories, 
TABLE 10. Observed Percentages and Estimate Errors of Unchanged Ratings, 1970-89

\begin{tabular}{|c|c|c|c|c|}
\hline \multirow[b]{2}{*}{ Age and Rating } & \multirow[b]{2}{*}{ Observed } & \multicolumn{3}{|c|}{ Estimate Errors $(\%)$} \\
\hline & & MKV-S & MKV-NS & MS \\
\hline \multicolumn{5}{|l|}{3 Years } \\
\hline AAA & 81.0 & -3.6 & -0.7 & -4.8 \\
\hline AA & 77.8 & -2.9 & -1.4 & -2.4 \\
\hline A & 78.9 & -2.1 & -1.1 & 1.9 \\
\hline $\mathrm{BB}$ & 73.4 & -7.3 & -3.1 & 0.3 \\
\hline NIG & 92.8 & -10.0 & -2.1 & -4.8 \\
\hline \multicolumn{5}{|l|}{5 Years } \\
\hline AAA & 69.8 & -4.2 & -2.6 & -3.0 \\
\hline $\mathrm{AA}$ & 67.9 & -5.0 & -3.3 & -1.5 \\
\hline A & 72.5 & -5.8 & -6.0 & 3.2 \\
\hline $\mathrm{BB}$ & 65.7 & -12.5 & -10.3 & 2.0 \\
\hline NIG & 86.4 & -11.9 & -6.2 & -2.2 \\
\hline \multicolumn{5}{|l|}{7 Years } \\
\hline $\mathrm{AAA}$ & 66.0 & -10.2 & -7.8 & -5.7 \\
\hline $\mathrm{AA}$ & 56.4 & -2.9 & -3.0 & 4.1 \\
\hline A & 68.1 & -8.8 & -7.2 & 4.9 \\
\hline BB & 58.8 & -14.1 & -13.8 & 6.1 \\
\hline NIG & 80.6 & -12.7 & -8.1 & 1.4 \\
\hline \multicolumn{5}{|l|}{10 Years } \\
\hline AAA & 52.1 & -7.9 & -8.5 & 2.1 \\
\hline $\mathrm{AA}$ & 46.7 & -3.6 & -3.8 & 8.2 \\
\hline $\mathrm{A}$ & 61.5 & -10.0 & -10.1 & 9.6 \\
\hline BB & 43.3 & -6.1 & -4.5 & 19.6 \\
\hline $\mathrm{NIG}$ & 75.2 & -15.1 & -16.2 & 5.0 \\
\hline
\end{tabular}

Note: MKV-S $=$ Stationary Markov chains, MKV-NS = Nonstationary Markov chains, MS $=$ Mover-Stayer model, and NIG = Noninvestment grade.

except for the 10-year transition horizon. Of the two simple Markov chains, the nonstationary model consistently performs better (i.e., has smaller estimate errors) than the stationary model, except for the 10-year horizon, when the estimate errors were quite similar.

The underestimation of diagonal elements in the observed transition probability matrixes indicates that more issues than expected remained in the same rating categories (i.e., there were more stayers) based on the results of the simple Markov chains. The phenomenon of underestimating the diagonal 
elements of a transition matrix is also found in the studies of the mobility of industrial labor (Blumen et al. 1955) and the payment behavior of retail credit accounts (Frydman et al. 1985). Both studies suggested the MS specification as the best modeling alternative.

The MS model produces low estimate errors for most rating categories up to the seven-year transition horizon. For the 10-year transition horizon, the estimation ability of the MS model was significantly dampened by the large estimate errors in the BBB rating category. The MS model, in contrast to other models, had a preponderance of positive estimate errors. The estimate errors from the MS model are positive for all five rating categories for the 10-year period. This indicates that the "stayers" over the long term were actually fewer than those estimated by the MS model. The only consistently negative MS estimated error was for the AAA category, at least through seven years.

Similar conclusions are observed if the analysis is performed for the periods of 1970 to 1979 and 1980 to 1989 , as shown in Table 11. As expected, all three models performed significantly better in the 1970s than in the 1980s, especially the MKV-S model. In fact, the MKV-S model produced the lowest estimate errors in most rating categories for the 10-year transition horizon in the 1970s. The superiority of the nonstationary model over the two stationary models (MKV-S and MS) is most evident in the 1980s.

The models are more successful in estimating unchanged rankings than in estimating upgrades and downgrades. Table 12 and Table 13 compare the models' estimates of upgrades and downgrades. The errors are considered to be larger than those for unchanged ratings because percentages of rating changes are much smaller than those remaining unchanged. With regard to the upgrading process, the estimate errors of the MKV-S and MKV-NS models were smaller than those of the MS model for the 1970-89 period. The MKV-NS provided the best fit up to the seven-year transition horizon. For the 10-year horizon, the MKV-S and MKV-NS performed equally well. Similar results are observed for the two subperiods. Again, the results for the 1970 s were better than those for the 1980s.

For the downgrading process, the MS model performed well for the $1970-89$ period. The MKV-NS model generally provided the best estimates for the subperiods of the $1970 \mathrm{~s}$ and $1980 \mathrm{~s}$, especially for the $1980 \mathrm{~s}$.

\section{Measurements of Predictive Ability}

Several tests were used to measure and compare the three Markov chain models' predictive abilities. The goodness-of-fit test developed by Frydman (1984) can be used to examine a Markov chain model's capability in describing the transition process and to compare the relative estimation abilities of various 
TABLE 11. Estimate Errors of Unchanged Rating Percentages

\begin{tabular}{|c|c|c|c|c|c|c|}
\hline \multirow[b]{2}{*}{ Age and Rating } & \multicolumn{3}{|c|}{$1970-79$} & \multicolumn{3}{|c|}{$1980-89$} \\
\hline & MKV-S & MKV-NS & MS & MKV-S & MKV-NS & MS \\
\hline \multicolumn{7}{|l|}{3 Years } \\
\hline AAA & -12.2 & -2.9 & -12.4 & 11.4 & 3.4 & 10.3 \\
\hline $\mathrm{AA}$ & -2.7 & -0.8 & -2.2 & -9.5 & -1.3 & -8.2 \\
\hline A & -6.9 & -0.8 & -5.1 & 0.4 & 1.6 & 4.6 \\
\hline $\mathrm{BB}$ & -16.6 & -1.1 & -11.4 & -5.2 & 1.2 & 5.3 \\
\hline $\mathrm{NIG}$ & -7.2 & -1.0 & -2.6 & -11.1 & -2.1 & 0.1 \\
\hline \multicolumn{7}{|l|}{5 Years } \\
\hline AAA & -10.9 & -4.7 & -10.0 & 17.6 & 8.4 & 17.7 \\
\hline $\mathrm{AA}$ & -1.2 & -0.8 & 1.0 & -16.4 & -5.0 & -13.1 \\
\hline A & -5.6 & -1.3 & -0.8 & -2.3 & -4.0 & 7.6 \\
\hline $\mathrm{BB}$ & -15.1 & -4.0 & -4.9 & -7.4 & -5.2 & 11.9 \\
\hline NIG & -8.5 & -2.7 & 0.3 & -15.4 & -10.0 & 2.7 \\
\hline \multicolumn{7}{|l|}{7 Years } \\
\hline $\mathrm{AAA}$ & -7.6 & -4.5 & -5.1 & -0.8 & 0.8 & 1.4 \\
\hline $\mathrm{AA}$ & -2.4 & -0.3 & 1.8 & 4.4 & -0.8 & 9.3 \\
\hline A & -4.9 & -1.0 & 3.2 & -5.3 & -3.4 & 9.6 \\
\hline $\mathrm{BB}$ & -11.4 & -6.0 & 3.2 & -2.9 & -1.2 & 22.0 \\
\hline $\mathrm{NIG}$ & -11.5 & -5.0 & 1.7 & -22.0 & -23.6 & 1.7 \\
\hline \multicolumn{7}{|l|}{10 Years } \\
\hline AAA & -3.1 & -5.2 & 2.3 & - & - & - \\
\hline $\mathrm{AA}$ & 0.5 & 1.0 & 7.7 & - & - & - \\
\hline A & -3.8 & -4.7 & 8.8 & - & - & - \\
\hline $\mathrm{BB}$ & -1.0 & 0.5 & 18.8 & - & - & - \\
\hline NIG & -15.3 & -14.9 & 3.8 & - & - & - \\
\hline
\end{tabular}

Note: MKV-S $=$ Stationary Markov chains, MKV-NS = Nonstationary Markov chains, MS $=$ Mover-Stayer Model, and NIG $=$ Noninvestment grade.

alternative models. Frydman's method requires substantial computation time, however, and the test may be unreliable if the number of states and transition steps in the test period are large relative to the number of observations (Frydman et al. 1985), as is the case in this study.

We used the conventional chi-square measure to summarize the model's estimation ability over time. This measure, which has an asymptotic chi-square distribution with $w-1$ degrees of freedom, is calculated as follows (Anderson and Goodman 1957): 
TABLE 12. Estimate Errors of Rating Upgrade Percentages

\begin{tabular}{|c|c|c|c|c|}
\hline \multirow{2}{*}{$\begin{array}{l}\text { Age and } \\
\text { Rating }\end{array}$} & \multicolumn{2}{|l|}{$1970-89$} & $1970-79$ & $1980-89$ \\
\hline & MKV-S MKV-NS & MS & MKV-S MKV-NS MS & MKV_S MKV-NS MS \\
\hline
\end{tabular}

3 Years

$\begin{array}{lrrrrrrrrr}\text { AA } & 0.9 & 0.2 & 0.7 & 0.8 & 1.3 & 0.7 & 1.6 & -0.3 & 1.5 \\ \text { A } & -0.6 & -0.6 & -1.8 & 1.4 & 0.4 & 0.8 & -0.9 & -2.5 & -1.9 \\ \text { BBB } & 2.3 & 0.6 & -1.3 & 7.4 & -0.5 & 4.9 & 0.4 & -0.4 & -2.7 \\ \text { NIG } & 9.9 & 1.8 & 4.8 & 7.2 & 1.0 & 2.6 & 11.2 & 2.1 & 0.0\end{array}$

5 Years

$\begin{array}{lrrrrrrrrr}\text { AA } & 1.5 & 0.6 & 0.8 & 1.8 & 2.0 & 1.4 & 2.6 & 0.0 & 2.3 \\ \text { A } & -0.2 & 0.4 & -3.0 & 0.2 & 0.1 & -1.3 & -0.5 & -0.9 & -3.0 \\ \text { BBB } & 3.3 & 2.4 & -3.4 & 4.8 & -0.1 & 0.2 & 0.1 & -0.4 & -5.2 \\ \text { NIG } & 12.0 & 6.0 & 2.3 & 8.6 & 2.7 & -0.2 & 15.4 & 9.9 & -2.7\end{array}$

7 Years

$\begin{array}{llllllllll}\text { AA } & 1.6 & 1.5 & 0.2 & 2.4 & 2.3 & 1.7 & 2.0 & 3.1 & 1.5\end{array}$

$\begin{array}{llllllllll}\mathrm{A} & 1.5 & 1.3 & -2.7 & 0.7 & 0.2 & -1.8 & 2.6 & 1.0 & -1.1\end{array}$

$\begin{array}{llllllllll}\text { BBB } & 1.4 & 1.8 & -7.7 & 1.6 & -0.3 & -4.8 & -7.2 & -6.6 & -13.3\end{array}$

$\begin{array}{llllllllll}\text { NIG } & 12.9 & 8.2 & -1.2 & 11.4 & 4.9 & -1.8 & 22.0 & 23.6 & -2.0\end{array}$

10 Years

$\begin{array}{lrrrrrrrrr}\text { AA } & 1.9 & 1.8 & -0.2 & 2.9 & 2.4 & 1.6 & - & - & - \\ \text { A } & 0.0 & 0.0 & -6.0 & -1.2 & -0.7 & -5.0 & - & - & - \\ \text { BBB } & -5.8 & -5.7 & -17.2 & -6.5 & -7.2 & -15.1 & - & - & - \\ \text { NIG } & 15.2 & 16.4 & -4.7 & 15.6 & 15.0 & -3.5 & - & - & -\end{array}$

Note: MKV-S = Stationary Markov chains, MKV-NS = Nonstationary Markov chains, MS $=$ Mover-Stayer Model, and NIG $=$ Noninvestment grade .

$$
X_{i}^{2}=\sum_{k=1}^{W} N_{i} \cdot \frac{\left(\hat{P}_{i k}-P_{i k}\right)^{2}}{P_{i k}}
$$

If this measure is less than the critical value found in the standard chi-square table for a given level of confidence, we can conclude that the estimate is reasonably reliable. In the case of bond rating data, the measure can be used to examine the model's ability to estimate subsequent rating changes from a particular rating at the beginning of the period.

Adding chi-square measures of individual states (rating categories) gives an aggregate chi-square, which indicates the model's overall ability to estimate rating transitions. The aggregate chi-square has $w(w-1)$ degrees of freedom. Further, by examining the chi-square measures (individual or aggregate) of 
TABLE 13. Estimate Errors of Rating Downgrade Percentages

\begin{tabular}{|c|c|c|c|c|c|c|c|c|c|}
\hline \multirow{2}{*}{$\begin{array}{l}\text { Age and } \\
\text { Rating }\end{array}$} & \multicolumn{3}{|c|}{$1970-89$} & \multicolumn{3}{|c|}{$1970-79$} & \multicolumn{3}{|c|}{$1980-89$} \\
\hline & MKV_S & MKV-NS & MS & MKV-S & MKV-NS & MS & MKV-S & MKV-NS & MS \\
\hline \multicolumn{10}{|l|}{3 Years } \\
\hline AAA & 3.6 & 0.8 & 4.8 & 12.1 & 2.7 & 12.2 & -11.3 & -3.3 & -10.2 \\
\hline $\mathrm{AA}$ & 2.0 & 1.3 & 1.7 & 1.9 & -0.7 & 1.5 & 7.9 & 1.5 & 6.7 \\
\hline $\mathrm{A}$ & 2.5 & 1.5 & -0.2 & 5.6 & 0.2 & 4.2 & 0.4 & 0.8 & -2.7 \\
\hline $\mathrm{BBB}$ & 4.9 & 2.4 & 1.0 & 9.4 & 1.7 & 6.6 & 5.0 & 1.9 & -2.3 \\
\hline \multicolumn{10}{|l|}{5 Years } \\
\hline $\mathrm{AAA}$ & 4.3 & 2.6 & 3.0 & 10.8 & 4.5 & 9.9 & -17.6 & -8.3 & -17.8 \\
\hline $\mathrm{AA}$ & 3.5 & 2.9 & 0.8 & -0.8 & -1.4 & -2.4 & 13.7 & 4.9 & 10.8 \\
\hline A & 5.9 & 5.3 & -0.2 & 5.5 & 1.0 & 2.1 & 2.6 & 4.8 & -4.7 \\
\hline BBB & 9.3 & 7.7 & 1.5 & 10.4 & 4.0 & 4.7 & 7.4 & 5.6 & -6.7 \\
\hline \multicolumn{10}{|l|}{7 Years } \\
\hline $\mathrm{AAA}$ & 10.2 & 7.8 & 5.7 & 7.6 & 4.5 & 5.2 & 1.0 & -0.6 & -1.3 \\
\hline $\mathrm{AA}$ & 1.3 & 1.4 & -4.4 & -0.1 & -2.0 & -3.4 & -6.3 & -2.2 & -10.7 \\
\hline $\mathrm{A}$ & 7.2 & 5.8 & -2.0 & 4.4 & 0.9 & -1.3 & 2.6 & 2.5 & -8.6 \\
\hline BBB & 12.5 & 11.7 & 1.5 & 9.9 & 6.2 & 1.5 & 10.2 & 7.9 & -8.8 \\
\hline \multicolumn{10}{|l|}{10 Years } \\
\hline AAA & 8.1 & 8.6 & -2.1 & 3.2 & 5.2 & -2.2 & - & - & - \\
\hline $\mathrm{AA}$ & 1.7 & 2.2 & -7.9 & -3.5 & -3.4 & -9.3 & - & - & - \\
\hline$A$ & 9.8 & 9.9 & -3.6 & 5.1 & 5.6 & -3.7 & - & - & $\ldots$ \\
\hline $\mathrm{BBB}$ & 11.8 & 10.0 & -2.5 & 7.6 & 6.7 & -3.7 & - & - & - \\
\hline
\end{tabular}

Note: MKV-S = Stationary Markov chains, MKV-NS = Nonstationary Markov chains, and MS = Mover-Stayer Model.

different time periods into the future, it is possible to determine the approximate upper bound of the time period for which the forecasted transition is reasonably reliable.

The chi-square tests of individual ratings for the entire period of 1970 to 1989 are shown in Table 14. All three models performed well in predicting the three-year transition horizon for most rating classes. The MS model provided significant chi-square results, even for the five-year transition horizon. Of the two simple Markov chains, the MKV-NS model outperformed its stationary counterpart for every rating through the seven-year transition. For the 10-year transition horizon, the MS model provided the highest (worst) chi-squares for the $\mathrm{AA}$ and $\mathrm{BBB}$ rating categories and lowest (best) for the AAAs. 
TABLE 14. Chi-Square Tests of Markov Chain and Mover-Stayer Models, by Rating, 1970-89

\begin{tabular}{lrrr}
\hline Age and Rating & MKV-S & MKV-NS & MS \\
\hline 3 Years & & & \\
AAA & $5.2^{*}$ & $0.2^{*}$ & $9.2^{*}$ \\
AA & $10.4^{*}$ & $2.4^{*}$ & $7.1^{*}$ \\
A & $6.7^{*}$ & $1.8^{*}$ & $5.6^{*}$ \\
BBB & 39.6 & $7.1^{*}$ & $0.1^{*}$ \\
NIG & 60.8 & $2.7^{*}$ & $14.0^{*}$ \\
5 Years & & & \\
AAA & $8.2^{*}$ & $3.1^{*}$ & $4.2^{*}$ \\
AA & 35.3 & 15.4 & $3.2^{*}$ \\
A & 55.9 & 59.8 & 17.0 \\
BBB & 129.6 & 88.0 & $3.3^{*}$ \\
NIG & 92.5 & 25.1 & $3.2^{*}$ \\
7 Years & & & \\
AAA & 51.2 & 29.9 & 16.0 \\
AA & 14.3 & 15.3 & 28.6 \\
A & 137.0 & 91.7 & 42.5 \\
BBB & 184.3 & 176.5 & 34.5 \\
NIG & 113.0 & 46.0 & $1.4^{*}$ \\
10 Years & & & \\
AAA & 38.9 & 45.0 & $2.7^{*}$ \\
AA & 26.6 & 29.6 & 138.0 \\
A & 195.9 & 199.9 & 180.6 \\
BBB & 25.5 & 483.5 \\
NIG & 171.2 & & 18.8 \\
*Signfint & &
\end{tabular}

*Significant at the 0.01 level.

Note: $\mathrm{MKV}-\mathrm{S}$ = Stationary Markov chains, MKV-NS = Nonstationary Markov chains, MS $=$ Mover-Stayer Model, and NIG = Noninvestment grade.

Table 15 presents separate chi-square tests for the 1970 s and the 1980 s. As expected, the results for the 1970s were significantly better than those for the 1980 s, especially for the five-year horizon. For the 1970s, the MKV-NS model performed extremely well in every rating but had slightly higher chi-square values than the other models in the AAA, A, and NIG categories for the 10-year transition horizon. Although not performing as well for the 1980s, the MKV-NS model provided a much better fit to the data than the MKV-S and MS models. Individual rating results in Tables 13 and 14 are summarized into aggregate 


\section{TABLE 15. Chi-Square Tests of Markov Chain and Mover-Stayer Models, by Rating, 1970-79 and 1980-89}

\begin{tabular}{|c|c|c|c|c|c|c|}
\hline \multirow{2}{*}{$\begin{array}{l}\text { Age and } \\
\text { Rating }\end{array}$} & \multicolumn{3}{|c|}{$1970-79$} & \multicolumn{3}{|c|}{$1980-89$} \\
\hline & MKV-S & MKV-NS & MS & MKV-S & MKV-NS & MS \\
\hline 3 Years & & & & & & \\
\hline $\mathrm{AAA}$ & 24.4 & $1.4^{*}$ & 25.2 & 33.7 & $3.0^{*}$ & 27.5 \\
\hline AA & $3.2^{*}$ & $0.3^{*}$ & $2.1^{*}$ & 72.6 & $1.4^{*}$ & 54.1 \\
\hline A & 28.9 & $0.4^{*}$ & 15.8 & $0.2^{*}$ & $2.5^{*}$ & 20.9 \\
\hline BBB & 51.3 & $0.2^{*}$ & 24.2 & 16.2 & $0.9^{*}$ & 16.8 \\
\hline $\mathrm{NIG}$ & $6.0^{*}$ & $0.1^{*}$ & $0.8^{*}$ & 60.5 & $2.2^{*}$ & $0.0^{*}$ \\
\hline
\end{tabular}

5 Years

$\begin{array}{lcccccr}\text { AAA } & 22.4 & 4.2^{*} & 18.9 & 109.0 & 24.8 & 110.3 \\ \text { AA } & 0.7^{*} & 0.3^{*} & 0.5^{*} & 239.0 & 22.2 & 152.5 \\ \text { A } & 21.5 & 1.2^{*} & 0.4^{*} & 6.0^{*} & 18.3 & 65.9 \\ \text { BBB } & 50.2 & 3.5^{*} & 5.3^{*} & 39.9 & 19.7 & 103.3 \\ \text { NIG } & 9.1^{*} & 0.9^{*} & 0.0^{*} & 121.1 & 51.1 & 3.7^{*}\end{array}$

7 Years

$\begin{array}{lcccccr}\text { AAA } & 12.9^{*} & 4.5^{*} & 5.8^{*} & 0.2^{*} & 0.2^{*} & 0.6^{*} \\ \text { AA } & 3.4^{*} & 0.1^{*} & 1.9^{*} & 31.1 & 1.0^{*} & 138.7 \\ \text { A } & 18.3 & 0.8^{*} & 7.8^{*} & 34.9 & 14.4 & 114.5 \\ \text { BBB } & 34.2 & 9.5^{*} & 2.7^{*} & 8.0^{*} & 1.4^{*} & 461.6 \\ \text { NIG } & 17.4 & 3.3^{*} & 0.4^{*} & 245.7 & 282.8 & 1.5^{*} \\ \text { 10 Years } & & & & & & \\ \text { AAA } & 2.8^{*} & 7.8^{*} & 1.5^{*} & - & - & - \\ \text { AA } & 0.2^{*} & 0.7^{*} & 44.3 & - & - & - \\ \text { A } & 12.5^{*} & 19.1 & 67.1 & - & - & - \\ \text { BBB } & 0.4^{*} & 0.1^{*} & 133.5 & - & - & - \\ \text { NIG } & 32.7 & 31.0 & 2.0^{*} & - & - & -\end{array}$

*Significant at the 0.01 level.

Note: MKV-S = Stationary Markov chains, MKV-NS = Nonstationary Markov chains, MS $=$ Mover-Stayer Model, and NIG = Noninvestment grade .

chi-square measures in Table 16 to provide a clear picture of relative overall performance of these three models. The performance of the MKV-NS model was slightly superior to that of the MS model in number of significant chi-square tests. This is also true for aggregate chi-square values, regardless of the significance tests (except for the long-term horizons in the 1970s). The simple 
TABLE 16. Aggregate Chi-Square Tests of Markov Chain Mover-Stayer Models, 1970-88

\begin{tabular}{lccc}
\hline $\begin{array}{l}\text { Period } \\
\text { and Age }\end{array}$ & MKV-S & MKV-NS & MS \\
\hline $1970-88$ & & & \\
3 & 122.7 & $14.3^{*}$ & $35.9^{*}$ \\
5 & 321.5 & 191.5 & $30.9^{*}$ \\
7 & 499.7 & 359.4 & 122.9 \\
10 & 479.4 & 497.0 & 823.6 \\
$1970-79$ & & & \\
3 & 113.7 & $2.4^{*}$ & 68.0 \\
5 & 103.9 & $10.1^{*}$ & $25.1^{*}$ \\
7 & 86.2 & $18.1^{*}$ & $18.6^{*}$ \\
10 & 48.5 & 58.8 & 248.4 \\
$1980-88$ & & & 199.3 \\
3 & 183.1 & $9.9^{*}$ & 435.6 \\
5 & 515.0 & 136.1 & 716.9 \\
7 & 319.9 & 299.7 & - \\
10 & - & - & \\
\hline
\end{tabular}

*Significant at the 0.01 level.

Note: $\mathrm{MKV}-\mathrm{S}=$ Stationary Markov chains, MKV-NS = Nonstationary Markov chains, and MS = Mover-Stayer Model.

MKV-S model is the least accurate for the shorter transition horizons in most cases but the best for the 10-year transition horizon.

\section{Back-Test Results}

So far, both parameter estimations and compatibility tests in the modeling procedures use the same set of sample data. The question is, how do the models perform on data other than those used in estimating their parameters? How will these models do compared to a naive model that uses only previous transition information?

A back test on data outside the modeling sample was conducted by collecting, at the end of a particular calendar year, the rating transition information for the previous 10 years. ${ }^{5}$ For example, using the end of calendar

${ }^{5}$ We also conducted a back test using previous 1-year rating transition information only and found that the results are worse than those using previous 10-year transition information. 
year 1982, the previous transition information on a bond will be used, regardless of its issuance date, as long as it existed between January 1973 and December 1982. Thus, the historical transition information that was used includes all the possible $P(k, k+t)$, where $k$ is the age of a bond, $k=0,1, \ldots, T-t$, and $t$ is the number of years (steps) during which the rating transition takes place, $t=$ $1,2, \ldots, 7$ for the 1982 back test.

The parameters of three stochastic models were estimated from successive one-step transition matrixes, $P(k, k+1)$. These parameters and the properties of the models were then used to estimate the transition probabilities during the next several years for all the bonds (new or seasoned) existing at the end of 1982. Thus, for a five-year transition horizon, we estimated $P(0,5), P(1,6)$, $P(2,7), P(3,8), \ldots, P(T, T+5)$. These estimated five-year transition matrixes were then compared with the actual transition matrixes observed from January 1983 to December 1987. Chi-square measures of all the estimated five-year transition matrixes were further aggregated into a composite five-year chisquare measure. In addition, a performance benchmark was constructed by applying a naive model using historical five-year transition matrixes observed during the past 10 years.

This back test was repeated for all of the possible transition horizons and for the calendar years 1982 through 1987. These results are presented in Table 17. In the 1987 test, only the two-year transition horizon is possible. The MKV-S and MKV-NS models did significantly better than the historical naive model in almost all cases from 1982 to 1984 and for the two-year transition horizon in 1985. The MS model also outperformed the historical model in most cases, although the length of transition horizon in which the estimation was applied decreased from up to five years in 1982 and 1983 to just two years in 1985.

Table 18 presents the results in Table 17 according to the time of transition horizon. The MKV-S and MKV-NS outperformed the historical models for all the transition horizons examined (up to seven years). The poor performance of the three stochastic models in comparison with the historical model in recent years was attributable to the drastic deterioration in credit quality of issuers and their consequent downratings (see Lucas and Lonski 1991).

Among the three stochastic models, the MKV-S model generally had the edge over MKV-NS and MS models when applying the model in the back tests. The underperformance of the MS model compared with the MKV-S model is primarily attributable to the fact that the parameters (stayer and mover matrixes) of the MS model were not stable over time, which violates the model's underlying assumption of constant parameters. This can be seen clearly by examining Table 9. Estimated stayer proportions and mover transition probabilities of the MS models for almost every rating category changed 
TABLE 17. Aggregate Chi-Square Tests Based on Prior 10-Year Transition Information, by Year, 1982-87

\begin{tabular}{|c|c|c|c|c|c|c|c|c|}
\hline \multirow{2}{*}{$\begin{array}{l}\text { Years in } \\
\text { Transition } \\
\text { Period }\end{array}$} & \multirow{2}{*}{$\begin{array}{c}\text { Prior } \\
10 \\
\text { Years }\end{array}$} & \multirow{2}{*}{\multicolumn{2}{|c|}{ MKV-S MKV-NS }} & \multirow[b]{2}{*}{ MS } & \multicolumn{3}{|c|}{ Difference from Prior 10 Years } & \multirow{2}{*}{$\begin{array}{l}\text { Number } \\
\text { of Bonds }\end{array}$} \\
\hline & & & & & MKV-S & MKV-NS & MS & \\
\hline \multicolumn{9}{|l|}{1982} \\
\hline 2 & 37.8 & $32.2^{*}$ & $36.2^{*}$ & $31.2^{*}$ & -5.6 & -1.6 & -6.6 & 2,092 \\
\hline 3 & 56.6 & 46.7 & 52.2 & 50.1 & -9.9 & -4.4 & -6.5 & 1,763 \\
\hline 4 & 68.6 & 53.3 & 59.3 & 59.4 & -15.3 & -9.3 & -9.2 & 1,368 \\
\hline 5 & 53.0 & 39.7 & 42.2 & 49.0 & -13.3 & -10.8 & -4.0 & 860 \\
\hline 6 & $31.3^{*}$ & $22.7^{*}$ & $24.7^{*}$ & 39.6 & -8.6 & -6.6 & 8.3 & 523 \\
\hline 7 & 39.0 & $27.7^{*}$ & $32.4^{*}$ & 47.2 & -11.3 & -6.6 & 8.2 & 244 \\
\hline \multicolumn{9}{|l|}{1983} \\
\hline 2 & 50.1 & 43.5 & 48.6 & 41.7 & -6.6 & -1.5 & -8.4 & 2,117 \\
\hline 3 & 55.3 & 48.1 & 54.5 & 45.5 & -7.2 & -0.8 & -9.8 & 1,698 \\
\hline 4 & 51.5 & 38.5 & 43.9 & 45.5 & -13.0 & -7.6 & -6.0 & 1,157 \\
\hline 5 & 43.7 & $37.6^{*}$ & 46.7 & 40.2 & -6.1 & 3.0 & -3.5 & 770 \\
\hline 6 & 41.1 & $35.1^{*}$ & 37.9 & 44.7 & -6.0 & -3.2 & 3.6 & 408 \\
\hline \multicolumn{9}{|l|}{1984} \\
\hline 2 & $30.0^{*}$ & $25.0^{*}$ & $27.6^{*}$ & $25.6^{*}$ & -5.0 & -2.4 & -4.4 & 2,087 \\
\hline 3 & 42.9 & $34.9^{*}$ & 39.1 & 38.3 & -8.0 & -3.8 & -4.6 & 1,510 \\
\hline 4 & $31.7^{*}$ & $26.5^{*}$ & $30.8^{*}$ & $27.9 *$ & -5.2 & -0.9 & -3.8 & 1,082 \\
\hline 5 & $28.3^{*}$ & $26.0^{*}$ & $26.6^{*}$ & $31.7^{*}$ & -2.3 & -1.7 & 3.4 & 609 \\
\hline \multicolumn{9}{|l|}{1985} \\
\hline 2 & 38.4 & $36.8^{*}$ & 37.3 & 37.7 & -1.6 & -1.1 & -0.7 & 2,192 \\
\hline 3 & 48.3 & 61.0 & 50.3 & 51.4 & 12.7 & 2.0 & 3.1 & 1,693 \\
\hline 4 & $34.9^{*}$ & 42.3 & 41.1 & 38.3 & 7.4 & 6.2 & 3.4 & 986 \\
\hline \multicolumn{9}{|l|}{1986} \\
\hline 2 & 38.3 & 84.9 & 41.9 & 56.2 & 46.6 & 3.6 & 17.9 & 2,618 \\
\hline 3 & $32.1^{*}$ & 48.7 & $33.0^{*}$ & 40.8 & 16.6 & 0.9 & 8.7 & 1,645 \\
\hline \multicolumn{9}{|l|}{1987} \\
\hline 2 & 56.9 & 59.6 & 75.5 & 48.0 & 2.7 & 18.6 & -8.9 & 2,174 \\
\hline
\end{tabular}

*Significant at the 0.01 level.

Note: MKV-S = Stationary Markov chains, MKS-NS = Nonstationary Markov chains, and MS = Mover-Stayer Model. 
TABLE 18. Aggregate Chi-Square Tests Based on Prior 10Year Transition Information, by Number of Years in Transition Horizon

\begin{tabular}{|c|c|c|c|c|c|c|c|c|}
\hline Years in & Prior & & & & Difference & from Prior 1 & Years & \\
\hline Period & Years & MKV-S & MKV-NS & MS & MKV-S & MKV-NS & MS & of Bonds \\
\hline 2 Years & & & & & & & & \\
\hline 1982 & 37.8 & $32.2^{*}$ & $36.2^{*}$ & $31.2^{*}$ & -5.6 & -1.6 & -6.6 & 2,092 \\
\hline 1983 & 50.1 & 43.5 & 48.6 & 41.7 & -6.6 & -1.5 & -8.4 & 2,117 \\
\hline 1984 & $30.0^{*}$ & $25.0^{*}$ & $27.6^{*}$ & $25.6^{*}$ & -5.0 & -2.4 & -4.4 & 2,087 \\
\hline 1985 & 38.4 & $36.8^{*}$ & $37.3^{*}$ & 37.7 & -1.6 & -1.1 & -0.7 & 2,192 \\
\hline 1986 & 38.3 & 84.9 & 41.9 & 56.2 & 46.6 & 3.6 & 17.9 & 2,618 \\
\hline 1987 & 56.9 & 59.6 & 75.5 & 48.0 & 2.7 & 18.6 & -8.9 & 2,174 \\
\hline 3 Years & & & & & & & & \\
\hline 1982 & 56.6 & 46.7 & 52.2 & 50.1 & -9.9 & -4.4 & -6.5 & 1,763 \\
\hline 1983 & 55.3 & 48.1 & 54.5 & 45.5 & -7.2 & -0.8 & -9.8 & 1,698 \\
\hline 1984 & 42.9 & $34.9^{*}$ & 39.1 & 38.3 & -8.0 & -3.8 & -4.6 & 1,510 \\
\hline 1985 & 48.3 & 61.0 & 50.3 & 51.4 & 12.7 & 2.0 & 3.1 & 1,693 \\
\hline 1986 & $32.1^{*}$ & 48.7 & $33.0^{*}$ & 40.8 & 16.6 & 0.9 & 8.7 & 1,645 \\
\hline 4 Years & & & & & & & & \\
\hline 1982 & 68.6 & 53.3 & 59.3 & 59.4 & -15.3 & -9.3 & -9.2 & 1,368 \\
\hline 1983 & 51.5 & 38.5 & 43.9 & 45.5 & -13.0 & -7.6 & -6.0 & 1,157 \\
\hline 1984 & $31.7^{*}$ & $26.5^{*}$ & $30.8^{*}$ & $27.9^{*}$ & -5.2 & -0.9 & -3.8 & 1,082 \\
\hline 1985 & $34.9^{*}$ & 42.3 & 41.1 & 38.3 & 7.4 & 6.2 & 3.4 & 986 \\
\hline 5 Years & & & & & & & & \\
\hline 1982 & 53.0 & 39.7 & 42.2 & 49.0 & -13.3 & -10.8 & -4.0 & 860 \\
\hline 1983 & 43.7 & $37.6^{*}$ & 46.7 & 40.2 & -6.1 & 3.0 & -3.5 & 770 \\
\hline 1984 & $28.3^{*}$ & $26.0^{*}$ & $26.6^{*}$ & $31.7^{*}$ & -2.3 & -1.7 & 3.4 & 609 \\
\hline 6 Years & & & & & & & & \\
\hline 1982 & $31.3^{*}$ & $22.7^{*}$ & $24.7^{*}$ & 39.6 & -8.6 & -6.6 & 8.3 & 523 \\
\hline 1983 & 41.1 & $35.1^{*}$ & 37.9 & 44.7 & -6.0 & -3.2 & 3.6 & 408 \\
\hline 7 Years & & & & & & & & \\
\hline 1982 & 39.0 & $27.7^{*}$ & $32.4^{*}$ & 47.2 & -11.3 & -6.6 & 8.2 & 244 \\
\hline
\end{tabular}


dramatically from the 1970 s to the 1980 s. The stayer proportions for the $1980 \mathrm{~s}$ were also significantly different from those in the entire 1970-89 sample period. The "average" transition matrixes of the MKV-S model were very similar in all three time periods.

\section{Conclusions}

These results indicate that stochastic models can describe the bond rating drift process reasonably well. In most cases, all three stochastic models were found to perform better than a naive model using historical rating transition probabilities. Of the three models examined, the MKV-NS and MKV-S performed equally well in the back test.

The MS model was not able to extend its superiority from the in-sample compatibility test to the out-of-sample back test. Moreover, the MS model results should be carefully interpreted. This model is assumed to have constant proportions of stayers and a constant mover transition matrix. In reality, the proportions of stayers and the mover matrix varied from time to time during our test period. Possible reasons for the deviations of actual results from the assumptions of the stochastic models include the following:

- Most studies of social mobility indicate that for various social characteristics, the total number of movements before entering the state as observed at a discrete time point differ (Spilerman 1972). This is also possible in our study. That is, a bond's rating could change once or more during time $t$ and time $(t+1)$. Thus, two bonds with an identical rating transition at time $t$ and $(t+1)$ need not have the same transition path. ${ }^{6}$

- The length of time observed for a bond's rating to change or remain unchanged may be an important factor in determining transition probabilities.

- The underlying process of rating changes is assumed to be described by a first-order transition matrix in the cases of the MKV-S and MS models. A higher order Markovian property is possible; namely, the rating state at time $t$ may depend on the state $(s)$ before time $(t-1)$.

- The rating drift process may in fact be time varying. The incorporation of general economic factors should improve the model's predictability, as long as the predictive horizon's economic performance is similar to that of the estimated transition period.

\footnotetext{
6This analysis was repeated using a semiannual transition horizon, and the results were not materially different.
} 
- The plus or minus subrating categories, ignored in our study, may contribute to populational heterogeneity. The inclusion of subrating categories, however, would require a much larger sample size to include a sufficient number of observations in each rating class. 



\section{Rating Changes and Bondholders' Wealth}

Bond portfolio managers and individual investors are concerned with changes in credit quality of debt issues because they affect net return. Upgrades in rating are usually associated with increases in price, while downgrades connote price declines. The exact timing of rating and price changes has been the topic of a long-lasting controversy. Most analysts have concluded that a substantial part of the price change occurs prior to the actual rating change. With the advent of other early warnings of possible rating changes (e.g., S\&P's Credit Watch), the exact association between rating and price has become even more uncertain. The Credit Watch announcement of a possible rating change focuses on the point in time when S\&P is first considering a change of some type. This announcement is an event in itself.

The most comprehensive previous work on the impact of rating changes was that of Weinstein (1977). He examined the behavior of bond prices surrounding the rating change event. After analyzing rating changes during the 1962-74 period, he concluded that, although there was some evidence of price changes during the period from 18 to 7 months prior to the rating change month, no statistically significant price reaction occurred during the 6 months prior to the actual change nor during the 6 months after the rating change.

Support for the view, implicit in Weinstein's findings, that rating changes reflect all available information and therefore the rating or its change should not convey any new information is found in Wakeman (1978) and Pinches and Singleton (1978). Ho and Michaely (1988) argue differently, stating that market prices may not reflect all public information if the cost of collecting new data and opinions is greater than the perceived benefits to existing or prospective bondholders.

These findings conflict with those of three prior studies-Katz (1974), Grier and Katz (1976), and Hettenhouse and Satoris (1976). Each of these studies 
reported evidence of significant bond price reaction after the rating change announcement, as well as before. In addition, it has been suggested that rating agencies possess "inside information" from their discussions with management and that their research brings new information to the market, which affects prices.

In addition to the few studies concerned with rating changes and their impact on bond returns, some recent work has analyzed the effect bond defaults - the ultimate negative rating change--have on returns. Altman (1989a) assessed the effects that bond defaults, recovery rates just after default, and reinvested coupons, calls, sinking funds, and other cash flows have on net returns for investors concentrating on specific bond rating investment classes. The implicit assumption of Altman's "mortality rate and return" analysis was that a bond either defaulted or it did not. No adjustment was made for bonds that incurred rating changes, regardless of whether they defaulted. Hence, any price change associated with rating adjustments was not specifically incorporated.

The effect of a rating change is not relevant if the investor's strategy is to buy and hold until maturity. If the investor does not hold to maturity, however, and if the propensity for a rating change is greater for one direction than for another, then those rating adjustments that reflect credit quality changes will indeed affect bondholder returns. For example, from Table 3, we observe that an initial issue of an AAA-rated bond had a 30.2 percent probability of being downgraded during a five-year horizon. Clearly, the net return to investors in this class, assuming no change in interest rates during that five years, will be lower than the initial yield expected by investors who did not consider rating changes. In the case of a BBB-rated bond, however, the tendency to be upgraded appears to be greater than that of being downgraded during the first five years of its life, so the net return should improve. The amount of the upgrade or downgrade is also relevant to the effect of the change on returns. For example, a two-letter downgrade (from BBB to $\mathrm{B}$, for example) will have a greater effect on returns than a single-letter change.

The exact amount that rating changes will affect net returns to bond investors is beyond the scope of this study. We fully expect, however, to incorporate our descriptive and analytical findings in this monograph into future research on the effects of creditworthiness factors and propensities for change on bond portfolio performance. 


\section{Practical Implications and Future Research}

Our findings have a number of applications for investment analysts, portfolio managers, and rating agencies. These applications include the following:

- A useful early step in assessing the credit quality risks of different corporate bond investments;

- The establishment of more precise loss reserves and capital allocations by bond actuaries and analysts at investment institutions;

- The establishment of guidelines for the construction of more precise features in structured finance obligations, most directly for collateralized bond obligations (CBOs);

- The establishment of tolerance levels for aggregate changes in a portfolio's composition before liquidation procedures are enforced-for example, the proportion of a portfolio that can fall to noninvestment-grade levels (fallen angels); and

- The attainment of better estimates of expected return performance for bond portfolios. This involves using predictive models of credit quality changes over various scenarios of interest rate volatility, investment horizons, and bond portfolio characteristics. These results have implications for bond selection as well as assessment of existing portfolios.

\section{Historical Experience}

We believe that knowledge of the past credit quality experience of bond rating classes is a useful early step in the assessment of future estimates of investment performance. This becomes especially relevant for actively managed portfolios rather than the buy-and-hold portfolios found in static, unit-trust funds. The association between historical performance of the various bond rating classes and the credit quality changes across rating classes is a 
meaningful analytic comparison. For example, we observed (Altman 1990b) that BBB-class mutual funds outperformed all other rating class categories in the 1980 s and also that $\mathrm{BBB}$ new issues had the most favorable upgrade/downgrade balance in both the 1970 s and the 1980 s as well as for the entire 20 -year sample period.

A useful caveat is related to the temptation to blindly extrapolate historical results into the future. Because the period examined may be atypical of future environments, it is important to create different scenarios for performance analysis. Also, the rating agency standards for rating assignment may change. This study examined credit quality changes under favorable (1970s) as well as unfavorable (1980s) conditions, which provides a diverse basis for discussion and action.

\section{Loss Reserves and Structured Finance Obligations}

The next two application areas, which are closely related to each other, deal with the establishment of more precise loss reserves and capital allocations in corporate bond portfolios. In general, financial institutions have policies and procedures to set aside reserves to cover anticipated losses from defaults on risky assets. Most of the analytical work has naturally centered on default rates and loss estimates using traditional and mortality/aging approaches (see Altman 1990a). An added ingredient could be an estimate of one or more years of credit-rating transitions of an investor's portfolio.

We advocate using a "net" approach — considering both expected upgrades and downgrades in the estimation of expected losses. Table 19, for example, shows net changes in the proportion of new-issue A-rated and BBB-rated bonds based strictly on one-year historical experience.

Combining the short-term gains and losses from these expected rating changes with expected loss rates and amounts from expected defaults, an analyst could more precisely estimate changes in a portfolio's value. An analysis that includes different interest rate scenarios would be even more complete.

The collateralized bond obligation market would seem to be an excellent application of our findings. This structured finance market has been growing rapidly in the past three years and has attained sufficient status that the major rating agencies have set up special groups to evaluate them. Structured finance instruments, such as CBOs, are based on certain explicit assumptions as to the appropriate overcollateralization of the amounts outstanding where the collateral consists of risky obligations such as noninvestment-grade bonds. Increasingly, $\mathrm{CBO}$ s are based on expected cash flows from the collateral with a number of "trigger" events calling for more collateral and cash flow assurances. One 


\section{TABLE 19. Net Effect of Rating Grade Changes, One-Year Historical Experience (percent of initial issue)}

\begin{tabular}{lrr}
\hline Grade Changes & $\mathrm{A}$ & $\mathrm{BBB}$ \\
\hline One upgrade & 2.6 & 5.5 \\
One downgrade & 4.7 & $\frac{2.9}{+2.6}$ \\
$\quad$ Net & $-\frac{2.1}{2.1}$ & 0.0 \\
Two upgrades & 0.0 & -1.1 \\
Two downgrades & 0.3 & -1.1 \\
$\quad$ Net & -0.3 & 0.0 \\
Three upgrades & - & 0.1 \\
Three downgrades & $-\frac{0.2}{-0.1}$ \\
$\quad$ Net & -0.2 & -0.1 \\
\hline
\end{tabular}

trigger mechanism that a creator of a $\mathrm{CBO}$ frequently includes is credit quality deterioration of the underlying collateral. The rating agencies look for conservative standards in the $\mathrm{CBO}$ structure to assign a high investment-grade rating, such as $\mathrm{A}$ or $\mathrm{AA}$, to the safest, most senior tranche of the $\mathrm{CBO}$.

If the $\mathrm{CBO}$ issue is insured and the senior tranche receives an AAA rating, then the insurer will be the one who looks at or requires conservative trigger mechanisms. The credit quality of the portfolio over time is of primary concern, and bond rating change estimates could be used in the creation and review process. Although the rating agencies tend to assess the issuer, rather than the market value of the issue, our results should still be of interest and importance.

\section{Portfolio Drift Tolerance Levels}

Some financial institutions and investment partnerships have charter restrictions and policies as to the risk level of their investment portfolios. For instance, investment-grade bond funds may not be able to hold junk bonds, including fallen angels, or they may be limited to a small percentage of such high-risk assets. Our analysis and results can be used to estimate the proportion of the original issue of investment-grade bonds that will become noninvestment grade within, say, five years.

If, for example, a portfolio of original-issue investment-grade bonds is held in the same proportions as the amounts listed in Table 2 for one year, the estimated number of issues that will fall to noninvestment-grade level within five 
years (using a naive, simple extrapolation model from Table 3 ) is as follows:

$\begin{array}{lcc}\text { Rating } & \begin{array}{c}\text { Original } \\ \text { Proportions }\end{array} & \begin{array}{c}\text { Fifth-Year } \\ \text { Proportions }^{7}\end{array} \\ \text { AAA } & 10.6 \% & 8.5 \% \\ \text { AA } & 31.6 & 27.9 \\ \text { A } & 39.8 & 39.8 \\ \text { BBB } & 18.0 & 19.8 \\ \text { NIG } & 0.0 & 4.0 \\ \text { Total } & -100.0 \% & 100.0 \%\end{array}$

So, if the guideline for this investment fund is that no more than 5 percent of the portfolio can be fallen angels, then the manager can expect to be in accordance with the policy at the end of the fifth year. After the fifth year, only 4 percent of the remaining portfolio of bonds had fallen into the noninvestment-grade category.

\section{Stochastic Predictive Model Application}

One of the primary applications of the estimated transition probabilities from a stochastic model is to predict and evaluate credit rating drift during the expected holding period of a single bond or a portfolio of bonds.

Table 20 presents estimated rating transition probability matrixes based on the MKV-S and MKV-NS models at the end of 1987 for a three-year holding period. Because of the stationary nature of the MKV-S model, estimated three-year transition probabilities should be used for all the bonds regardless of their ages. For an MKV-NS model, however, different three-year transition matrixes will be applied to bonds according to the number of years since the bond was issued.

Thus, given a bond's rating and age, the probabilities that its rating will change or remain unchanged in the next three years are indicated by the corresponding row in the transition matrix. These probabilities are then multiplied by the bond's weighting in the portfolio. Summing up these weighted probabilities for all the bonds results in the portfolio's expected rating distribution at the end of the three-year holding period.

Table 21 illustrates this application using a hypothetical portfolio consisting of five bonds. It presents the ending rating profiles of this hypothetical bond

\footnotetext{
${ }^{7}$ These percentages are attained by multiplying the original proportion by ( 1 minus the proportion of each rating class that fell to noninvestment grade status after the fifth year).
} 
TABLE 20. Estimated Three-Year Transition Probability Matrixes, 1987 (percent of original rating group)

\begin{tabular}{|c|c|c|c|c|c|}
\hline Years since & Original & & & den & ting \\
\hline Issuance & Rating & $\overline{\mathrm{AAA}}$ & $\mathrm{AA}$ & $\mathrm{A}$ & \\
\hline
\end{tabular}

Stationary Markov Chains

\begin{tabular}{llrrrrr}
- & AAA & 81.9 & 16.2 & 1.7 & 0.1 & 0.0 \\
- & AA & 1.9 & 83.9 & 12.7 & 1.3 & 0.3 \\
- & A & 0.3 & 5.5 & 81.6 & 11.5 & 1.1 \\
- & BBB & 0.2 & 0.7 & 13.3 & 73.5 & 12.4 \\
Nonstationary Markov Chains & NIG & 0.1 & 0.1 & 1.4 & 10.8 & 87.7 \\
New Issues & & & & & & \\
& AAA & 75.3 & 21.0 & 3.5 & 0.2 & 0.0 \\
& AA & 2.8 & 77.9 & 16.9 & 1.9 & 0.5 \\
& A & 0.5 & 9.5 & 73.1 & 14.4 & 2.5 \\
1 Year & BBB & 0.2 & 1.5 & 16.8 & 66.3 & 15.2 \\
& NIG & 0.2 & 0.1 & 2.0 & 7.5 & 90.2 \\
& AAA & 74.3 & 21.6 & 3.5 & 0.6 & 0.1 \\
& AA & 2.8 & 76.5 & 17.9 & 2.2 & 0.5 \\
2 Years & A & 0.9 & 8.4 & 73.0 & 15.1 & 2.7 \\
& BBB & 0.3 & 1.7 & 17.7 & 61.8 & 18.5 \\
& NIG & 0.2 & 0.1 & 2.3 & 10.5 & 86.8 \\
& AAA & 72.7 & 23.7 & 3.0 & 0.6 & 0.1 \\
3 Years & AA & 2.7 & 76.5 & 17.8 & 2.5 & 0.5 \\
& A & 0.8 & 8.1 & 73.4 & 15.6 & 2.2 \\
& BBB & 0.1 & 1.7 & 18.8 & 61.1 & 18.4 \\
& NIG & 0.2 & 0.2 & 2.7 & 12.6 & 84.3 \\
& AAA & 73.6 & 23.6 & 2.4 & 0.4 & 0.1 \\
4 Years & AA & 2.6 & 77.4 & 17.3 & 2.2 & 0.5 \\
& A & 0.9 & 7.2 & 74.7 & 15.5 & 1.7 \\
& BBB & 0.4 & 1.4 & 17.5 & 63.6 & 17.1 \\
& NIG & 0.1 & 0.1 & 3.1 & 12.4 & 84.4 \\
& AAA & 73.6 & 22.7 & 3.5 & 0.2 & 0.0 \\
& AA & 2.8 & 78.3 & 16.6 & 1.9 & 0.4 \\
& A & 0.4 & 6.4 & 77.0 & 14.0 & 2.2 \\
& BBB & 0.6 & 1.3 & 19.3 & 64.0 & 14.9 \\
& NIG & 0.0 & 0.5 & 2.5 & 12.2 & 84.8 \\
& AAA & 77.2 & 19.0 & 3.6 & 0.3 & 0.0 \\
& AA & 3.5 & 76.4 & 17.9 & 2.0 & 0.2 \\
& A & 0.6 & 4.5 & 78.9 & 14.3 & 1.7 \\
& BBB & 0.7 & 1.0 & 18.1 & 65.0 & 15.2 \\
& NIG & 0.0 & 0.5 & 2.6 & 15.3 & 81.6 \\
\hline & & & & & & \\
& & & &
\end{tabular}

Note: NIG $=$ Noninvestment grade. 


\section{TABLE 21. Hypothetical Use of Estimated Transition Matrixes,} Three-Year Holding Period (percentages)

\begin{tabular}{|c|c|c|c|c|c|c|c|c|}
\hline \multicolumn{2}{|c|}{ Beginning } & \multirow[b]{2}{*}{$\begin{array}{l}\text { Original } \\
\text { Rating }\end{array}$} & \multicolumn{5}{|c|}{$\begin{array}{c}\text { Rating Transition } \\
\text { Probabilities }\end{array}$} & \multirow{2}{*}{$\begin{array}{c}\text { Ending } \\
\text { Rating } \\
\text { Weights }\end{array}$} \\
\hline $\begin{array}{l}\text { Age } \\
\text { (Years) }\end{array}$ & $\begin{array}{c}\text { Rating } \\
\text { Weights }\end{array}$ & & $\mathrm{AAA}$ & $\mathrm{AA}$ & $A$ & $\mathrm{BBB}$ & $\mathrm{NIG}$ & \\
\hline \multicolumn{9}{|c|}{ MKV_S Model } \\
\hline 0 & 25.0 & $\mathrm{AAA}$ & 81.9 & 16.2 & 1.7 & 0.1 & 0.0 & 21.3 \\
\hline 2 & 40.0 & $\mathrm{AA}$ & 1.9 & 83.9 & 12.7 & 1.3 & 0.3 & 38.8 \\
\hline 5 & 20.0 & A & 0.3 & 5.5 & 81.6 & 11.5 & 1.1 & 23.2 \\
\hline 3 & 10.0 & $\mathrm{BBB}$ & 0.2 & 0.7 & 13.3 & 73.5 & 12.4 & 10.7 \\
\hline 1 & 5.0 & $\mathrm{NIG}$ & 0.1 & 0.1 & 1.4 & 10.8 & 87.7 & 6.0 \\
\hline \multicolumn{9}{|c|}{$M K V-N S$ Model } \\
\hline 0 & 25.0 & AAA & 75.3 & 21.0 & 3.5 & 0.2 & 0.0 & 20.1 \\
\hline 2 & 40.0 & $\mathrm{AA}$ & 2.7 & 76.5 & 17.8 & 2.5 & 0.5 & 36.9 \\
\hline 5 & 20.0 & $A$ & 0.6 & 4.5 & 78.9 & 14.3 & 1.7 & 25.6 \\
\hline 3 & 10.0 & $\mathrm{BBB}$ & 0.4 & 1.4 & 17.5 & 63.6 & 17.1 & 10.8 \\
\hline 1 & 5.0 & NIG & 0.2 & 0.1 & 2.3 & 10.5 & 86.8 & 6.6 \\
\hline
\end{tabular}

Note: $\mathrm{NIG}=$ Noninvestment grade.

portfolio based on estimated transition matrixes in Table 20. By taking into account the probabilities of bond rating drift in the future, the ending rating profile becomes different from the beginning rating profile for individual bonds as well as for the whole portfolio. In Table 21, all noninvestment-grade issues are aggregated into the NIG category to accommodate their smaller sample size. The estimated transition matrixes can be easily applied to the full range of rating categories and corresponding transition probabilities.

\section{Implications for Bond Portfolio Management}

Although a discussion of the implications of rating drift to a full range of bond portfolio management practices is beyond the scope of this paper, we present an example of how estimated rating transition matrixes can be incorporated into the analysis of expected total returns on bonds (price changes, coupon income, and coupon reinvestments) during the assumed holding period.

Depending upon the expected change in yields of the bonds, given the estimated transition, a portfolio manager can assess the effect of the change on returns. Continuing the hypothetical example in Table 21 , Table 22 presents credit/yield relationships and performance profiles for a three-year holding 


\section{TABLE 22. Hypothetical Bond Credit/Yield Relationships and Performance Profiles (percentages)}

\begin{tabular}{|c|c|c|c|c|c|c|c|}
\hline \multirow{2}{*}{$\begin{array}{l}\text { Original } \\
\text { Rating }\end{array}$} & \multirow{2}{*}{$\begin{array}{c}\text { Actual } \\
\text { Beginning } \\
\text { Yields }\end{array}$} & \multirow{2}{*}{$\begin{array}{c}\text { Expected } \\
\text { Ending } \\
\text { Yields }\end{array}$} & \multicolumn{5}{|c|}{ Total Returns with Ending Rating } \\
\hline & & & AAA & $\mathrm{AA}$ & A & $\mathrm{BBB}$ & NIG \\
\hline AAA & 9.75 & 8.75 & 38.21 & 36. & 35.60 & 34.32 & 18.41 \\
\hline AA & 10.00 & 9.00 & 38.99 & 37.97 & 36.96 & 35.96 & 23.23 \\
\hline A & 10.25 & 3.25 & 37.67 & 37.21 & 36.76 & 36.31 & 30.26 \\
\hline BBB & 10.50 & y. 50 & 41.74 & 40.89 & 40.04 & 39.20 & 28.33 \\
\hline NIG & 13.00 & 13.00 & 65.43 & 64.15 & 62.89 & 61.64 & 44.91 \\
\hline T-Bond & 9.25 & 8.25 & & & & & \\
\hline
\end{tabular}

Note: NIG $=$ Noninvestment grade.

period. The assumptions are that (1) all five bonds were originally issued with a 10-year maturity and purchased at par at the beginning of the expected three-year investment horizon; (2) yields will decrease by 100 basis points by the end of the holding period, except for the NIG issue; (3) yield spreads between any of the two investment-grade categories remains constant at 25 basis points; and (4) expected returns are based on the use of the MKV-S model.

Table 22 also presents expected total returns over three years, given the bond's beginning and ending ratings. For example, if the AAA-rated bond were downgraded to the AA category, total return over the three-year holding period is expected to be 36.89 percent, which is 1.32 percentage points less than those AAA-rated bonds that were not downrated. Because the yields decline over time in this example, when a bond is downgraded, the magnitude of yield decrease (and hence the return attributable to price appreciation) is less than it would be if the bond's rating remains the same.

Based on the performance profile in Table 22, Table 23 shows total returns on these five hypothetical bonds and the entire portfolio under the following scenarios: (1) ratings remain unchanged, (2) the rating transition during the holding period follows a stationary Markov chain process, and (3) the rating drift process is a nonstationary Markov chain. It shows that failing to consider bond rating drift would overestimate the performance of individual bonds and the whole portfolio under the assumed yield curve changes. The expected performance of Treasury bonds with comparable years to maturity is also presented as a risk-free benchmark. All three scenarios result in returns greater than the risk-free benchmark. 
TABLE 23. Total Returns under Various Rating Transition Assumptions

\begin{tabular}{|c|c|c|c|c|c|c|c|}
\hline \multirow[b]{2}{*}{$\begin{array}{l}\text { Bond } \\
\text { Number }\end{array}$} & \multicolumn{2}{|c|}{ Beginning } & \multirow[b]{2}{*}{ Original } & \multicolumn{4}{|c|}{ Total Returns (\%) Assuming: } \\
\hline & $\begin{array}{c}\text { Bond } \\
\text { Age } \\
\text { (years) }\end{array}$ & $\begin{array}{c}\text { Rating } \\
\text { Weights } \\
(\%)\end{array}$ & & $\begin{array}{l}\text { Rating } \\
\text { Unchanged }\end{array}$ & $\begin{array}{l}\text { MKV_S } \\
\text { Transition }\end{array}$ & $\begin{array}{l}\text { MKV-NS } \\
\text { Transition }\end{array}$ & $\begin{array}{c}\text { T-Bond } \\
\text { Benchmark } \\
\text { Portfolio }^{\mathrm{a}}\end{array}$ \\
\hline 1 & 0 & 25 & AAA & 38.21 & 37.90 & 37.83 & 36.40 \\
\hline 2 & 2 & 40 & $\mathrm{AA}$ & 37.97 & 37.83 & 37.69 & 35.19 \\
\hline 3 & 5 & 20 & $\mathrm{~A}$ & 36.76 & 36.66 & 36.61 & 32.97 \\
\hline 4 & 3 & 10 & $\mathrm{BBB}$ & 39.20 & 38.01 & 37.52 & 34.51 \\
\hline 5 & 1 & 5 & NIG & 44.91 & 47.05 & 47.10 & 35.82 \\
\hline Portfolio & & 100 & & 38.26 & 38.09 & 37.96 & 35.01 \\
\hline
\end{tabular}

a 10 -year Treasury bonds with comparable years to maturity.

Note: $\mathrm{NIG}=$ Noninvestment grade.

\section{Conclusions}

Empirical results indicate that three stochastic Markov chain models can describe the bond rating drift reasonably well. A back test of the models' predictive ability on the data set outside the modeling sample demonstrated that, in most cases, all three stochastic models performed better than a naive model using historical rating transition probabilities. Of the models examined, the Markov stationary and nonstationary models performed equally well in the back test.

The Markov stationary model was not able to extend its superiority from the in-sample compatibility to the out-of-sample back test, however. Moreover, the results should be carefully interpreted with regard to this model. By definition, it is assumed to have constant proportions of stayers and a constant mover transition matrix. In reality, the proportions of stayers and the mover matrix varied from time to time during the test period-for example, the 1970 s had fewer movers than did the 1980 s.

\section{Future Research}

Two important questions have not been answered completely in this report. The first is this: What have been the actual wealth effects on bond portfolio performance of changes or expected changes in bond ratings across the entire spectrum of possible rating changes? The second: Once we observe a bond rating change, do particular bond rating issues have a tendency to change again in the future in the same direction-that is, is there serial correlation of bond 
rating changes? In a sense, the latter question is a refinement of analyzing the mover population of bonds from the Markov mover-stayer model. It is also an interesting empirical question.

These questions have direct and concrete relevance for bond portfolio managers and for bond actuaries, who are responsible for recommending allocations of capital to reserves against loss of principal. When the investment horizon is not restricted to the full maturity of a fixed-income instrument, changes in credit quality, reflected in bond ratings, become relevant. Heretofore, loss reserves have been set on the assumption of default probabilities and recoveries after default only. Our analysis can add other, less dramatic changes to the process.

The whole question of bond rating drift over time, as applied to municipal bonds, is also worth considering. Much of the discussion and methodology applying to corporate bonds is also relevant to municipal issues. 



\section{Appendix A. \\ Bond Rating Agencies and Systems}

The largest U.S. rating agencies are Moody's, a subsidiary of Dun and Bradstreet; Standard \& Poor's (S\&P), a subsidiary of McGraw-Hill; and the newly merged firm of Duff and Phelps and McCarthy, Crisanti, and Maffei. This merger was effected in early 1991 to enable the two entities to compete with the larger agencies. Fitch and Company is an established and respected, but smaller, rating agency. The approximate number of companies these firms rate and their publications and services are shown in Table A-1.

Moody's, S\&P, and Fitch all began assigning ratings in the early 20th century. Moody's rated railroad bonds in 1909 and started rating utility and industrial debt in 1914. Poor's, the predecessor of S\&P, began issuing ratings in 1922, and the firm of Standard Statistics started in 1923; the two merged into Standard \& Poor's in 1941. Fitch ratings first appeared in 1923. All three of these agencies issue publicly available ratings and use similar, although not identical, rating symbols to summarize their opinions of a bond issue. (Fitch sold rights to its symbol system to S\&P.)

McCarthy, Crisanti, and Maffei, the newest of the rating agencies, was founded in 1975. It issued only private ratings, which it made available only to its clients. Chicago-based Duff and Phelps, the only non-New York agency, used to assign numbers between 1 (the highest) and 17 (the lowest), which it related to the usual letter symbols, but this system has been replaced by a letter rating system similar to those of the other rating services.

Duff and Phelps began evaluating utility bonds in the 1930s but did not issue public ratings until 1980 . At present, it issues both public and private ratings. In 1984, Security Pacific Corporation (a bank holding company) sought to acquire Duff and Phelps under a plan approved by both companies. Although the Federal Reserve Board allowed most of the acquisition, it ruled that Security Pacific would not be allowed to continue to issue public ratings. The Board stated that lending to many of the same companies the firm would be rating would

Note: This appendix updates materials found in Ederington and Yawitz (1987). 
TABLE A-1. U.S. Bond Rating Agencies

\begin{tabular}{|c|c|c|}
\hline Agency & $\begin{array}{l}\text { Approximate } \\
\text { Number of } \\
\text { Companies } \\
\text { Rated }\end{array}$ & $\begin{array}{l}\text { Representative Rating } \\
\text { Publications and Services }\end{array}$ \\
\hline Standard \& Poor's & 4,000 & $\begin{array}{l}\text { CreditWeek (weekly) } \\
\text { CreditWeek International (monthly) } \\
\text { Bond Guide (monthly) } \\
\text { Commercial Paper Ratings (monthly) } \\
\text { Municipal Bond Book (bimonthly) } \\
\text { Structured Finance Guide } \\
\text { High Yield Quarterly } \\
\text { CreditWire }\end{array}$ \\
\hline Moody's & 4,000 & $\begin{array}{l}\text { Bond Record (monthly) } \\
\text { Bond Survey (weekly) } \\
\text { Municipal and Government Manual (biweekly) } \\
\text { Speculative Grade Report Service (monthly) } \\
\text { Corporate Credit Reports (weekly) } \\
\text { Global Ratings (monthly) } \\
\text { Structured Finance (monthly) } \\
\text { Credit Opinions - Financial Institutions and } \\
\quad \text { Euromarkets (quarterly) }\end{array}$ \\
\hline Fitch & 1,000 & $\begin{array}{l}\text { Rating Register (monthly) } \\
\text { Insights (biweekly) } \\
\text { New Issues and Special Reports } \\
\text { Financial Wire (electronic) }\end{array}$ \\
\hline $\begin{array}{l}\text { Duff and Phelps } \\
\text { McCarthy, Crisanti, } \\
\text { and Maffei }\end{array}$ & 1,150 & $\begin{array}{l}\text { The Rating Guide (monthly) } \\
\text { Credit Decisions (weekly) } \\
\text { Fixed Income Research Digest (monthly) } \\
\text { Short Term Ratings and Research Guide with } \\
\text { Daily Alerts (quarterly and daily) } \\
\text { Structured Finance (quarterly) } \\
\text { Asset Backed Monitor (quarterly) }\end{array}$ \\
\hline
\end{tabular}

constitute a conflict of interest. As a result of this ruling, the acquisition plans were abandoned. In 1986, Duff and Phelps's management participated in a leveraged buyout. In 1991, Duff and Phelps acquired McCarthy, Crisanti, and Maffei.

In recent years, the rating agencies have refined their bond ratings to 
provide a more precise indication of their judgment of a security's creditworthiness. In 1973 and 1974, Fitch and S\&P, respectively, began attaching plus and minus symbols to many of their ratings to indicate above- or below-average standing within the major rating categories $B$ through $A A$. Officials at S\&P indicate that this refinement followed a decision to devote more effort and human resources to evaluating creditworthiness-a change it says was made possible by the institution of issuer fees in the early 1970s. Prior to that time, revenue was derived solely from the sale of its publications. In 1988, S\&P expanded the plus and minus refinement to CCC-rated bonds. Moody's instituted user fees in 1969, and in 1982, it refined its ratings by attaching the modifiers 1,2 , or 3 to ratings from $\mathrm{B}$ to $\mathrm{Aa}$, inclusive.

International Rating Systems. Other countries with extensive rating systems are Japan, Australia, Canada, and France. Recently, S\&P has entered into a number of joint ventures with various local institutions in European countries. For example, S\&P had a joint venture (now wholly owned) in Sweden to evaluate country and company debt of entities in Scandinavia. It also has a 50 percent ownership interest in the French rating agency, S\&P-ADEF. Moody's maintains offices in London, Paris, Frankfort, Tokyo, and Sydney.

NAIC Debt Ratings. Another type of rating of corporate debt is performed by the National Association of Insurance Commissioners (NAIC) through its Securities Valuation Office (SVO). For a number of years until 1990, the NAIC used four bond rating categories on all public and privately issued debt held by insurance companies. In 1990, these ratings were revised into the current system of six classes, which are more closely aligned with other rating systems; these include:

New System
Category
1
2
3
4
5
6

Equivalent Rating
AAA, AA, or A
BBB (or Baa)
BB (or Ba)
B
CCC (or Caa)
D (Default)

The categories in the old and new systems refer to the amount of the annual and total loss reserve percentages that must be appropriated by insurance companies. 
The NAIC-SVO data base comprises approximately 11,500 different issuers of debt that have received ratings on more than 42,000 debt issues. Some 10,000 of these issues are already rated by one or more of the four rating agencies described above. Others are rated by guarantees, corporate or government, and receive the guarantor's rating. For those issues not covered by other rating services or by guarantees, a three-part system is applied: 8

1. Where appropriate, the SVO staff will apply the ZETA@ Services, Inc. (Hoboken, N.J.), quantitative financial model to current and past financial statement data to determine a preliminary measure of financial soundness of the issuer. The result is a numeric score that can be ranked against other similar scores related to various NAIC designations. (See Table A-2. $)^{9}$

2. Five years of historical financial data (when available) and any projected data from the issuer are reviewed. In addition, the SVO analyst will review the auditor's opinion and any news media articles or research reports relating to the issuer.

3. The final part of the analysis focuses on factors that are specific to the security under review. These include covenants, structure, collateral, third-party support, and ratings performed by any other recognized rating agency.

\footnotetext{
${ }^{8}$ See "Purposes and Procedures of the Securities Valuation Office of the NAIC as of December 1989, Section B," Corporate Bonds-General Procedure, Securities Valuation Office, New York City (1990).

${ }^{9}$ Based on original work by Altman, Haldeman, and Narayanan (1977), this model consists of seven variables, which encompass six firm characteristics: (1) capital structure, (2) income stability, (3) liquidity, (4) profitability, (5) ability to service debt, and (6) size of firm. Table A-2 shows the relationship between average Zeta scores and Moody's and $\$ \& P$ bond ratings from 1981 through 1990 . In most years, the Zeta scores were quite symmetrical-that is, adjacent ratings are separated by about two points.
} 
TABLE A-2. Average Zeta ${ }^{\circledR}$ Scores by Rating Agency and by Senior Debt Bond Rating Category

\begin{tabular}{lrrrrrrrrrrr}
\hline $\begin{array}{l}\text { Agency } \\
\text { and Rating }\end{array}$ & 1990 & 1989 & 1988 & 1987 & 1986 & 1985 & 1984 & 1983 & 1982 & 1981 \\
\hline Moody's & & & & & & & & & & \\
AAA & 8.03 & 8.09 & 9.08 & 9.34 & 9.54 & 10.75 & 11.55 & 10.90 & 10.54 & 9.87 \\
AA & 7.21 & 7.30 & 7.68 & 7.36 & 7.36 & 8.03 & 7.77 & 7.74 & 7.57 & 7.61 \\
A & 5.47 & 5.61 & 5.88 & 5.33 & 5.05 & 5.32 & 5.48 & 5.35 & 5.42 & 5.60 \\
BAA & 2.88 & 2.87 & 3.34 & 2.77 & 2.97 & 3.30 & 3.42 & 2.96 & 2.88 & 3.43 \\
BA & -0.69 & -0.35 & 0.81 & 0.90 & 1.47 & 0.66 & 0.75 & 0.81 & 1.29 & 1.00 \\
B & -3.07 & -2.16 & -1.88 & -2.01 & -1.25 & -1.50 & -1.62 & -2.18 & -1.62 & -0.69 \\
CAA & -5.03 & -3.35 & -3.97 & -4.62 & -6.32 & -7.63 & -6.95 & -4.50 & -4.97 & -3.69 \\
NR & 0.63 & 0.79 & -0.05 & -0.52 & -0.22 & 0.35 & 1.33 & 1.09 & 1.36 & - \\
S\&P & & & & & & & & & & \\
AAA & 7.94 & 7.81 & 8.76 & 8.95 & 8.78 & 9.95 & 11.01 & 10.80 & 10.34 & 10.03 \\
AA & 7.12 & 7.08 & 7.25 & 7.02 & 6.82 & 7.55 & 7.48 & 7.58 & 7.29 & 7.58 \\
A & 5.36 & 5.48 & 5.87 & 5.29 & 5.19 & 5.34 & 5.47 & 5.20 & 5.39 & 5.65 \\
BBB & 2.56 & 2.80 & 3.25 & 2.94 & 2.87 & 3.26 & 3.51 & 2.83 & 2.71 & 3.61 \\
BB & -0.71 & 0.03 & 0.85 & 0.59 & 1.47 & 1.08 & 0.86 & 0.78 & 1.09 & 1.38 \\
B & -2.19 & -2.02 & -1.53 & -1.70 & -0.59 & -1.88 & -2.08 & -1.56 & -1.43 & -0.79 \\
CCC & -6.16 & -5.74 & -8.19 & -6.27 & -8.36 & -5.24 & -4.35 & -4.23 & -4.23 & -2.59 \\
NR ${ }^{a}$ & 1.52 & 2.15 & 3.30 & 2.40 & 2.83 & 4.20 & 4.52 & 0.82 & 0.64 & - \\
\hline
\end{tabular}

aNonrated.

Source: Zeta ${ }^{\circledR}$ Services, Inc., Bond Rating Analysis Book, Fall 1990. 


\section{Appendix B.}

Rating Drift Tables,

1970-79 and $1980-89$

TABLE B-1. Rating Drift, 1970-79 (percent of original rating group)

\begin{tabular}{|c|c|c|c|c|c|c|c|c|c|c|c|}
\hline \multirow{2}{*}{$\begin{array}{l}\text { Age and } \\
\text { Number } \\
\text { of Issues }\end{array}$} & \multirow{2}{*}{$\begin{array}{l}\text { Original } \\
\text { Rating }\end{array}$} & \multicolumn{10}{|c|}{ Rating at Given Age } \\
\hline & & AAA & $\mathrm{AA}$ & A & $\mathrm{BBB}$ & $\mathrm{BB}$ & B & $\mathrm{CCC}$ & $\mathrm{CC}$ & $\mathrm{C}$ & $\mathrm{D}$ \\
\hline \multicolumn{12}{|l|}{1 Year } \\
\hline 302 & $\mathrm{AAA}$ & 97.4 & 2.6 & 0.0 & 0.0 & 0.0 & 0.0 & 0.0 & 0.0 & 0.0 & 0.0 \\
\hline 698 & AA & 1.1 & 95.3 & 3.6 & 0.0 & 0.0 & 0.0 & 0.0 & 0.0 & 0.0 & 0.0 \\
\hline 1,066 & A & 0.1 & 1.2 & 96.3 & 2.3 & 0.0 & 0.0 & 0.0 & 0.0 & 0.0 & 0.0 \\
\hline 327 & $\mathrm{BBB}$ & 0.0 & 0.0 & 2.1 & 96.3 & 1.2 & 0.3 & 0.0 & 0.0 & 0.0 & 0.0 \\
\hline 69 & $\mathrm{BB}$ & 0.0 & 0.0 & 0.0 & 0.0 & 98.6 & 1.4 & 0.0 & 0.0 & 0.0 & 0.0 \\
\hline 122 & B & 0.0 & 0.0 & 0.8 & 0.0 & 1.6 & 97.5 & 0.0 & 0.0 & 0.0 & 0.0 \\
\hline 18 & $\mathrm{CCC}$ & 0.0 & 0.0 & 0.0 & 0.0 & 0.0 & 0.0 & 100.0 & 0.0 & 0.0 & 0.0 \\
\hline 1 & $\mathrm{CC}$ & 0.0 & 0.0 & 0.0 & 0.0 & 0.0 & 0.0 & 0.0 & 100.0 & 0.0 & 0.0 \\
\hline 0 & $\mathrm{C}$ & 0.0 & 0.0 & 0.0 & 0.0 & 0.0 & 0.0 & 0.0 & 0.0 & 0.0 & 0.0 \\
\hline 0 & D & 0.0 & 0.0 & 0.0 & 0.0 & 0.0 & 0.0 & 0.0 & 0.0 & 0.0 & 0.0 \\
\hline \multicolumn{12}{|l|}{2 Years } \\
\hline 302 & AAA & 94.7 & 4.6 & 0.0 & 0.0 & 0.0 & 0.0 & 0.0 & 0.0 & 0.0 & 0.0 \\
\hline 696 & $\mathrm{AA}$ & 2.0 & 87.5 & 10.2 & 0.3 & 0.0 & 0.0 & 0.0 & 0.0 & 0.0 & 0.0 \\
\hline 1,062 & A & 0.1 & 2.9 & 92.3 & 4.5 & 0.2 & 0.0 & 0.0 & 0.0 & 0.0 & 0.0 \\
\hline 326 & $\mathrm{BBB}$ & 0.0 & 0.3 & 4.3 & 93.6 & 1.5 & 0.0 & 0.0 & 0.0 & 0.0 & 0.3 \\
\hline 68 & $\mathrm{BB}$ & 0.0 & 0.0 & 0.0 & 2.9 & 88.2 & 7.4 & 1.5 & 0.0 & 0.0 & 0.0 \\
\hline 121 & B & 0.0 & 0.0 & 0.8 & 0.0 & 1.7 & 97.5 & 0.0 & 0.0 & 0.0 & 0.0 \\
\hline 16 & $\mathrm{CCC}$ & 0.0 & 0.0 & 0.0 & 0.0 & 0.0 & 18.8 & 81.3 & 0.0 & 0.0 & 0.0 \\
\hline 1 & $\mathrm{CC}$ & 0.0 & 0.0 & 0.0 & 0.0 & 0.0 & 0.0 & 0.0 & 100.0 & 0.0 & 0.0 \\
\hline 0 & $\mathrm{C}$ & 0.0 & 0.0 & 0.0 & 0.0 & 0.0 & 0.0 & 0.0 & 0.0 & 0.0 & 0.0 \\
\hline 0 & $\mathrm{D}$ & 0.0 & 0.0 & 0.0 & 0.0 & 0.0 & 0.0 & 0.0 & 0.0 & 0.0 & 0.0 \\
\hline
\end{tabular}

Note: Numbers in boldface are percentages of issues with unchanged ratings.

Table continued on page 64 . 
TABLE B-1-Continued

\begin{tabular}{|c|c|c|c|c|c|c|c|c|c|c|c|}
\hline \multirow{2}{*}{$\begin{array}{l}\text { Age and } \\
\text { Number } \\
\text { of Issues }\end{array}$} & \multirow{2}{*}{$\begin{array}{c}\text { Original } \\
\text { Rating }\end{array}$} & \multicolumn{10}{|c|}{ Rating at Given Age } \\
\hline & & AAA & $\mathrm{AA}$ & $\mathrm{A}$ & BBB & $\mathrm{BB}$ & B & $\mathrm{CCC}$ & $\mathrm{CC}$ & $\mathrm{C}$ & $\mathrm{D}$ \\
\hline \multicolumn{12}{|l|}{3 Years } \\
\hline 302 & AAA & 92.1 & 7.3 & 0.0 & 0.7 & 0.0 & 0.0 & 0.0 & 0.0 & 0.0 & 0.0 \\
\hline 695 & AA & 2.4 & 80.3 & 16.1 & 1.2 & 0.0 & 0.0 & 0.0 & 0.0 & 0.0 & 0.0 \\
\hline 1,058 & A & 0.3 & 4.0 & 87.9 & 7.4 & 0.4 & 0.1 & 0.0 & 0.0 & 0.0 & 0.0 \\
\hline 323 & $\mathrm{BBB}$ & 0.0 & 0.6 & 8.0 & 87.9 & 2.2 & 0.3 & 0.0 & 0.0 & 0.0 & 0.9 \\
\hline 67 & $\mathrm{BB}$ & 0.0 & 0.0 & 1.5 & 17.9 & 70.1 & 6.0 & 1.5 & 0.0 & 0.0 & 3.0 \\
\hline 120 & B & 0.8 & 0.8 & 0.8 & 1.7 & 7.5 & 82.5 & 5.0 & 0.0 & 0.0 & 0.8 \\
\hline 15 & $\mathrm{CCC}$ & 0.0 & 0.0 & 6.7 & 0.0 & 0.0 & 40.0 & 46.7 & 0.0 & 0.0 & 0.0 \\
\hline 1 & $\mathrm{CC}$ & 0.0 & 0.0 & 0.0 & 0.0 & 0.0 & 0.0 & 0.0 & 100.0 & 0.0 & 0.0 \\
\hline 0 & $\mathrm{C}$ & 0.0 & 0.0 & 0.0 & 0.0 & 0.0 & 0.0 & 0.0 & 0.0 & 0.0 & 0.0 \\
\hline 0 & D & 0.0 & 0.0 & 0.0 & 0.0 & 0.0 & 0.0 & 0.0 & 0.0 & 0.0 & 0.0 \\
\hline \multicolumn{12}{|l|}{4 Years } \\
\hline 302 & AAA & 87.7 & 11.3 & 0.3 & 0.7 & 0.0 & 0.0 & 0.0 & 0.0 & 0.0 & 0.0 \\
\hline 695 & $\mathrm{AA}$ & 2.6 & 73.1 & 20.6 & 3.7 & 0.0 & 0.0 & 0.0 & 0.0 & 0.0 & 0.0 \\
\hline 1,052 & $A$ & 0.4 & 5.8 & 83.1 & 9.6 & 0.9 & 0.3 & 0.0 & 0.0 & 0.0 & 0.0 \\
\hline 319 & $\mathrm{BBB}$ & 0.0 & 0.3 & 13.8 & 80.9 & 2.8 & 0.9 & 0.6 & 0.0 & 0.0 & 0.6 \\
\hline 67 & $\mathrm{BB}$ & 0.0 & 0.0 & 6.0 & 19.4 & 62.7 & 6.0 & 1.5 & 0.0 & 0.0 & 4.5 \\
\hline 120 & B & 0.8 & 0.0 & 1.7 & 4.2 & 10.0 & 75.8 & 5.8 & 0.0 & 0.0 & 1.7 \\
\hline 15 & $\mathrm{CCC}$ & 0.0 & 0.0 & 6.7 & 6.7 & 0.0 & 40.0 & 40.0 & 6.7 & 0.0 & 0.0 \\
\hline 1 & $\mathrm{CC}$ & 0.0 & 0.0 & 0.0 & 0.0 & 0.0 & 0.0 & 0.0 & 100.0 & 0.0 & 0.0 \\
\hline 0 & $\mathrm{C}$ & 0.0 & 0.0 & 0.0 & 0.0 & 0.0 & 0.0 & 0.0 & 0.0 & 0.0 & 0.0 \\
\hline 0 & $\mathrm{D}$ & 0.0 & 0.0 & 0.0 & 0.0 & 0.0 & 0.0 & 0.0 & 0.0 & 0.0 & 0.0 \\
\hline \multicolumn{12}{|l|}{5 Years } \\
\hline 300 & AAA & 80.0 & 19.0 & 1.0 & 0.0 & 0.0 & 0.0 & 0.0 & 0.0 & 0.0 & 0.0 \\
\hline 688 & $\mathrm{AA}$ & 2.8 & 67.6 & 24.0 & 5.4 & 0.3 & 0.0 & 0.0 & 0.0 & 0.0 & 0.0 \\
\hline 1,040 & A & 0.4 & 7.6 & 77.7 & 12.6 & 1.3 & 0.4 & 0.0 & 0.0 & 0.0 & 0.0 \\
\hline 315 & $\mathrm{BBB}$ & 0.0 & 1.0 & 17.1 & 74.3 & 4.4 & 0.3 & 1.6 & 0.0 & 0.0 & 1.3 \\
\hline 64 & $\mathrm{BB}$ & 0.0 & 0.0 & 7.8 & 23.4 & 46.9 & 15.6 & 1.6 & 0.0 & 0.0 & 4.7 \\
\hline 115 & $\mathrm{~B}$ & 0.9 & 0.0 & 4.3 & 3.5 & 11.3 & 68.7 & 9.6 & 0.0 & 0.0 & 1.7 \\
\hline 14 & $\mathrm{CCC}$ & 0.0 & 0.0 & 7.1 & 7.1 & 0.0 & 42.9 & 35.7 & 7.1 & 0.0 & 0.0 \\
\hline 1 & $\mathrm{CC}$ & 0.0 & 0.0 & 0.0 & 0.0 & 0.0 & 0.0 & 0.0 & 100.0 & 0.0 & 0.0 \\
\hline 0 & $\mathrm{C}$ & 0.0 & 0.0 & 0.0 & 0.0 & 0.0 & 0.0 & 0.0 & 0.0 & 0.0 & 0.0 \\
\hline 0 & $\mathrm{D}$ & 0.0 & 0.0 & 0.0 & 0.0 & 0.0 & 0.0 & 0.0 & 0.0 & 0.0 & 0.0 \\
\hline
\end{tabular}

Note: Numbers in boldface are percentages of issues with unchanged ratings. 
TABLE B-1-Continued

\begin{tabular}{|c|c|c|c|c|c|c|c|c|c|c|c|}
\hline \multirow{2}{*}{$\begin{array}{l}\text { Age and } \\
\text { Number } \\
\text { of Issues }\end{array}$} & \multirow{2}{*}{$\begin{array}{c}\text { Original } \\
\text { Rating }\end{array}$} & \multicolumn{10}{|c|}{ Rating at Given Age } \\
\hline & & AAA & $\mathrm{AA}$ & A & BBB & $\mathrm{BB}$ & B & $\mathrm{CCC}$ & $\mathrm{CC}$ & $\mathrm{C}$ & $\mathrm{D}$ \\
\hline \multicolumn{12}{|l|}{6 Years } \\
\hline 281 & AAA & 73.3 & 24.9 & 1.8 & 0.0 & 0.0 & 0.0 & 0.0 & 0.0 & 0.0 & 0.0 \\
\hline 664 & $\mathrm{AA}$ & 2.6 & 64.2 & 26.4 & 6.2 & 0.8 & 0.0 & 0.0 & 0.0 & 0.0 & 0.0 \\
\hline 1,004 & A & 0.7 & 8.1 & 73.5 & 15.6 & 1.7 & 0.4 & 0.0 & 0.0 & 0.0 & 0.0 \\
\hline 295 & BBB & 0.0 & 1.0 & 19.7 & 69.8 & 6.1 & 1.7 & 0.3 & 0.0 & 0.0 & 1.4 \\
\hline 60 & $\mathrm{BB}$ & 0.0 & 0.0 & 11.7 & 26.7 & 45.0 & 10.0 & 3.3 & 0.0 & 0.0 & 3.3 \\
\hline 110 & B & 0.9 & 0.0 & 7.3 & 3.6 & 8.2 & 61.8 & 15.5 & 0.0 & 0.0 & 2.7 \\
\hline 11 & $\mathrm{CCC}$ & 9.1 & 0.0 & 0.0 & 0.0 & 0.0 & 54.5 & 27.3 & 9.1 & 0.0 & 0.0 \\
\hline , & $\mathrm{CC}$ & 0.0 & 0.0 & 0.0 & 0.0 & 0.0 & 0.0 & 0.0 & 100.0 & 0.0 & 0.0 \\
\hline 0 & $\mathrm{C}$ & 0.0 & 0.0 & 0.0 & 0.0 & 0.0 & 0.0 & 0.0 & 0.0 & 0.0 & 0.0 \\
\hline 0 & D & 0.0 & 0.0 & 0.0 & 0.0 & 0.0 & 0.0 & 0.0 & 0.0 & 0.0 & 0.0 \\
\hline
\end{tabular}

7 Years

$\begin{array}{llllllllllll}266 & \text { AAA } & 67.7 & 28.9 & 3.4 & 0.0 & 0.0 & 0.0 & 0.0 & 0.0 & 0.0 & 0.0\end{array}$

$\begin{array}{llllllllllll}638 & \text { AA } & 3.1 & \mathbf{5 9 . 9} & 28.8 & 6.9 & 1.3 & 0.0 & 0.0 & 0.0 & 0.0 & 0.0\end{array}$

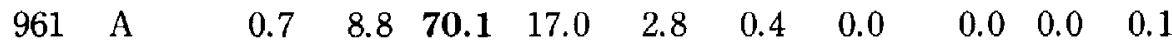

$\begin{array}{llllllllllll}285 & \text { BBB } & 0.0 & 1.1 & 25.3 & \mathbf{6 2 . 1} & 7.4 & 2.1 & 0.7 & 0.0 & 0.0 & 1.4\end{array}$

$\begin{array}{llllllllllll}57 & \mathrm{BB} & 0.0 & 1.8 & 12.3 & 22.8 & \mathbf{3 8 . 6} & 17.5 & 1.8 & \mathbf{0 . 0} & 0.0 & 5.3\end{array}$

$\begin{array}{llllllllllll}102 & \text { B } & 1.0 & 0.0 & 6.9 & 4.9 & 7.8 & \mathbf{5 4 . 9} & 15.7 & 2.0 & 0.0 & 6.9\end{array}$

$\begin{array}{llllllllllll}11 & \text { CCC } & 9.1 & 0.0 & 0.0 & 0.0 & 0.0 & 54.5 & 27.3 & 9.1 & 0.0 & 0.0\end{array}$

$\begin{array}{llllllllllll}1 & C C & 0.0 & 0.0 & 0.0 & 0.0 & 0.0 & 0.0 & 0.0 & 100.0 & 0.0 & 0.0\end{array}$

$\begin{array}{llllllllllll}0 & \mathrm{C} & 0.0 & 0.0 & 0.0 & 0.0 & 0.0 & 0.0 & 0.0 & 0.0 & 0.0 & 0.0\end{array}$

$\begin{array}{llllllllllll}0 & \mathrm{D} & 0.0 & 0.0 & 0.0 & 0.0 & 0.0 & 0.0 & 0.0 & 0.0 & 0.0 & \mathbf{0 . 0}\end{array}$

8 Years

$\begin{array}{llllllllllll}246 & \text { AAA } & 61.0 & 31.3 & 6.5 & 1.2 & 0.0 & 0.0 & 0.0 & 0.0 & 0.0 & 0.0\end{array}$

$\begin{array}{llllllllllll}611 & \text { AA } & 4.6 & 52.7 & 31.3 & 10.3 & 1.1 & 0.0 & 0.0 & 0.0 & 0.0 & 0.0\end{array}$

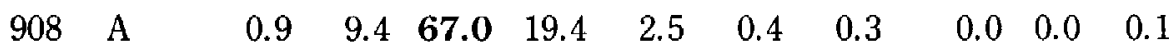

$\begin{array}{llllllllllll}259 & \text { BBB } & 0.0 & 0.8 & 28.6 & \mathbf{5 6 . 0} & 8.5 & 3.5 & 1.5 & 0.0 & 0.0 & 1.2\end{array}$

$\begin{array}{llllllllllll}52 & \mathrm{BB} & 0.0 & 1.9 & 13.5 & 21.2 & 32.7 & 21.2 & 5.8 & 0.0 & 0.0 & 3.8\end{array}$

$\begin{array}{llllllllllll}87 & \mathrm{~B} & 1.1 & 1.1 & 6.9 & 4.6 & 6.9 & \mathbf{4 8 . 3} & 16.1 & 1.1 & 3.4 & 10.3\end{array}$

$\begin{array}{llllllllllll}11 & \text { CCC } & 9.1 & 0.0 & 0.0 & 0.0 & 0.0 & 54.5 & \mathbf{2 7 . 3} & 9.1 & 0.0 & 0.0\end{array}$

$\begin{array}{llllllllllll}1 & \mathrm{CC} & 0.0 & 0.0 & 0.0 & 0.0 & 0.0 & 0.0 & 0.0 & 100.0 & 0.0 & 0.0\end{array}$

$\begin{array}{llllllllllll}0 & \mathrm{C} & 0.0 & 0.0 & 0.0 & 0.0 & 0.0 & 0.0 & 0.0 & 0.0 & \mathbf{0 . 0} & 0.0\end{array}$

$\begin{array}{llllllllllll}0 & \mathrm{D} & 0.0 & 0.0 & 0.0 & 0.0 & 0.0 & 0.0 & 0.0 & 0.0 & 0.0 & \mathbf{0 . 0}\end{array}$ 
TABLE B-1-Continued

\begin{tabular}{|c|c|c|c|c|c|c|c|c|c|c|c|}
\hline \multirow{2}{*}{$\begin{array}{l}\text { Age and } \\
\text { Number } \\
\text { of Issues }\end{array}$} & \multirow{2}{*}{$\begin{array}{c}\text { Original } \\
\text { Rating }\end{array}$} & \multicolumn{10}{|c|}{ Rating at Given Age } \\
\hline & & $\mathrm{AAA}$ & $\mathrm{AA}$ & A & $\mathrm{BBB}$ & $\mathrm{BB}$ & B & $\mathrm{CCC}$ & $\mathrm{CC}$ & $\mathrm{C}$ & $\mathrm{D}$ \\
\hline \multicolumn{12}{|l|}{9 Years } \\
\hline 242 & $\mathrm{AAA}$ & $\mathbf{5 5 . 8}$ & 34.3 & 7.4 & 2.5 & 0.0 & 0.0 & 0.0 & 0.0 & 0.0 & 0.0 \\
\hline 592 & AA & 4.1 & 50.5 & 28.2 & 15.5 & 1.5 & 0.0 & 0.2 & 0.0 & 0.0 & 0.0 \\
\hline 866 & A & 0.8 & 11.3 & 64.4 & 18.9 & 3.2 & 0.8 & 0.3 & 0.0 & 0.0 & 0.1 \\
\hline 236 & BBB & 0.0 & 2.5 & 31.8 & 50.0 & 7.2 & 5.9 & 1.3 & 0.0 & 0.0 & 1.3 \\
\hline 45 & $\mathrm{BB}$ & 0.0 & 2.2 & 13.3 & 24,4 & 20.0 & 17.8 & 15.6 & 0.0 & 0.0 & 6.7 \\
\hline 65 & B & 1.5 & 1.5 & 1.5 & 9.2 & 10.8 & 47.7 & 10.8 & 1.5 & 1.5 & 13.8 \\
\hline 9 & $\mathrm{CCC}$ & 11.1 & 0.0 & 0.0 & 0.0 & 0.0 & 11.1 & 77.8 & 0.0 & 0.0 & 0.0 \\
\hline 1 & $\mathrm{CC}$ & 0.0 & 0.0 & 0.0 & 0.0 & 0.0 & 0.0 & 0.0 & 100.0 & 0.0 & 0.0 \\
\hline 0 & $\mathrm{C}$ & 0.0 & 0.0 & 0.0 & 0.0 & 0.0 & 0.0 & 0.0 & 0.0 & 0.0 & 0.0 \\
\hline 0 & $\mathrm{D}$ & 0.0 & 0.0 & 0.0 & 0.0 & 0.0 & 0.0 & 0.0 & 0.0 & 0.0 & 0.0 \\
\hline \multicolumn{12}{|l|}{10 Years } \\
\hline 238 & AAA & 52.1 & 35.7 & 7.1 & 4.6 & 0.0 & 0.4 & 0.0 & 0.0 & 0.0 & 0.0 \\
\hline 576 & AA & 3.5 & 46.7 & 27.6 & 19.3 & 2.4 & 0.2 & 0.0 & 0.0 & 0.0 & 0.3 \\
\hline 831 & $\mathrm{~A}$ & 0.8 & 12.5 & 61.5 & 20.2 & 3.4 & 0.8 & 0.6 & 0.0 & 0.0 & 0.1 \\
\hline 217 & BBB & 0.0 & 2.8 & 36.9 & 43.3 & 8.3 & 4.6 & 1.8 & 0.0 & 0.0 & 2.3 \\
\hline 37 & $\mathrm{BB}$ & 0.0 & 0.0 & 10.8 & 27.0 & 21.6 & 13.5 & 18.9 & 2.7 & 0.0 & 5.4 \\
\hline 52 & B & 1.9 & 0.0 & 7.7 & 9.6 & 5.8 & 53.8 & 9.6 & 0.0 & 0.0 & 11.5 \\
\hline 7 & $\mathrm{CCC}$ & 0.0 & 0.0 & 0.0 & 0.0 & 0.0 & 0.0 & 85.7 & 0.0 & 0.0 & 14.3 \\
\hline 1 & $\mathrm{CC}$ & 0.0 & 0.0 & 0.0 & 0.0 & 0.0 & 0.0 & 0.0 & 100.0 & 0.0 & 0.0 \\
\hline 0 & $\mathrm{C}$ & 0.0 & 0.0 & 0.0 & 0.0 & 0.0 & 0.0 & 0.0 & 0.0 & 0.0 & 0.0 \\
\hline 0 & $\mathrm{D}$ & 0.0 & 0.0 & 0.0 & 0.0 & 0.0 & 0.0 & 0.0 & 0.0 & 0.0 & 0.0 \\
\hline
\end{tabular}

Note: Numbers in boldface are percentages of issues with unchanged ratings. 
TABLE B-2. Rating Drift, 1980-89 (percent of original rating group)

\begin{tabular}{|c|c|c|c|c|c|c|c|c|c|c|c|}
\hline \multirow{2}{*}{$\begin{array}{l}\text { Age and } \\
\text { Number } \\
\text { of Issues }\end{array}$} & \multirow{2}{*}{$\begin{array}{c}\text { Original } \\
\text { Rating }\end{array}$} & \multicolumn{10}{|c|}{ Rating at Given Age } \\
\hline & & $\mathrm{AAA}$ & $\mathrm{AA}$ & A & BBB & $\mathrm{BB}$ & B & $\mathrm{CCC}$ & $\mathrm{CC}$ & $\mathrm{C}$ & $\mathrm{D}$ \\
\hline \multicolumn{12}{|l|}{1 Year } \\
\hline 347 & AAA & 91.6 & 8.1 & 0.3 & 0.0 & 0.0 & 0.0 & 0.0 & 0.0 & 0.0 & 0.0 \\
\hline 1,219 & AA & 0.4 & 91.1 & 8.0 & 0.2 & 0.1 & 0.2 & 0.0 & 0.0 & 0.0 & 0.0 \\
\hline 1,344 & A & 0.0 & 3.8 & 88.6 & 6.6 & 0.6 & 0.4 & 0.0 & 0.0 & 0.0 & 0.0 \\
\hline 763 & BBB & 0.0 & 0.0 & 6.9 & 87.4 & 3.7 & 1.4 & 0.1 & 0.0 & 0.0 & 0.4 \\
\hline 168 & BB & 0.0 & 0.0 & 0.0 & 9.5 & 81.0 & 8.3 & 1.2 & 0.0 & 0.0 & 0.0 \\
\hline 580 & $\mathrm{~B}$ & 0.0 & 0.0 & 0.0 & 1.9 & 1.7 & 93.3 & 2.1 & 0.3 & 0.0 & 0.7 \\
\hline 155 & $\mathrm{CCC}$ & 0.0 & 0.0 & 0.0 & 0.0 & 0.0 & 3.2 & 91.6 & 0.0 & 2.6 & 2.6 \\
\hline 12 & $\mathrm{CC}$ & 0.0 & 0.0 & 0.0 & 0.0 & 0.0 & 0.0 & 0.0 & 83.3 & 16.7 & 0.0 \\
\hline 1 & $\mathrm{C}$ & 0.0 & 0.0 & 0.0 & 0.0 & 0.0 & 0.0 & 0.0 & 0.0 & 100.0 & 0.0 \\
\hline 3 & D & 0.0 & 0.0 & 0.0 & 0.0 & 0.0 & 0.0 & 0.0 & 0.0 & 0.0 & 100.0 \\
\hline \multicolumn{12}{|l|}{2 Years } \\
\hline 307 & AAA & 79.2 & 19.5 & 0.3 & 0.7 & 0.3 & 0.0 & 0.0 & 0.0 & 0.0 & 0.0 \\
\hline 1,048 & $\mathrm{AA}$ & 0.9 & 83.1 & 13.9 & 1.4 & 0.1 & 0.6 & 0.0 & 0.0 & 0.0 & 0.0 \\
\hline 1,132 & $\mathrm{~A}$ & 0.0 & 7.7 & 76.9 & 13.3 & 1.7 & 0.4 & 0.0 & 0.0 & 0.0 & 0.0 \\
\hline 624 & BBB & 0.2 & 0.5 & 12.3 & 76.8 & 5.8 & 3.4 & 0.3 & 0.2 & 0.0 & 0.6 \\
\hline 149 & $\mathrm{BB}$ & 0.0 & 0.0 & 1.3 & 14.1 & 67.1 & 14.8 & 2.0 & 0.0 & 0.0 & 0.7 \\
\hline 473 & B & 0.0 & 0.0 & 0.8 & 1.7 & 3.6 & 81.6 & 8.7 & 1.1 & 0.8 & 1.7 \\
\hline 102 & $\mathrm{CCC}$ & 0.0 & 0.0 & 0.0 & 0.0 & 0.0 & 4.9 & 80.4 & 2.0 & 4.9 & 7.8 \\
\hline 10 & $\mathrm{CC}$ & 0.0 & 0.0 & 0.0 & 0.0 & 0.0 & 10.0 & 10.0 & 50.0 & 0.0 & 30.0 \\
\hline 1 & $\mathrm{C}$ & 0.0 & 0.0 & 0.0 & 0.0 & 0.0 & 0.0 & 0.0 & 0.0 & 100.0 & 0.0 \\
\hline 2 & $\mathrm{D}$ & 0.0 & 0.0 & 0.0 & 0.0 & 0.0 & 0.0 & 0.0 & 0.0 & 0.0 & 100.0 \\
\hline \multicolumn{12}{|l|}{3 Years } \\
\hline 239 & $\mathrm{AAA}$ & 66.9 & 26.4 & 5.9 & 0.8 & 0.0 & 0.0 & 0.0 & 0.0 & 0.0 & 0.0 \\
\hline 815 & $\mathrm{AA}$ & 1.6 & 75.8 & 18.7 & 2.7 & 0.4 & 0.1 & 0.1 & 0.0 & 0.0 & 0.6 \\
\hline 880 & A & 0.2 & 10.5 & 68.0 & 17.5 & 2.4 & 1.4 & 0.0 & 0.0 & 0.0 & 0.1 \\
\hline 484 & BBB & 0.4 & 0.8 & 19.0 & 63.6 & 10.1 & 3.3 & 1.2 & 0.0 & 0.0 & 1.4 \\
\hline 103 & BB & 1.0 & 1.0 & 1.9 & 16.5 & 58.3 & 15.5 & 3.9 & 1.0 & 0.0 & 1.0 \\
\hline 311 & B & 0.0 & 0.0 & 1.3 & 1.9 & 2.9 & 72.7 & 12.9 & 1.6 & 1.9 & 4.8 \\
\hline 62 & $\mathrm{CCC}$ & 0.0 & 0.0 & 0.0 & 0.0 & 3.2 & 8.1 & 71.0 & 0.0 & 3.2 & 14.5 \\
\hline 8 & $\mathrm{CC}$ & 0.0 & 0.0 & 0.0 & 0.0 & 0.0 & 12.5 & 12.5 & 37.5 & 0.0 & 37.5 \\
\hline 0 & $\mathrm{C}$ & 0.0 & 0.0 & 0.0 & 0.0 & 0.0 & 0.0 & 0.0 & 0.0 & 0.0 & 0.0 \\
\hline 2 & $\mathrm{D}$ & 0.0 & 0.0 & 0.0 & 0.0 & 0.0 & 0.0 & 0.0 & 0.0 & 0.0 & 100.0 \\
\hline
\end{tabular}

Note: Numbers in boldface are percentages of issues with unchanged ratings.

Table continued on page 68. 
TABLE B-2-Continued

\begin{tabular}{|c|c|c|c|c|c|c|c|c|c|c|c|}
\hline \multirow{2}{*}{$\begin{array}{l}\text { Age and } \\
\text { Number } \\
\text { of Issues }\end{array}$} & \multirow{2}{*}{$\begin{array}{c}\text { Original } \\
\text { Rating }\end{array}$} & \multicolumn{10}{|c|}{ Rating at Given Age } \\
\hline & & $\mathrm{AAA}$ & $\mathrm{AA}$ & A & $\mathrm{BBB}$ & $\mathrm{BB}$ & $\mathrm{B}$ & $\mathrm{CCC}$ & $\mathrm{CC}$ & $\mathrm{C}$ & $\mathrm{D}$ \\
\hline \multicolumn{12}{|l|}{4 Years } \\
\hline 190 & AAA & $\mathbf{5 7 . 9}$ & 30.0 & 6.3 & 5.3 & 0.0 & 0.5 & 0.0 & 0.0 & 0.0 & 0.0 \\
\hline 535 & $\mathrm{AA}$ & 1.1 & 71.8 & 21.5 & 3.6 & 1.9 & 0.0 & 0.0 & 0.0 & 0.0 & 0.2 \\
\hline 592 & A & 0.8 & 11.7 & 62.2 & 19.9 & 4.1 & 1.2 & 0.0 & 0.0 & 0.0 & 0.2 \\
\hline 317 & BBB & 0.6 & 1.6 & 21.1 & 56.8 & 11.7 & 4.7 & 2.2 & 0.0 & 0.0 & 1.3 \\
\hline 62 & $\mathrm{BB}$ & 0.0 & 0.0 & 3.2 & 19.4 & 50.0 & 16.1 & 3.2 & 3.2 & 0.0 & 4.8 \\
\hline 173 & $\mathrm{~B}$ & 0.0 & 0.0 & 1.2 & 3.5 & 5.8 & $\mathbf{5 7 . 8}$ & 17.3 & 1.2 & 2.9 & 10.4 \\
\hline 29 & $\mathrm{CCC}$ & 0.0 & 0.0 & 0.0 & 0.0 & 0.0 & 17.2 & 48.3 & 10.3 & 0.0 & 24.1 \\
\hline 2 & $\mathrm{CC}$ & 0.0 & 0.0 & 0.0 & 0.0 & 0.0 & 50.0 & 50.0 & 0.0 & 0.0 & 0.0 \\
\hline 0 & $\mathrm{C}$ & 0.0 & 0.0 & 0.0 & 0.0 & 0.0 & 0.0 & 0.0 & 0.0 & 0.0 & 0.0 \\
\hline 0 & D & 0.0 & 0.0 & 0.0 & 0.0 & 0.0 & 0.0 & 0.0 & 0.0 & 0.0 & 0.0 \\
\hline
\end{tabular}

5 Years

$\begin{array}{llllllllllll}150 & \text { AAA } & 49.3 & 32.7 & 6.7 & 10.7 & 0.0 & 0.0 & 0.0 & 0.0 & 0.7 & 0.0\end{array}$

$\begin{array}{llllllllllll}360 & \text { AA } & 1.9 & \mathbf{6 8 . 6} & 20.6 & 5.0 & 2.8 & 0.8 & 0.3 & 0.0 & 0.0 & 0.0\end{array}$

$\begin{array}{llllllllllll}389 & \mathrm{~A} & 0.3 & 13.4 & \mathbf{5 8 . 9} & 22.4 & 3.3 & 1.5 & 0.0 & 0.0 & 0.0 & 0.3\end{array}$

$\begin{array}{llllllllllll}199 & \mathrm{BBB} & 1.0 & 2.5 & 23.6 & \mathbf{5 2 . 3} & 12.6 & 4.0 & 2.5 & 0.0 & 0.0 & 1.5\end{array}$

$\begin{array}{llllllllllll}39 & \mathrm{BB} & 0.0 & 0.0 & 7.7 & 15.4 & \mathbf{3 0 . 8} & 17.9 & 15.4 & 2.6 & 0.0 & 10.3\end{array}$

$\begin{array}{llllllllllll}107 & \mathrm{~B} & 0.0 & 0.0 & 0.9 & 5.6 & 5.6 & \mathbf{5 0 . 5} & 17.8 & 0.9 & 1.9 & 16.8\end{array}$

$\begin{array}{llllllllllll}14 & \text { CCC } & 0.0 & 0.0 & 0.0 & 0.0 & 0.0 & 28.6 & 21.4 & 7.1 & 0.0 & 42.9\end{array}$

$\begin{array}{llllllllllll}0 & \mathrm{CC} & 0.0 & 0.0 & 0.0 & 0.0 & 0.0 & 0.0 & 0.0 & \mathbf{0 . 0} & 0.0 & 0.0\end{array}$

$\begin{array}{llllllllllll}0 & \mathrm{C} & 0.0 & 0.0 & 0.0 & 0.0 & 0.0 & 0.0 & 0.0 & 0.0 & \mathbf{0 . 0} & 0.0\end{array}$

$\begin{array}{llllllllllll}0 & \mathrm{D} & 0.0 & 0.0 & 0.0 & 0.0 & 0.0 & 0.0 & 0.0 & 0.0 & 0.0 & \mathbf{0 . 0}\end{array}$

6 Years

$\begin{array}{llllllllllll}94 & \text { AAA } & 53.2 & 25.5 & 8.5 & 11.7 & 0.0 & 0.0 & 0.0 & 0.0 & 0.0 & 1.1\end{array}$

$\begin{array}{llllllllllll}211 & \text { AA } & 2.4 & 61.1 & 25.1 & 5.2 & 3.3 & 1.4 & 0.0 & 0.0 & 0.0 & 1.4\end{array}$

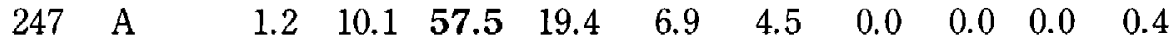

$\begin{array}{llllllllllll}102 & \text { BBB } & 1.0 & 5.9 & 25.5 & \mathbf{4 5 . 1} & 9.8 & 6.9 & 2.9 & 0.0 & 0.0 & 2.9\end{array}$

$\begin{array}{llllllllllll}18 & \text { BB } & 0.0 & 0.0 & 5.6 & 16.7 & \mathbf{2 7 . 8} & 16.7 & 22.2 & 0.0 & 0.0 & 11.1\end{array}$

$\begin{array}{llllllllllll}53 & \mathrm{~B} & 0.0 & 0.0 & 0.0 & 1.9 & 1.9 & \mathbf{4 9 . 1} & 15.1 & 0.0 & 1.9 & 30.2\end{array}$

$\begin{array}{llllllllllll}6 & \mathrm{CCC} & 0.0 & 0.0 & 0.0 & 0.0 & 0.0 & 66.7 & 16.7 & 16.7 & 0.0 & 0.0\end{array}$

$\begin{array}{llllllllllll}0 & \mathrm{CC} & 0.0 & 0.0 & 0.0 & 0.0 & 0.0 & 0.0 & 0.0 & \mathbf{0 . 0} & 0.0 & 0.0\end{array}$

$\begin{array}{llllllllllll}0 & \mathrm{C} & 0.0 & 0.0 & 0.0 & 0.0 & 0.0 & 0.0 & 0.0 & 0.0 & \mathbf{0 . 0} & 0.0\end{array}$

$\begin{array}{llllllllllll}0 & \mathrm{D} & 0.0 & 0.0 & 0.0 & 0.0 & 0.0 & 0.0 & 0.0 & 0.0 & 0.0 & \mathbf{0 . 0}\end{array}$

Note: Numbers in boldface are percentages of issues with unchanged ratings. 
TABLE B-2-Continued

\begin{tabular}{llllllllllll}
$\begin{array}{l}\text { Age and } \\
\text { Number } \\
\text { of Issues }\end{array}$ & $\begin{array}{c}\text { Original } \\
\text { Rating }\end{array}$ & AAA & AA & A & BBB & BB & B & CCC & CC & C & D \\
\hline
\end{tabular}

7 Years

$\begin{array}{llllllllllll}55 & \text { AAA } & \mathbf{5 8 . 2} & 23.6 & 3.6 & 14.5 & 0.0 & 0.0 & 0.0 & 0.0 & 0.0 & 0.0\end{array}$

$\begin{array}{llllllllllll}121 & \mathrm{AA} & 3.3 & \mathbf{3 8 . 0} & 47.9 & 6.6 & 2.5 & 0.8 & 0.0 & 0.0 & 0.0 & 0.8\end{array}$

$\begin{array}{llllllllllll}135 & \mathrm{~A} & 0.0 & 12.6 & \mathbf{5 4 . 1} & 24.4 & 6.7 & 2.2 & 0.0 & 0.0 & 0.0 & 0.0\end{array}$

$\begin{array}{llllllllllll}50 & \mathrm{BBB} & 0.0 & 10.0 & 28.0 & \mathbf{4 0 . 0} & 14.0 & 2.0 & 2.0 & 0.0 & 0.0 & 4.0\end{array}$

$\begin{array}{llllllllllll}3 & \text { BB } & 0.0 & 0.0 & 33.3 & 0.0 & 0.0 & 33.3 & 33.3 & 0.0 & 0.0 & 0.0\end{array}$

$\begin{array}{llllllllllll}16 & \mathrm{~B} & 0.0 & 0.0 & 0.0 & 6.3 & 0.0 & \mathbf{3 7 . 5} & 25.0 & 0.0 & 6.3 & 25.0\end{array}$

$\begin{array}{llllllllllll}2 & \mathrm{CCC} & 0.0 & 0.0 & 0.0 & 0.0 & 0.0 & 100.0 & \mathbf{0 . 0} & 0.0 & 0.0 & 0.0\end{array}$

$\begin{array}{llllllllllll}0 & \text { CC } & 0.0 & 0.0 & 0.0 & 0.0 & 0.0 & 0.0 & 0.0 & \mathbf{0 . 0} & 0.0 & 0.0\end{array}$

$\begin{array}{llllllllllll}0 & \mathrm{C} & 0.0 & 0.0 & 0.0 & 0.0 & 0.0 & 0.0 & 0.0 & 0.0 & \mathbf{0 . 0} & 0.0\end{array}$

$\begin{array}{llllllllllll}0 & \mathrm{D} & 0.0 & 0.0 & 0.0 & 0.0 & 0.0 & 0.0 & 0.0 & 0.0 & 0.0 & 0.0\end{array}$

8 Years

$\begin{array}{llllllllllll}16 & \text { AAA } & 43.8 & 37.5 & 0.0 & 12.5 & 0.0 & 6.3 & 0.0 & 0.0 & 0.0 & 0.0\end{array}$

$\begin{array}{llllllllllll}38 & \mathrm{AA} & 5.3 & 39.5 & 39.5 & 10.5 & 2.6 & 2.6 & 0.0 & 0.0 & 0.0 & 0.0\end{array}$

$\begin{array}{llllllllllll}61 & \mathrm{~A} & 0.0 & 23.0 & \mathbf{3 9 . 3} & 26.2 & 8.2 & 3.3 & 0.0 & 0.0 & 0.0 & 0.0\end{array}$

$\begin{array}{llllllllllll}28 & \mathrm{BBB} & 0.0 & 10.7 & 21.4 & \mathbf{5 0 . 0} & 10.7 & \mathbf{0 . 0} & 7.1 & 0.0 & 0.0 & 0.0\end{array}$

$\begin{array}{llllllllllll}2 & \text { BB } & 0.0 & 0.0 & 0.0 & 0.0 & 0.0 & 50.0 & 50.0 & 0.0 & 0.0 & 0.0\end{array}$

$\begin{array}{llllllllllll}7 & \mathrm{~B} & 0.0 & 0.0 & 0.0 & 0.0 & 0.0 & \mathbf{4 2 . 9} & 42.9 & 0.0 & 14.3 & 0.0\end{array}$

$\begin{array}{llllllllllll}1 & \text { CCC } & 0.0 & 0.0 & 0.0 & 0.0 & 0.0 & 100.0 & 0.0 & 0.0 & 0.0 & 0.0\end{array}$

$\begin{array}{llllllllllll}0 & \mathrm{CC} & 0.0 & 0.0 & 0.0 & 0.0 & 0.0 & 0.0 & 0.0 & \mathbf{0 . 0} & 0.0 & 0.0\end{array}$

$\begin{array}{llllllllllll}0 & \mathrm{C} & 0.0 & 0.0 & 0.0 & 0.0 & 0.0 & 0.0 & 0.0 & 0.0 & \mathbf{0 . 0} & 0.0\end{array}$

$\begin{array}{llllllllllll}0 & \mathrm{D} & 0.0 & 0.0 & 0.0 & 0.0 & 0.0 & 0.0 & 0.0 & 0.0 & 0.0 & \mathbf{0 . 0}\end{array}$

9 Years

$\begin{array}{llllllllllll}6 & \text { AAA } & 16.7 & 50.0 & 0.0 & 16.7 & 0.0 & 16.7 & 0.0 & 0.0 & 0.0 & 0.0\end{array}$

$\begin{array}{llllllllllll}19 & \text { AA } & 5.3 & 26.3 & 57.9 & 5.3 & 0.0 & 5.3 & 0.0 & 0.0 & 0.0 & 0.0\end{array}$

$\begin{array}{llllllllllll}25 & \mathrm{~A} & 4.0 & 40.0 & \mathbf{2 0 . 0} & 24.0 & 8.0 & 4.0 & 0.0 & 0.0 & 0.0 & 0.0\end{array}$

$\begin{array}{llllllllllll}9 & \text { BBB } & 0.0 & 0.0 & 55.6 & \mathbf{3 3 . 3} & 11.1 & 0.0 & 0.0 & 0.0 & 0.0 & 0.0\end{array}$

$\begin{array}{llllllllllll}1 & \mathrm{BB} & 0.0 & 0.0 & 0.0 & 0.0 & \mathbf{0 . 0} & 0.0 & 100.0 & 0.0 & 0.0 & 0.0\end{array}$

$\begin{array}{llllllllllll}2 & \mathrm{~B} & 0.0 & 0.0 & 0.0 & 0.0 & 0.0 & \mathbf{0 . 0} & 50.0 & 0.0 & 50.0 & 0.0\end{array}$

$\begin{array}{llllllllllll}0 & \mathrm{CCC} & 0.0 & 0.0 & 0.0 & 0.0 & 0.0 & 0.0 & \mathbf{0 . 0} & 0.0 & 0.0 & 0.0\end{array}$

$\begin{array}{llllllllllll}0 & \mathrm{CC} & 0.0 & 0.0 & 0.0 & 0.0 & 0.0 & 0.0 & 0.0 & \mathbf{0 . 0} & 0.0 & 0.0\end{array}$

$\begin{array}{llllllllllll}0 & \mathrm{C} & 0.0 & 0.0 & 0.0 & 0.0 & 0.0 & 0.0 & 0.0 & 0.0 & \mathbf{0 . 0} & 0.0\end{array}$

$\begin{array}{llllllllllll}0 & \mathrm{D} & 0.0 & 0.0 & 0.0 & 0.0 & 0.0 & 0.0 & 0.0 & 0.0 & 0.0 & \mathbf{0 . 0}\end{array}$

Table continued on page 70. 
TABLE B-2-Continued

\begin{tabular}{|c|c|c|c|c|c|c|c|c|c|c|c|}
\hline \multirow{2}{*}{$\begin{array}{l}\text { Age and } \\
\text { Number } \\
\text { of Issues }\end{array}$} & \multirow{2}{*}{$\begin{array}{c}\text { Original } \\
\text { Rating }\end{array}$} & \multicolumn{10}{|c|}{ Rating at Given Age } \\
\hline & & AAA & $\mathrm{AA}$ & A & $\mathrm{BBB}$ & $\mathrm{BB}$ & $\mathrm{B}$ & $\mathrm{CCC}$ & $\mathrm{CC}$ & $\mathrm{C}$ & $\mathrm{D}$ \\
\hline \multicolumn{12}{|l|}{10 Years } \\
\hline 0 & AAA & 0.0 & 0.0 & 0.0 & 0.0 & 0.0 & 0.0 & 0.0 & 0.0 & 0.0 & 0.0 \\
\hline 0 & $\mathrm{AA}$ & 0.0 & 0.0 & 0.0 & 0.0 & 0.0 & 0.0 & 0.0 & 0.0 & 0.0 & 0.0 \\
\hline 0 & A & 0.0 & 0.0 & 0.0 & 0.0 & 0.0 & 0.0 & 0.0 & 0.0 & 0.0 & 0.0 \\
\hline 0 & BBB & 0.0 & 0.0 & 0.0 & 0.0 & 0.0 & 0.0 & 0.0 & 0.0 & 0.0 & 0.0 \\
\hline 0 & $\mathrm{BB}$ & 0.0 & 0.0 & 0.0 & 0.0 & 0.0 & 0.0 & 0.0 & 0.0 & 0.0 & 0.0 \\
\hline 0 & B & 0.0 & 0.0 & 0.0 & 0.0 & 0.0 & 0.0 & 0.0 & 0.0 & 0.0 & 0.0 \\
\hline 0 & $\mathrm{CCC}$ & 0.0 & 0.0 & 0.0 & 0.0 & 0.0 & 0.0 & 0.0 & 0.0 & 0.0 & 0.0 \\
\hline 0 & $\mathrm{CC}$ & 0.0 & 0.0 & 0.0 & 0.0 & 0.0 & 0.0 & 0.0 & 0.0 & 0.0 & 0.0 \\
\hline 0 & C & 0.0 & 0.0 & 0.0 & 0.0 & 0.0 & 0.0 & 0.0 & 0.0 & 0.0 & 0.0 \\
\hline 0 & $\mathrm{D}$ & 0.0 & 0.0 & 0.0 & 0.0 & 0.0 & 0.0 & 0.0 & 0.0 & 0.0 & 0.0 \\
\hline
\end{tabular}

Note: Numbers in boldface are percentages of issues with unchanged ratings. 


\section{Appendix C. \\ Parameter Estimation of Markov Chain Models}

The parameters of the MKV-S and MKV-NS models are estimated from the initial sample distribution and the observed transition probabilities during the test period. The basic estimation technique, which involves maximizing the likelihood functions, was provided by Anderson and Goodman (1957).

The maximum likelihood estimate of the MKV-S model embodies information over the entire time period. It assumes the following:

(1) $P_{i k(t)}=\hat{P}_{i k}$ for $t=1,2, \ldots, T$, and

(2) $\hat{P}_{i k}=N_{i k} / N_{i *}$

where $N_{i k}=\sum_{t=1}^{T} N_{i k(t)}$, and $N_{i k(t)}$ is the number of observations in state $i$ at time $(t-1)$ and state $k$ at time $(t)$; and $N_{i *}=\sum_{t=1}^{T} N_{i *(t-1)}$, and $N_{i *(t-1)}$ is the number of observations in the initial state $i$ at time $(t-1), 0<t \leq T$.

Thus, the estimator in essence represents the one-step "average" transition probabilities. It has been shown empirically that this "averaging" transition matrix method is superior to simply assuming the transition probability matrix of a specific time interval is applicable to the whole period (Collins 1974). The estimated transition matrix over a longer period is obtained by raising the MKV-S estimated one-step transition matrix to the $T$ th power ( $T$ is the number of time units from the beginning of the period). For example, the two-step transition matrix of a stationary Markov process should be equal to the square of the "average" one-step matrix obtained from the test period. Mathematically,

$$
P(0, T) \approx \hat{P}(0, T)=\left[\sum_{t=1}^{T} P(t-1, t) / T\right]^{T},
$$

where $P(0, T)$ is the observed $T$-step transition probability matrix from time zero to time $T$, and $\hat{P}(0, T)$ is the estimated transition matrix over period $T$.

These estimated multiple-step transition matrixes can then be compared with the ones observed in the actual drift process. The pattern of positive or negative deviations in cells may indicate that a different model should be 
selected or that the partition of segments of the array within the matrix is necessary.

For an MKV-NS model, the estimated one-step matrix is simply computed this way:

$$
\hat{P}_{i k}=N_{i k(t)} / N_{i^{*}(t-1)}
$$

A multiple-step matrix is estimated through the multiplication of successive one-step transition matrixes. Mathematically,

$$
P(0, T) \approx \hat{P}(0, T)=\prod_{t=1}^{T} P(t-1, t) .
$$

Thus, to satisfy the properties of a nonstationary Markov process, the two-step transition matrix, $P(0,2)$, should be equal to the product of the first and second one-step transition matrixes, that is, $P(0,1)$ times $P(1,2)$.

The estimation of a mover-stayer model's parameters requires more complicated computations than are needed for simple Markov chains. A mover-stayer (MS) model can be stated as follows in Equation (1):

$$
P(0, T) \approx \hat{P}(0, T)=S+(I-S) M^{T},
$$

where $S$ is a diagonal matrix for stayers, $S=\left\{s_{1}, s_{2}, \ldots, s_{w}\right\}, I$ is an identity matrix, and $M$ is a stationary transition matrix for movers. The transition probabilities of the mover matrix, $m_{i k}$, are assumed to have the following properties: $M=\left\|m_{i k}\right\|$, and $M^{\infty}=\left\|m_{i}\right\|$, where $m_{i}=\lim _{t \rightarrow \infty} m_{i k(0, t)}, i, k=$ $1,2, \ldots, w$.

Several methods of estimating these matrixes were developed by Blumen et al. (1955), Goodman (1961), Spilerman (1972), and Frydman (1984). Frydman's method has been proved to be consistent and practical (e.g., by Frydman et al. 1985 and by Sampson 1990) and was used in this study. It was shown by Frydman (1984) that for each state $i$, the following Equation (2) can be derived from the maximum likelihood function of a discreet-time MS model:

$$
\begin{aligned}
\left(T N_{i^{*}(0)}\right. & \left.-N_{i^{*}}\right) M_{i i}{ }^{T}-\left(N_{i^{*}}-N_{i i}\right)\left(m_{i i}+m_{i i}{ }^{2}+\ldots+m_{i i}{ }^{T}-1\right) \\
& +N_{i i}-T N_{i}=0,
\end{aligned}
$$

where $N_{i}$ is the number of observations remaining in the same state $i$ over the entire period $(0, T)$.

To solve this equation, we first assume $T \rightarrow \infty$. Equation (2) can then be rewritten as: 


$$
-\left(N_{i^{*}}-N_{i i}\right)\left[\hat{m}_{i i} /\left(1-\hat{m}_{i i}\right)\right]+N_{i i}-T N_{i}=0 .
$$

Rearranged, it becomes Equation (3):

$$
\hat{m}_{i i}=\left(N_{i i}-T N_{i}\right) /\left(N_{i^{*}}-T N_{i}\right) .
$$

We can use $\hat{m}_{i i}$ as the starting point to find $m_{i i}$. By substituting $m_{i i}$ in Equation (2), we can determine whether $\hat{m}_{i i}$ is too large or too small. Continuing this iterative procedure, the root of Equation (2) can be solved.

By differentiating the log-likelihood function of each state on corresponding $s_{i}$ and $m_{i k}(i \neq k)$ (see Frydman 1984 for the derivation), the following equations are obtained:

$$
\begin{aligned}
& m_{i k}=N_{i k} \cdot\left(1-m_{i i}-\sum_{j=1, j \neq 1}^{\mathrm{k}-1} m_{i j}\right) / \sum_{j=k, j \neq \mathrm{i}}^{w} N_{i j}, \\
& \text { for } i \neq k, \text { and } i, k=1,2, \ldots w . \\
& S_{i}=\left(N_{i}-N_{i^{*}(0)} m_{i i}{ }^{T}\right) / N_{i^{*}(0)}\left(1-m_{i i}\right) .
\end{aligned}
$$

Using $m_{i i}$ determined above, we are able to calculate the values of individual $m_{i k}$ and $s_{i}$ through Equations (4) and (5).

A multiple-step matrix of an MS model is computed by weighting the estimated stayer matrix and the $T$ th power of the estimated mover (one-step) matrix according to the relative proportions of stayers and movers as shown in Equation (1). 



\section{References}

Altman, E.I. 1991. Distressed Securities: Analyzing and Evaluating Market Potential and Investment Risk. Chicago: Probus Publishing Co.

1990a. "How 1989 Changed the Hierarchy of Fixed-Income Security Performance." Financial Analysts Journal (May/June):9-20.

1990b. "Setting the Record Straight on Junk Bonds: A Review of the Research on Default Rates." Joumal of Applied Corporate Finance (Summer):82-95.

1989a. Default Risk Mortality Rates and the Performance of Corporate Bonds. Charlottesville, Va.: The Research Foundation of the Institute of Chartered Financial Analysts.

1989b. "Junk Bond Studies: What Do They Really Tell Us." Conference on Managing Credit Risk and Identifying Opportunities in Distressed Assets. Infoline (December 12).

1987. Handbook of Financial Markets and Institutions. 6th ed. Edited by E.I. Altman. New York: John Wiley and Sons.

Altman, E.I., R. Haldeman, and P. Narayanan. 1977. "ZETA Analysis: A New Model to Identify Bankruptcy Risk of Corporations." Joumal of Banking and Finance (June):29-54.

Altman, E.I., and D.L. Kao. 1991. "Appendices to the Research Foundation of the Institute of Chartered Financial Analysts Report on Corporate Bond Rating Drift: An Examination of Rating Agency Drift Over Time." Working paper no. S-40-91, Salomon Center, New York University.

Altman, E.I., and S. Nammacher. 1987. Investing in Junk Bonds. New York: John Wiley and Sons.

Anderson, T.W. 1954. "Probability Models for Analyzing Time Changes in Attitudes." In Mathematical Thinking in the Social Sciences, edited by P.F. Lazarsfeld. Glencoe, Ill.: The Free Press.

Anderson, T.W., and L.A. Goodman. 1957. "Statistical Inference About Markov Chains." Annals of Mathematical Statistics:89-110.

Asquith, P., D. Mullins, and E. Wolff. 1989. "Original Issue High Yield Bonds: Aging Analysis of Defaults Exchanges and Calls." Joumal of Finance (September).

Blume, M., and D. Keim. 1991. "Realized Returns and Defaults On Low Grade Bonds: The Cohort of 1977 and 1978." Financial Analysts Journal (March/April):63-72.

Blume, M., D. Keim, and S. Patel. 1991. "Return and Volatility of Low Grade Bonds, 1977-1989." Journal of Finance (March):49-74. 
Blumen, I., M. Kogan, and P.J. McCarthy. 1955. The Industrial Mobility of Labor as a Probability Process. Cornell Studies of Industrial and Labor Relations, vol. 6. Ithaca, N. Y.: Cornell University Press.

Collins, L. 1974. "Estimating Markov Transition Probabilities from Micro-Unit Data." Applied Statistics:355-71.

Cyert, R.M., H.J. Davidson, and G.L. Thompson. 1962. "Estimation of the Allowance for Doubtful Accounts by Markov Chains." Management Science: 3:287-303.

Dryden, M. 1969. "Share Price Movements: A Markovian Approach." Journal of Finance:14969.

Ederington, L., and J. Yawitz. 1987. "The Bond Rating Process." In Handbook of Financial Markets and Institutions, edited by E. Altman. New York: John Wiley and Sons.

Fridson, M. 1991. “Are Bond Ratings Consistent Over Time?" American Banker (February 25):7.

Frydman, H. 1984. "Maximum Likelihood Estimation in the Mover-Stayer Model." Journal of the American Statistical Association:632-38.

Frydman, H., J.G. Kallberg, and D. Kao. 1985. "Testing the Adequacy of Markov Chain and Mover-Stayer Models as Representations of Credit Behavior." Operations Research:61203-14.

Goldenberg, D.H. 1988. "Trading Frictions and Futures Price Movements." Journal of Financial and Quantitative Analysis:4465-81.

Goodman, L.A. 1961. "Statistical Methods of the Mover-Stayer Model." Journal of the American Statistical Association:841-68.

Grier, P., and S. Katz. 1976. "The Differential Effects of Bond Rating Changes Among Industrial and Public Utility Bonds by Maturity." Journal of Business: 249 .

Hettenhouse, G., and W. Satoris. 1976. "An Analysis of the Informational Value of Bond Rating Changes." Quarterly Review of Economics and Business 16:65-78.

Ho, T., and R. Michaely. 1988. "Information Quality and Market Efficiency."Joumal of Financial and Quantitative Analysis: 153-70.

Katz, S. 1974. "The Price Adjustment Process of Bonds to Rating Reclassifications: A Test of Bond Market Efficiency." Journal of Finance 29:2551-59.

Lucas, D., and J. Lonski. 1991. "Changes in Corporate Credit Quality 1970-1990." Moody's Special Report (February).

McQueen, G., and S. Thorley. 1991. "Are Stock Returns Predictable? A Test Using Markov Chains." Journal of Finance (March):239-63. 
Pinches, G., and J. Singleton. 1978. "The Adjustment of Stock Prices to Bond Rating Changes." Journal of Finance: $129-44$.

Pye, G. 1966. "A Markov Theory of the Term Structure." Quarterly Journal of Economics:6072 .

Ryan, T. 1973. "Security Prices as Markov Processes." Journal of Financial and Quantitative Analysis: $117-36$.

Sampson, M. 1990. "A Markov Chain Model for Unskilled Workers and the Highly Mobile." Journal of the American Statistical Association:177-80.

Samuelson, P. 1971. "Stochastic Speculative Price." In The Collected Scientific Papers of Paul Samuelson, edited by R. Merton. Cambridge, Mass.: MIT Press.

Sinler, B., and S. Spilerman. 1974. "Social Mobility Models for Heterogeneous Populations." In Sociological Methodology 1973-1974, edited by H. Costner. San Francisco: Jossey-Bass.

Spilerman, S. 1972. "Extensions of the Mover-Stayer Model." American Journal of Sociology: $599-626$.

Telser, L.G. 1963. "Least Squares Estimates of Transition Probabilities." In Measurement of Economics, edited by C. Crist. Stanford: Stanford University Press.

Vanderhoof, I., F. Albert, A. Tenenbein, and R. Verni. 1989. "The Risk of Asset Default." Transactions of the Society of Actuaries, vol. 41. Schaumberg, Ill.: Society of Actuaries.

Wakeman, L. 1978. "Bond Rating Agencies and the Capital Markets." Working paper, University of Rochester.

Weinstein, M. 1977. "The Effect of A Rating Change Announcement on Bond Price." Joumal of Financial Economics 5:3329-50.

White, D. 1988. "Further Real Applications of Markov Decision Process." Interface:55-61. 1985. "Real Applications of Markov Decision Process." Interface:77-83.

Wigmore, B. 1990. "The Decline in Credit Quality of New Issue Junk Bonds." Financial Analysts Journal (September/October):53-62.

Wilbur, W.L. 1983. "The Forecasting of Interest Rates-A Markovian Approach." In Proceedings of the American Statistical Association:553-58. 